\title{
Decontamination Systems Information and Research Program -- Literature Review in Support of Development of Standard Test Protocols and Barrier Design Models for In Situ Formed Barriers Project
}

Topical Report

December 1994

\section{RECEIVED \\ JUL 17 1996 \\ OSTI}

\author{
Topical Report
}

December 1994

Work Performed Under Contract No.: DE-FC21-92MC29467

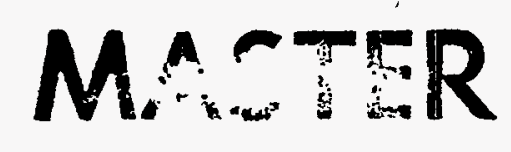

U.S. Department of Energy

Office of Environmental Management Office of Technology Development Washington, DC

By

West Virginia University

National Research Center for Coal and Energy Morgantown, West Virginia
For

U.S. Department of Energy

Office of Fossil Energy

Morgantown Energy Technology Center

Morgantown, West Virginia 


\section{DISCLAIMER}

Portions of this document may be illegible in electronic image products. Images are produced from the best available original document. 


\section{DISCLAIMER}

This report was prepared as an account of work sponsored by an agency of the United States Government. Neither the United States Government nor any agency thereof, nor any of their employees, makes any warranty, express or implied, or assumes any legal liability or responsibility for the accuracy, completeness, or usefulness of any information, apparatus, product, or process disclosed, or represents that its use would not infringe privately owned rights. Reference herein to any specific commercial product, process, or service by trade name, trademark, manufacturer, or otherwise does not necessarily constitute or imply its endorsement, recommendation, or favoring by the United States Government or any agency thereof. The views and opinions of authors expressed herein do not necessarily state or reflect those of the United States Government or any agency thereof.

Available to the public from the National Technical Information Service, U.S. Department of Commerce, 5285 Port Royal Road, Springfield, VA 22161; phone orders accepted at (703) 487-4650.

This report has been reproduced directly from the best available copy. 


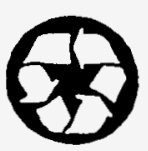

This cover stock is $30 \%$ post-consumer waste and $30 \%$ pre-consumer waste, and is recyclable. 

STANDARD TEST PROTOCOLS AND BARRIER.DESIGN MODELS

USDOE FOR IN STIU FORMIED BARRIERS PROJECT 


\title{
Decontamination Systems Information and Research Program -- Literature Review in Support of Development of Standard Test Protocols and Barrier Design Models for In Situ Formed Barriers Project
}

\author{
Topical Report
}

Work Performed Under Contract No.: DE-FC21-92MC29467

U.S. Department of Energy

Office of Environmental Management

Office of Technology Development

1000 Independence Avenue

Washington, DC 20585
For

U.S. Department of Energy

Office of Fossil Energy

Morgantown Energy Technology Center

P.O. Box 880

Morgantown, West Virginia 26507-0880

By

West Virginia University

National Research Center for Coal and Energy

P. O. Box 6064

Morgantown, West Virginia 26506

December 1994 


\section{TABLE OF CONTENTS}

1.0 INTRODUCTION AND BACKGROUND .........................................................1

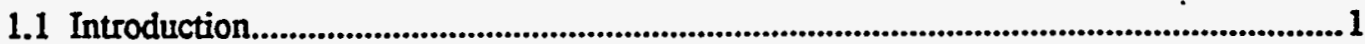

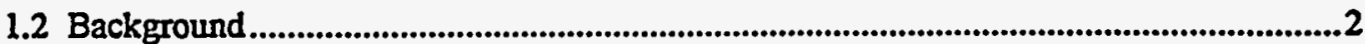

\subsection{REVIEW OF IDENTIFIED BARRIER SYSTEMS AND THEIR}

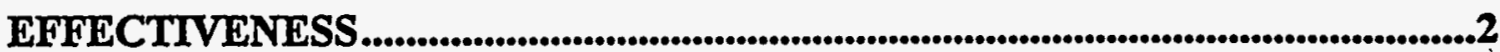

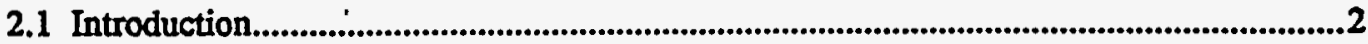

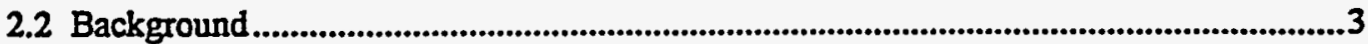

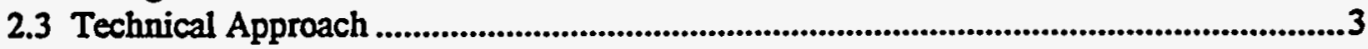

2.3.1 Define Barrier Systems Functional Requirements...............................................4

2.3.2 Identify Current Subsurface Barrier Systems From Literature.........................4

2.3.3 Develop Screening System for Selection of In Situ Barrier System ....................4

2.3.4 Identify Deployment Systems for Barrier Installation ........................................5

2.3.5 Evaluate and Rank Barrier Systems According to Effectiveness as

Determined by Screening System........................................................................................5

2.3.6 Identify Key Problem Areas That Need to Be Investigated................................5

2.4. Literature Review - Results and Analysis.........................................................................5

2.4.1 Functional Requirements of Subsurface Barrier Systems ...................................5

2.4.2 Current Barrier Systems Technologies From The Literature...............................6

2.4.2.1 Freeze Barrier System ............................................................................7

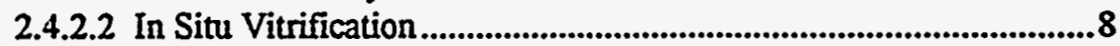

2.4.2.4 Circulating Air Barrier System.....................................................9

2.4.2.5 Permeation Grouting System .......................................................10

2.4.2.6 Encapsulation Barrier......................................................................10

2.4.2.7 Direct-Coupled Barrier..................................................................11

2.4.2.8 Controlled Advection (Sequestering Agent) Barrier System..............11

2.4.2.9 Mined Barrier System............................................................................11

2.4.3 Screening Criteria Development ..................................................................12

2.4.3.1 Screening Criteria .............................................................................12

2.4.3.2 Performance Criteria ..........................................................................13

2.4.3.3 Barrier System Selection Criteria..................................................16

2.4.4 Deployment Systems for Barrier Installation ...................................................18

2.4.5 Evaluation and Ranking of Barrier Systems ................................................. 18

2.4.5.1 Application of Selection Criteria to Barrier Systems ........................ 19

2.4.6 Identification of Key Problem Areas Needing Additional Evaluation................ 19

2.4.6.1 Desiccant Barrier System Additional Evaluation Needs...................19

2.4.6.2 Permeation Grout Barrier Identified Research Needs........................20

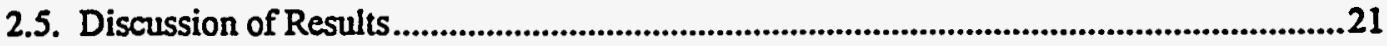

2.5.1 Screening Activities .........................................................................................22

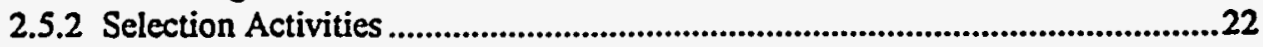

2.6. Conclusions And Recommendations...............................................................................22

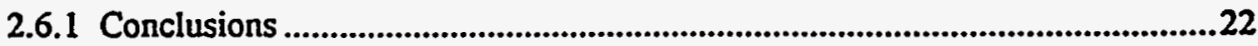

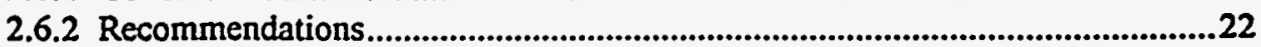

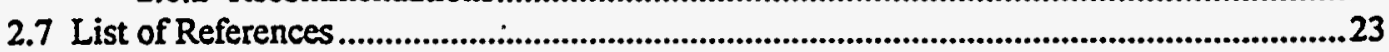

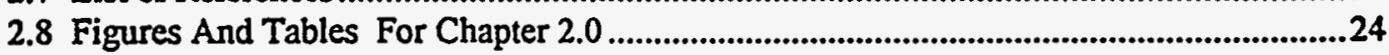

Figure 2.4.2.1 - Diagrammatic Illustration of the Freeze Barrier System.................................25

Figure 2.4.2.2 - Diagrammatic Illustration of the In Situ Vitrification Process for

Encapsulation of Hazardous and Toxic Waste .....................................................................26

Figure 2.4.2.3 - Diagrammatic Illustration of the Emplacement of a Horizontal Barrier

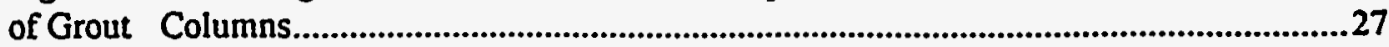

Figure 2.4.2.4 - Elevation and Plan Views of the Circulating Air Barrier System .....................28 
Figure 2.4.2.5 - Elevation and Plan View of a Cone Permeation Grout Barrier Installed Beneath a Single Shell Tank

Figure 2.4.2.6 - Diagrammatic Illustration of a Single Shell Tank Encapsulated by Resin When Confined by a Sheet Pile Barrier and a Permeation Grout Bottom Barrier .....................30 Figure 2.4.2.7 - Diagrammatic Illustration of a Direct Coupled Barrier Composed of a Cone Grout and Encapsulation Barrier to Form a Dual Barrier System.................................................31

Figure 2.4.2.8 - Schematic Diagram of a Controlled Advection Barrier System .........................32

Figure 2.4.2.9 - Schematic Diagram of a Robot Mined Barrier System ......................................33

Figure 2.5.2.1 - Ranking of Barrier Systems Results........................................................................34

Table 2.4.5.1 - Initial Screening of Barrier Systems...................................................................35

Table 2.4.5.2 - Barrier Systems Evaluation.......................................................................................36

\subsection{REVIEW OF CHEMICAL GROUTS FOR USE WITH PERMEATION}

GROUT DEPLOYMENT SYSTEMS..................................................................37

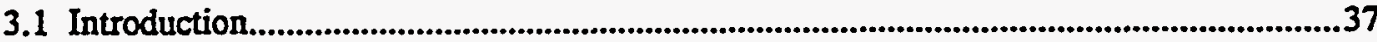

3.2. Chemical Grouts............................................................................................................38

3.2.1 Grout Mixing and Preparation Methods.................................................................38

3.2.2 Properties of Chemical Grouts...................................................................................38

3.2.2.1 Urethanes/Polyurethanes .........................................................39

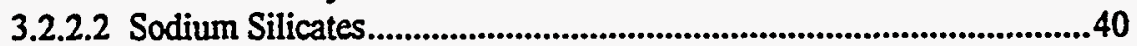

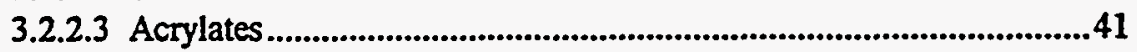

3.2.2.4 Acrylamides ...............................................................................41

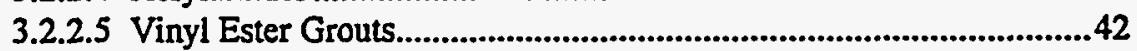

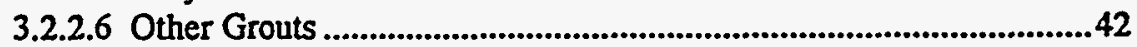

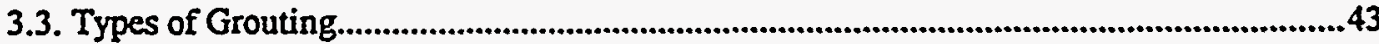

3.3.1 Injection Grouting...........................................................................................43

3.3.1.1 Containment Methods ....................................................................44

3.3.2 Jet Grouting..........................................................................................................45

3.3.2.1 Jetting Equipment ................................................................................. 45

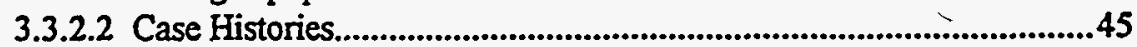

3.3.2.3 Containment Methods ...............................................................46

3.3.4 Block Displacement Method ..............................................................................47

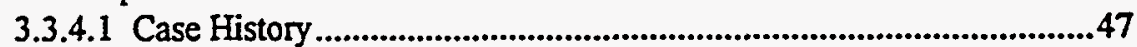

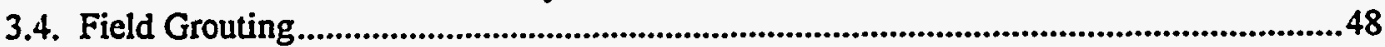

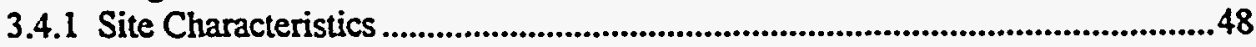

3.4.1.1 Soil and Rock Characteristics.........................................................48

3.4.1.2 Geochemical Characteristics.......................................................48

3.4.2 Grouting Pressures...............................................................................................49

3.5. Chemical Compatibility of Grouts ..................................................................................49

3.5.1 Chemical Compatibility of Selected Grouts ......................................................49

3.5.2 Selected Case Studies on the Use of Grouting as a Confinement Technique......50

3.5.3 Characteristics of Selected Grouts....................................................................51

3.6. Specimen Preparation Techniques ...................................................................................51

3.7. Computer Simulation of Grout Injection ....................................................................52

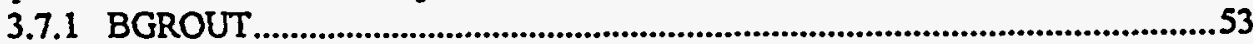

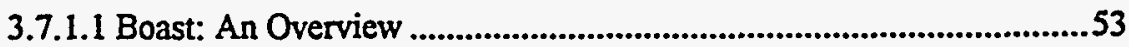

3.7.1.2 BGROUT Parameters ..............................................................53

3.7.1.3 BOAST3 Parameters ................................................................54

3.7.1.4 Program Output Evaluation ...................................................................56

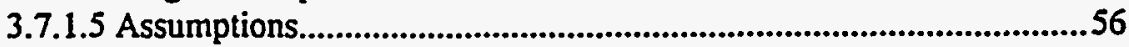

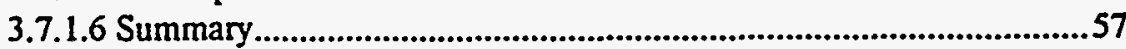

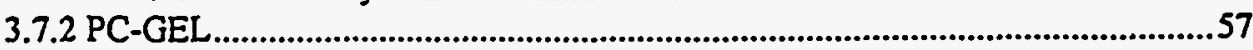

3.7.2.1 Mathematical Modeling of In-Situ Gelation.....................................57

3.7.2.2 Input Parameters .......................................................................58 


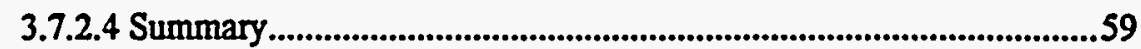

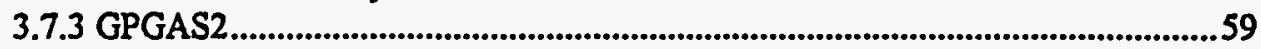

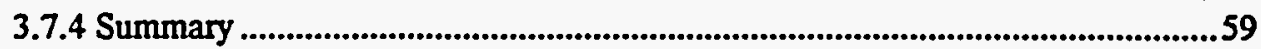

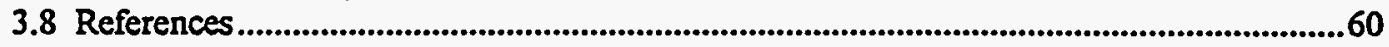

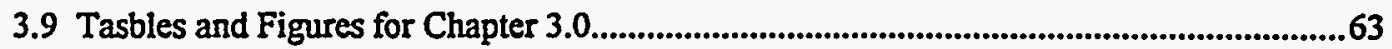

Table 3.1 Advantages and Disadvantages of Various Grouts....................................................63

Table 3.2 Chemicals Used in Bodocsi and Bowers (1990) Experiments .................................64

Table 3.3 Baseline Hydraulic Conductivities for Each Soil-Grout Mixture Used in Bodocsi

and Bowers (1990) Experiments..................................................................................................65

Table 3.4 Hydraulic Conductivities in the Presence of Selected Chemicals From the

Bodocsi and Bowers (1990) Experiments............................................................................66

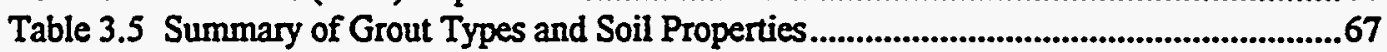

Table 3.6 Hydraulic Conductivities Before and After Lab-Scale Study. .................................67

Table 3.7 Hydraulic Conductivities Before and After Grouting For Field-Studies Conducted by Spalding et al. (1985) .....................................................................................................68

Figure 3.1 - Schematic of Typical Grout Injection System .............................................................6.69

Figure 3.2 - Diagrammatic View of Grout Cone ...........................................................................70

Figure 3.3 - Diagrammatic View of Grout trough for Containment............................................72

Figure 3.4 - Schematic Diagram of Jet Grouting System............................................................72

Figure 3.5 - Geometric Layout For Jet Grouted Columns ...........................................................73

Figure 3.6 - Diagrammatic View of Horizontal Plane Hydraulic Fracturing..............................74

Figure 3.7 - Cross-Sectional View of Block Displacement Method Grouting.............................75

4.0 REVIEW OF DESICCANT BARRIER SYSTEM.......................................76

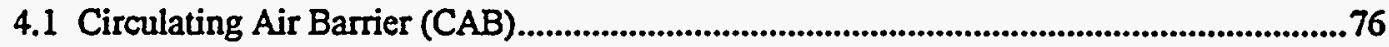

4.2 Phase Equilibria and Mass Transfer in Porous Media ........................................................77

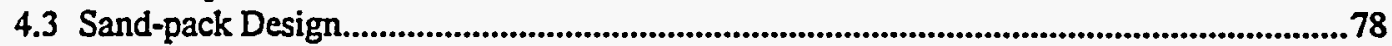

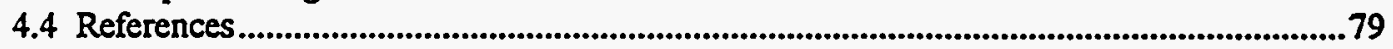

APPENDIX A..................................................................................................80

A.1 BDM LITERATURE SEARCH

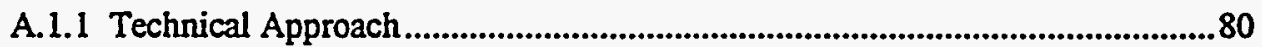

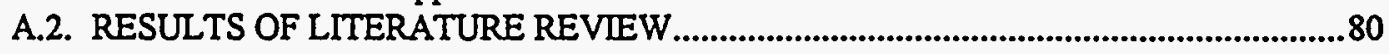

A.3. LITERATURE REVIEW FOR IN SITU BARRIERS ............................................8

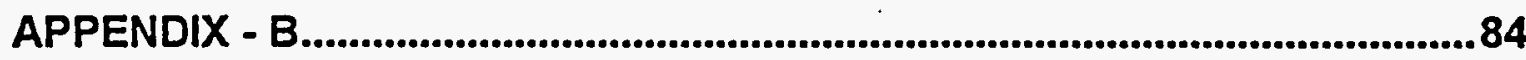

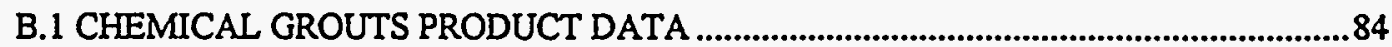

$1.13 \mathrm{M}$ Scotch-Seal ${ }^{\mathrm{T}}$ Chemical Grout 5610 (Gei) .................................................8.

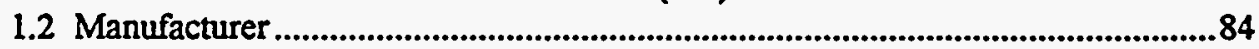

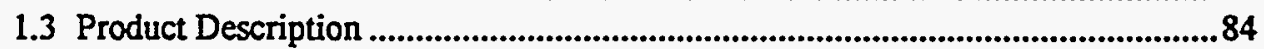

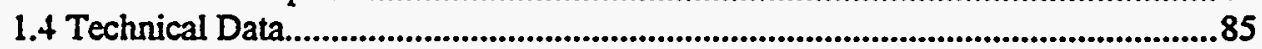

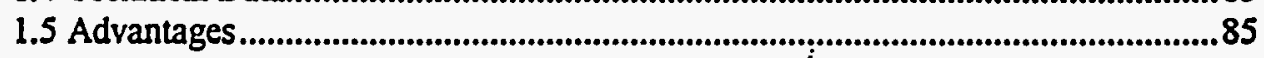

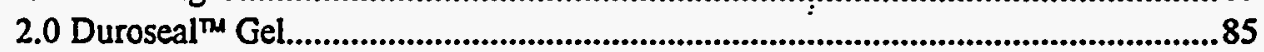

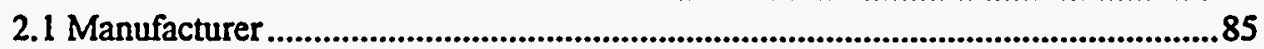

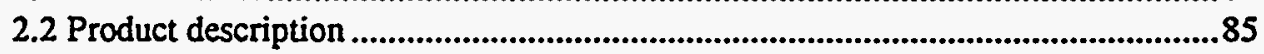

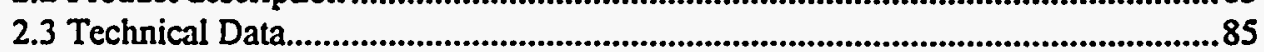

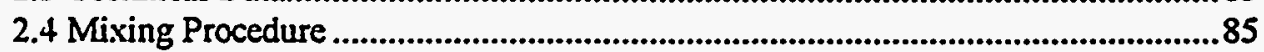

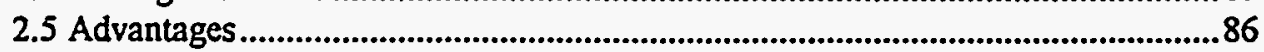

Table B1. Typical Physical Properties of Uncured Materials of Chemical Grout 5610.............86

Table B2. Typical Performance Properties of Cured Materials From Chemical Grout $5610 . . . . .87$

Table B3. Chemical Resistance Data of Chemical Gout 5610 .................................................88

Table Bt. Typical Physical Properties of Uncured Material of Duroseal TM Gel......................88

Table B5. Typical Performance Properties of Cured Materials from Duroseal TM Gel.............89

Table B6. Chemical Resistance Data of Duroseal TM Gel .....................................................89 
APPENDIX C - SELECTED LITERATURE FOR REFERENCES ......................92 


\section{LITERATURE REVIEW IN SUPPORT OF DEVELOPMENT OF STANDARD TEST PROTOCOLS AND BARRIER DESIGN MODELS FOR IN SITU FORMED BARRIERS PROJECT}

\subsection{INTRODUCTION AND BACKGROUND}

\subsection{Introduction}

Research efforts are currently being conducted in the United States and around the world in support of efforts to remediate contaminated soils and groundwater. Industrial development during the past 100 years has utilized many fresh water streams in the processing of raw or manufactured materials which resulted in contamination of the surface water and in many cases, the groundwater also. It is now apparent to most scientist around the world that our water resources must be remediated, protected and preserved if man is going to continue to inhabit the planet without a major reduction in the life forms which utilize fresh water resources.

The U. S. Department of Energy (DOE) is responsible for approximately 3000 sites in which contaminants such as carbon tetrachloride (CCL), trichlorethylene (TCE), perchlorethylene (PCE), non-volatile and soluble organic and insoluble organics (PCBs and pesticides) are encountered. In specific areas of these sites radioactive contaminants are stored in underground storage tanks (USTs) which were originally designed and constructed with a 30-year projected life. Many of these tanks are now 10 years beyond the design life and failures have occurred allowing the basic liquids (ph of 8 to 9) to leak in to the unconsolidated soils below. Nearly one half of the storage tanks located at the Hanford Washington Reservation are suspected of leaking and contaminating the soils beneath them. During one incident in 1973, 110,000 gallons of contaminated liquids are believed to have been released. Increased levels of radiation have been detected 110 feet below the surface or about one half the distance to the groundwater in the area (240 feet). These sites are located approximately 7 miles from the Columbia river which is one of the primary water resources in the Northwestern United States. The Hanford site is located in a semi-arid climate region with rainfall of less than 6 inches annually, and studies have indicated that very little of this water finds its way to the groundwater to move the water down gradient toward the Columbia river. This provides the government with time to develop a barrier system to prevent further contamination of the groundwater, and to develop and test remediation systems to stabilize or remove the contaminant materials.

In parallel to remediation efforts, confinement and containment technologies are needed to retard or prevent the advancement of contamination plumes through the environment until the implementation of remediation technology efforts are completed. This project examines the various confinement and containment technologies and protocols for testing the materials in relation to their function in-situ. 


\subsection{Background}

Members of the scientific community located at Hanford, Oak Ridge, and other DOE sites have been considering various types of barrier materials and methods for deploying them for the past five years or more. Early consideration was given to various types of cementicious grouts that could be injected into the formation below the USTs. The size and thickness of such barriers led to concerns about cracking and leaking of cementicious grout barriers. A Workshop was held at Tucson, Arizona to examine the various types of grout materials that should be logically considered for deployment beneath a single shell tank. $\mathrm{K} \& \mathrm{M}$ Engineering and Consulting Corporation was tasked by DOE to review the various types of deployment systems for barrier materials that were considered in the workshop and to determine if other materials could be identified. The $\mathrm{K} \& \mathrm{M}$ report identified eight types of barrier systems with differing deployment systems, one of which was the circulating air barrier (CAB) a desiccant barrier system that could be installed with either vertical, horizontal, or combinations of both types of drilled wells, and was developed by $\mathrm{K} \& \mathrm{M}$ and $\mathrm{BDM}$. This system was designed primarily for a tank farm size area of 500 feet by 500 feet square. Both larger and smaller systems could be designed for installation beneath a single tank or a tank farm. A single tank barrier system that was included in the analysis was the cone grout barrier system which is a cone shaped barrier installed utilizing a cementicious or chemical grout material that can be injected into permeable soils found beneath a single tank from inclined wellbores drilled with current SOA drill units such as the Sonic Drill Rig.

The ranking system employed by the $\mathrm{K} \& \mathrm{M}$ team identified the circulating air barrier as a desirable system because it did not reduce the number of options that remained to the DOE after the barrier was installed as compared to other systems such as the $3 \mathrm{M}$ polymer resin encapsulation system which creates a monolithic structure composed of hardened resin and soil particles. When large volumes of cementicious or chemical grout materials are injected into the soils, they trap the contaminants in place and provide stable containment for a few years, but not a final or ultimate solution (remediation) of the problem. The purpose of the current work is to provide additional data that would support the cold testing of these systems before a final decision is made relative to deployment of a barrier system prior to remediation operations.

\subsection{REVIEW OF IDENTIFIED BARRIER SYSTEMS AND THEIR EFFECTIVENESS}

\subsection{Introduction}

Contamination of soils and surface waters has become a major problem in every major country in the world. The most advanced nations technologically have also become the most polluted as a result of the development of these technologies. Remediation technologies are being developed to address both surface and subsurface pollution / contamination problems. Until the required and proven remediation technologies are developed, there is a need to prevent or reduce the amount of contamination of groundwater resources in this country and the world. One approach to containing contaminants is the development and deployment of subsurface barriers to prevent movement of contaminants into the groundwater. This is one approach being considered by the US Department of Energy at the former nuclear weapons development sites where high level 
radioactive and mixed wastes are contained in underground storage tanks. Many of these tanks are now 10 to 20 years beyond their original design life and are beginning to leak very toxic and hazardous materials into the subsurface beneath the tanks. High priority has been given to development and testing of barrier systems that can be deployed beneath the tanks to contain any leaked materials.

This project will examine the currently known or proposed barrier systems for their effectiveness and present suggestions regarding approaches to continue or improve their development activities.

\subsection{Background}

In 1991, the DOE was examining the potential use of subsurface barrier systems to prevent the loss of high level radioactive material from several underground storage tanks in to the subsurface where it might be mobilized and eventually reach and contaminate the groundwater resources located at Hanford, Washington former weapons manufacturing site. A milestone was established to remove the high level waste from tank $\mathrm{C}-106$ (the high heat tank) and thus reduce one of the major potential health and safety hazards located at the Hanford site. The milestone was established for Oct 1995. Initial plans were to have evaluated and tested one or more potential barrier systems for emplacement beneath C-106 prior to removal of the material in the tank by sluicing. Original estimates were that as much as 250,000 gallons of liquid could leak from the tank during the sluicing operation, so this became the target number for a barrier system that would be able to contain a potential leak of approximately 250,000 gallons of contaminated material.

The DOE Morgantown Energy Technology Center (METC), because of their previous experience with directional drilling, let a contract to $\mathrm{K} \& \mathrm{M}$ Engineering and Consulting Corporation to examine the various drilling technologies that might be required to install subsurface barriers, and to examine the potential subsurface barriers that might be required to contain leaking material from tanks that would undergo the sluicing process for tank remediation. BDM Engineering Services Company was selected by $\mathrm{K} \& \mathrm{M}$ to support them in this effort because of their previous experience in horizontal and directional drilling operations. A report was prepared which examined 28 drilling technologies and 8 subsurface barrier technologies for potential application at Hanford site. These technologies were ranked and the two highest ranked technologies were selected for a detailed design for a cold test demonstration. The circulating air barrier concept was ranked the highest while the permeation grout concept was ranked second. An encapsulation barrier concept was ranked third of all of the barrier systems examined.

\subsection{Technical Approach}

The purpose of this evaluation is to review the various barrier systems that have been identified or proposed by various DOE contractors as methods of preventing the further contamination of soils and groundwater resources at the various DOE former weapons manufacturing sites. A systems engineering approach was followed in evaluating the potential barrier systems. The key elements of the systems approach as followed are: 
1. Review Mission Requirements

2. Conduct Requirements Analysis

3. Document Feasible Concepts

4. Rank and Select Preferred Concepts

5. Develop Specific Design Support Study Recommendations

The Mission Requirements as interpreted from material published in "Hanford Mission Plan, Vol.1 Site Guidance" DOE/RL-93-08, are to prevent any further contamination of the soil and groundwater resources within the Hanford reservation. The problems as identified are $110,000,000$ metric tons of contaminated soils and 1 billion metric tons of groundwater. The 177 underground storage tanks contain 340,000 metric tons of high level mixed (radioactive and hazardous) waste which must be removed and stabilized for long term storage. Preventing additional contamination of the groundwater is an important aspect of the mission plan. Siskind and Heiser in a 1993 report 1 reviewed regulatory issues associated with various barrier materials being considered by DOE for use in deploying subsurface barriers and discussed regulatory issues that need to be address by $\mathrm{DOE}$ investigators. The regulations controlling the conditions under which certain polymers and monomers can be injected into the subsurface to develop in-situ formed barriers were examined.

The development of barriers that can be deployed beneath the USTs in a cost effective manner that would prevent migration of any leaked material during the remediation process is a key aspect of the mission plan. The following discussion addresses the key elements of the approach to evaluating the most effective of the studied barrier systems identified or proposed by previous investigators.

\subsubsection{Define Barrier Systems Functional Requirements}

The barrier system that is to be developed, tested, and deployed must perform specific functions as required by the Department of Energy (DOE), and the Environmental protection agency (EPA).These functional requirements will be defined by examining reports of barrier workshops and study analysis sessions relating to barrier selection.

\subsubsection{Identify Current Subsurface Barrier Systems From Literature}

DOE has sponsored workshops to examine the types of materials that might be used in developing a subsurface barrier system that would be placed beneath the buried single shell waste storage tanks that are located at Hanford, Savannah River, and Oak Ridge Sites. The largest number of tanks (177) are located at Hanford. DOE has also commissioned studies by various engineering firms to conduct feasibility studies of several types of barrier systems that could be deployed beneath the underground storage tanks (USTs.) The systems that have thus far been developed in studies and workshops will be identified from government reports, and workshops. Identify target soils that are most functional or applicable to the barrier systems identified.

\subsubsection{Develop Screening System for Selection of In Situ Barrier System}

A method of selecting the subsurface barrier systems that will satisfy all of the functional and regulatory requirements will be developed to determine the system or systems that will meet the 
highest number of screening criteria selected. The criteria will be developed by combining the most important functional and regulatory requirements into a screening set. $A$ ranking methodology will also be used in conjunction with the screening criteria set.

\subsubsection{Identify Deployment Systems for Barrier Installation}

Most of the barrier systems identified are associated with a specific deployment system, however, a few materials have been identified which could possibly function by being deployed by more than 1 technology. The most successful system will be recommended based on the state of development and demonstration of the technology in previous feasibility studies, or the results of reports submitted to DOE as conclusions of studies completed. Most of the systems require the drilling of either vertical, inclined or horizontal wellbores through which the barrier material is injected into the soil or rocks in the designed barrier interval.

\subsubsection{Evaluate and Rank Barrier Systems According to Effectiveness as Determined by Screening System}

A ranking system will be utilized that will identify the most effective barrier system as identified by the screening criteria. The screening criteria may identify five or more barrier systems, and the ranking methodology will identify the most effective barrier system in performing the functional and regulatory requirements.

\subsubsection{Identify Key Problem Areas That Need to Be Investigated}

As a result of screening and ranking the various barrier systems, key problems that may arise in the actual field demonstration of the ranked barrier systems will be identified. Specific aspects of the deployment or functioning of the identified barrier systems will be defined as areas where additional investigations should be performed to increase the effectiveness of the barrier system.

\subsection{Literature Review - Results and Analysis}

A review of literature discussing in-situ barrier materials or barrier systems was conducted to identify the various technologies available to support in-situ barrier deployment. The review began with a literature search which was conducted using the West Virginia University Library facilities, and the DOE Morgantown Energy Technology Center (METC) library facilities. A search of engineering and scientific journals and periodicals was conducted using a list of key words developed relative to the key elements of the various barrier systems.

The following discussion presents the results of the literature review and the analysis to determine the most effective barrier systems for use at the various DOE former weapons sites.

\subsubsection{Functional Requirements of Subsurface Barrier Systems}

A set of generic functional requirements have been developed based on the literature review and descriptions of work performed by various government contractors. Siskind and Heiser 1 discuss in considerable detail the various Congressional Acts such as CERCLA and determined that the development of materials and technologies for in-situ formed barriers will be controlled by the 
Superfund Process. A very good list of functional requirements was discussed in reports on two workshops2 , 3 sponsored by DOE in February and December of 1992.

The subsurface barrier systems under consideration are those that will prevent contamination of groundwater resources from leaking underground storage tanks which contain hazardous and radioactive materials. These barriers must function until the hazardous material is removed or remediated from the soil. The primary functional requirements of a subsurface barrier designed to contain contaminants is that they prevent movement of liquid contaminants into the groundwater. A barrier must be able to function without failing for a period of at least 30 years which will allow time for the removal of the potential contaminating material from the underground tanks.

Barriers must function in multiple climatic conditions such as temperate, arid, or semi-arid climatic condition regions:

- Arid or semi-arid climates usually have soils in the vadose zone with water saturation below the mobile water saturation level (water will not flow in the pore space).

- Temperate climates usually have soil water saturations higher than the mobile water saturation level

- Barriers must function in multiple geologic conditions or soil types with differing porosities, permeabilities and saturations. The vadose zone may contain consolidated or unconsolidated geologic materials.

- Barrier must be able to be deployed (installed) in soils or rocks that have hydraulic conductivity of $1 \times 10-6$ to $1 \times 10-2 \mathrm{~cm} / \mathrm{sec}$.

- Barrier must be seamless and 100 percent effective to prevent migration of contaminants to the groundwater aquifer.

- Barrier installation process must not result in the mobilization of the contaminant material in the vadose zone, or aquifer, or consolidated rock that it is contained in.

- Barrier materials must be environmentally acceptable (material is not a hazardous material after installation in the subsurface). The barrier installation should minimize the creation of secondary waste during the installation process.

- Barrier materials must be chemicaly inert to, or non-reactive with, the chemical and radioactive contaminant species should the barrier come in contact with the contaminating material.

- The barrier must satisfy the interface and regulatory requirements of DOE for the site being tested or applied.

\subsubsection{Current Barrier Systems Technologies From The Literature}

A barrier system is defined as a material or method of preventing the movement of contaminants from the surface or near surface to the watertable where it can find its way into the biosphere through migration as a plume to an exit point or utilization point, and the method of installing the barrier material or method in the subsurface beneath underground storage tanks.

During the course of several workshops held at different locations (Hanford Site, Tuscon, Arizona, references 2,3 ) since 1992, several vertical and horizontal barrier materials and 
deployment systems were reviewed and discussed. BDM has selected for consideration under this project only those technologies that are a part of a barrier system or can be combined to develop a barrier system. A system consisting of both horizontal and vertical barriers that when combined will provide positive containment for any toxic or hazardous material that may leak from the single shell underground storage tanks located at any one of several DOE facilities such as Savannah River Plant, Oak Ridge, or Hanford, WA. The following discussion examines the various technologies that should be screened for inclusion in the selection process for additional study or implementation. Included in the discussion is a review of the types of soils or geologic materials that are targeted for application by the barrier system.

\subsubsection{Freeze Barrier System}

A Freeze Barrier System was developed by R.K.K. Limited 4 , Belleview WA, and U S Patent 4,860,544 for" Closed Cryogenic Barrier for Containment of Hazardous Material Migration in the Earth" was awarded on Aug. 29, 1989. As presented in the abstract, the barrier is formed by drilling a series of parallel inclined boreholes which are equipped with casing and tubing for circulation of refrigerant materials. A V shaped trough is formed by the intersection of the wells. The refrigerant is circulated establishing ice columns around the wellbores. Eventually the ice columns overlap and coalesce to form a flow impervious barrier about the selected volume of earth and hazardous material as formed by the trough. Figure 2.4.2.1 is a diagrammatic representation of a freeze barrier installed beneath underground storage tanks.

Once the barrier is established, the rate of flow of refrigerant is decreased to that required to offset heat gain in the earth. The patent claims that the barrier is self healing of fractures as a result of pressure from earth materials that form the overburden. In some locations water may have to be injected to help form the barrier in areas where insufficient water saturation of the soil exists to form the barrier when the refrigerant is circulated in the boreholes.

Sensors placed in the cased boreholes can be used to monitor for the presence of radioactive materials, and the temperature of the barrier adjacent to the borehole. These sensors provide enough information to determine the state of the barrier installed. The patent describes potential situations where double barriers are installed.

In reply to critism of problems that are likely to occur with the freeze barrier, Dr. J. G. Dash 5 of the Department of Physics, University of Washington, prepared a paper which was presented at the Waste Management 1991 Conference, called "Ice Technology for Hazardous Waste Management" and addressed physical, thermal, and economic characteristics of cryogenic or freeze barriers. Dr. Dash's conclusions were that cryogenic barriers have excellent containment characteristics and are suitable for application at many locations for intermediate and long term storage of hazardous materials. Dr. Dash estimated that the problem of frost heave beneath a single shell tank in C tank farm at Hanford site, would be about $1 \mathrm{~mm}$ in 30 years of a cryogenic barrier operation at that location.

2.4.2.1.1 Geologic and Engineering Parameters that Support Proper Operation of a Subsurface Freeze Barrier 
1. Geologic media can be unconsolidated or consolidated geological materials. Grain sizes can range from fine to coarse size $(.25$ to $2 \mathrm{~mm}$ ) in diameter and can contain cobbles and boulders. Accessory minerals such as clays are acceptable in small percentages so that they do not make a major impact on permeability.

2. Permeability of unconsolidated materials is usually higher than that of consolidated materials, and should range from $500 \mathrm{md}$ to $10,000 \mathrm{md}$ to support proper operation of the barrier system. Permeability of consolidated materials should range from $100 \mathrm{md}$ to $2000 \mathrm{md}$.

3. Water saturation should be above the value of residual saturation. Higher saturation values provide the water required to form a continuous phase needed to form the ice barrier. Generally the saturation is preferred to be greater than 50 percent, otherwise water will need to be added during the process with the possibility of mobilizing contaminants that might escape the freeze zone when the permeability is very high. The most important aspect of saturation is that a continuous wetting phase should be present in the formation being frozen, or sufficient water will need to be added.

4. Temperate climatic conditions are most favorable to supporting a freeze barrier. This climate has a higher rate of aquifer recharge which should support the development of a freeze barrier. If recharge rates were low, the vadose zone would not be saturated or contain enough water to freeze for the barrier.

5. Depth to the water table should not be a major problem in installing a freeze barrier. The barrier should not be installed in the aquifer because of the flow of water and heat transfer problems. A freeze barrier should, like most other barriers, be kept out of the capillary fringe zone also. Capillary fringe is generally about 10 feet thick for coarse to medium grained sands and approximately 15 feet thick for fine to very fine grained sediments. This would make approximately fifteen feet as a minimum value above the top of the water table that a freeze barrier should be installed.

\subsubsection{In Situ Vitrification}

In situ vitrification is a stabilization process for containing previously leaked contaminants in a glass melt as opposed to a method or material that will prevent the migration of a leaked contaminant through the vadose zone to the groundwater below. It is included in this discussion because encapsulation of the contaminants provides a barrier to movement toward the groundwater. This process is also considered for vitrification of USTs in place without removal of the waste material inside according to Bates 6 . Figure 2.4.2.2 is a diagrammatic presentation of the in-situ vitrification process.

In situ vitrification is a process whereby large metal electrodes are placed in the ground and a high voltage current is passed between the electrodes. The current heats the soil and any contaminants to a high enough temperature that the silica is turned to glass encapsulating the contaminant materials in the vitrified material. The vitrification process has been successfully applied to encapsulate high level radioactive waste materials in a borasilicate mineral material which is converted to glass and usually placed inside of metal canisters for storage in deep geological 
repositories. This process was developed for mined storage of canisters and the process was modified to fit other situations such as subsurface encapsulation of leaked waste material from the single shell tanks. Attempts to simulate this process in the unit that is normally used for vitrification, resulted in a fire the halting of further testing until the cause of the fire in the test unit could be determined.

No actual tests of the in situ vitrification process with radioactive material have been conducted to date. There are perceived problems of the potential escape of some of the material in the vapor phase 6,7 when the soil is heated up to melt the sand and convert it to glass. Water contained in the soil and the contaminant materials will be converted to steam and possibly moved out in a thermal wave as steam prior to the vitrification process. This could provide a mobility to the contaminant material that would not be desirable. This process in conjunction with another barrier system that could trap the volatile liquids and gases may be considered as part of a scheme for in place storage / containment. Further testing of this process should only come about if DOE has decided to contain and abandon the tanks and previously leaked material in place as a landfill.

\subsubsection{Jet Grout Barrier System}

The jet grout barrier system uses a low viscosity cementicious grout material injected at pressures ranging from 3000 to 6000 psi through specially designed injection tubes and ports. The high pressure creates turbulent flow of the grout in the formation and is essentially a high pressure mixing system. The grout penetrates from 3 to 15 feet 8 depending upon the pressure of injection and creates cylinders of grout that are spaced to overlap and seal to make a barrier, either horizontal or vertical. Figure 2.4.2.3 is a diagrammatic illustration of the formation of a horizontal portion of a barrier system.

Another type of delivery system is capable of laying down a continuous grout barrier 1 foot thick, 12 feet wide and 200 to 400 feet long. The system uses 2 parallel wellbores to pull the jet grouting device through creating the barrier. This system has been tested partially at Fernald site 9 in Ohio during 1993 and 1994. Not all problems have been solved yet but there has been significant progress in deploying a single element of a multi-element barrier system.

\subsubsection{Circulating Air Barrier System}

The circulating air barrier system 10,11 is a desiccant-type barrier designed to prevent the movement of liquid contaminants toward the groundwater by using a gas circulation processing system to lower the water saturation in a targeted subsurface zone below the saturation required for liquid flow through the zone.

The system concept involves the circulation of air or another gas through a subsurface interval in order to lower and then maintain the water saturation required for liquids to flow. The barrier can be installed using either vertical or horizontal wells, establishing a pattern of air or gas injection and production so that the air moves from the injection well through the ground formation to the production wells. A schematic of the wells is shown in the figure 2.4.2.4. The moving air vaporizes water in the zone and carries the water vapor to the production wells. The production stream is then processed in a surface facility to remove the water and any contaminants or 
particulates. In time the circulating gas reduces the water saturation in the swept interval, and continues to remove by evaporation, liquids that move into the zone such as a leak plume. Thomson, et. al. 121994 , discusses theoretical considerations for a system used to dry the area beneath a landfill to act as a barrier to leachate materials. Their analysis concludes that there should be no engineering barriers to development of a desiccant barrier system as they discussed. This would indicate that the application at different depths and soils should be effective also In the event of a leak the system serves as a tool for early detection and provides a means to withdraw volatile organic contaminants to the surface for treatment as well.

\subsubsection{Permeation Grouting System}

The permeation grouting system is a means of injecting a selected permeable grout material into a geologic formation below the single shell tanks and /or other areas where radioactive material could be leaked where it might migrate to the groundwater. The deployment system would be through horizontal or vertical wells through the target formation. The chemical or cementicious grout material is injected at relative low pressures to prevent hydraulic fracturing of the soil which in turn could put pressure on the underground storage tanks located above the barrier being injected. Figure 2.4.2.5 is a schematic diagram of a permeation grout barrier whose geometry is a cone (Cone Grout Barrier 14). Several chemical have been proposed for consideration as a permeation grout barrier material(Naudts) 13 , of course the most important factor to be considered is the chemical and reactive nature of the barrier material after it is in place and formed as a barrier. If it is permeable to basic chemical compounds, it may not be suitable for use at the Hanford site. A chemical material which fits many of the functional requirements as a barrier material is polyurethane foam 16 (hydrophobic). Other materials which have been investigated by Heiser 17 and others include polyester styrene, and vinylester styrene. These investigators examined the materials for regulatory compliance with EPA standards when injected in place to form in situ barriers in the vadose zone. Test protocols for use of these materials in sandy and gravelly soils, similar to those found at Hanford, need to be developed.

\subsubsection{Encapsulation Barrier}

The encapsulation barrier system 2,18 is a concept that consists of three elements, a vertical sheet pile barrier that extends from the surface to a depth of 10 feet below the bottom of the UST generally about 50 feet below the surface, and a horizontal barrier installed by jacking pipes from three caissons sunk to the proper depth to install a grout barrier (resin or cement would be adequate) beneath the sheet pile barrier. The third element is the encapsulating resin that is injected through vertical boreholes to flood all of the pore space in the area between the sheet pile grout barrier and the tank wall. This resins is mixed with a hardener that sets (hardens) the resin and the tank into a monolithic mass trapping and stabilizing all waste material inside or outside the tank. Figure 2.4.2.6 is a schematic drawing of the encapsulation barrier concept.

This type of barrier could be installed now with current, off-the-shelf technology, but the decision would have to be made about the final disposition of the radioactive contaminants within and below the single shell tanks. That is, whether the contaminants will be removed or abandoned in place. There are engineering problems associated with the installation of the sheet pile vertical component, which is the penetration of the liquid waste transport lines generally found at a depth 
of 10 to 12 feet below the surface between the tanks within a tank farm. These lines could possibly be cautiously removed before installation of the sheet pile barrier.

\subsubsection{Direct-Coupled Barrier}

The direct-coupled barrier system concept 18 is in reality a double barrier system consisting of the coupling of a cone grout permeation barrier where the grout is a chemical grout such as silica gel, and the encapsulation barrier is a hardened resin as previously described. A schematic diagram of the Direct-Coupled Barrier is presented in figure 2.4.2.7. The primary components of the barrier system are the cone barrier installed through a series of closely spaced inclined wells and the permeation grout material is silica gel which provides an impermeable barrier to any material that might possibly permeate through the hardened resin barrier encapsulating the tank and the soil materials surrounding it. The permeation grout material could also be composed of a latex cement grout or some other chemical grout material with suitable viscosity and which would be approved by the regulators. Such a material could also be polyurethane foảm or vinylester styrene or polyester styrene which have somewhat similar properties that are desirable in a barrier material.

The Direct-Coupled Barrier System as conceptualized is a double barrier system designed to be installed under a single tank and not an entire tank farm. This may place it in the category of being a single purpose barrier system that would be installed beneath the most troublesome tanks such as the high heat tank (T-241-106-C) or the hydrogen generating tank (T-241-101-SY) at the Hanford site.

\subsubsection{Controlled Advection (Sequestering Agent) Barrier System}

The Controlled Advection 18 (flow through) Barrier system is a combination barrier and treatment system. The conceptual design of the barrier utilizes a vertical barrier composed of jet grouted or permeation grouted cylinders which are injected from vertical wellbores drilled and spaced as a function of the aquifer permeability in the area, and extend from the aquifer containing the contaminated groundwater to the surface in a semi-circular geometry. A central down gradient section of the barrier is composed of sequestering or reactive agents designed to selectively intercept and reduce contaminated water flow through the aquifer. The conceptual design is presented in figure 2.4.2.8. This system is designed to treat and reduce the level of hazard to the biosphere as a result of migration of contaminant plumes which already exist in the groundwater as a result of improper storage or disposal activities conducted at the Hanford site since the 1940 's era.

The sequestering agents will most likely have to be periodically renewed /or replaced to continue effective treatment over a long period of time. This system is more related to treatment of existing contaminant plumes than providing a barrier system to prevent initial contamination of the groundwater.

\subsubsection{Mined Barrier System}

All of the barrier systems discussed to this point are systems that would be deployed through the drilling of vertical, slant or horizontal wells and the development of a seamless barrier is somewhat suspect. A mined barrier system deployed by using a longwall mining unit to remove a 
3 foot section of soil and install an impermeable rubber mat to block the flow of any liquid that might leak from the single shell tanks is the only sure method of installing a barrier in the subsurface in which the regulatory agencies could be comfortable that they would be 100 percent effective.

The approach would be to determine the most safe and effective depth at which the barrier would be installed. The mining operation would start on the surface with stabilization of the roof area before mining into the subsurface to the required depth and then turning the unit into a horizontal orientation. A 480 foot wide by 650 foot long rubber mat would be unspooled by the longwall mining unit each time the cutter head unit was advanced. The mined material would be immediately backstowed on top of the rubber mat. If desirable, a cement mixture could be mixed and blown in with the mined material to add an additional element of safety to the barrier system.

This unit would have to be operated as a robot unit because of the high likelihood of encountering highly radioactive contaminated materials beneath some of the tanks which are known to have leaked. Robot units with Video monitors are believed to be able to successfully mine and install the rubber barrier material without exposing any human being to high levels of radiation. A conceptual design of a robot mined barrier system is presented in figure 2.4.2.9. This system could result in the accumulation of additional contaminated material at the surface since 100 percent of the material mined cannot be back stowed.

\subsubsection{Screening Criteria Development}

In order to be able to select a barrier system that will meet all of the requirements a set of criteria must be developed that will aid in selecting the barrier system most likely to function for a given set of functional requirements.

The barrier systems performance requirements provide the guidelines for development of screening criteria. The following list of criteria are generic and as such identify all of those that are critical to the performance of a subsurface barrier designed to block the flow and / or contain leaked contaminant material from a surface or near surface source. A specific set of screening criteria can be developed for a specific site or region of the country since a number of factors are developed that relate to, or are controlled by a specific site. All of the screening factors listed below will help in selecting the proper barrier system that is capable of meeting all or most of the criteria developed for a specific site.

\subsubsection{Screening Criteria}

The screening criteria selected to determine which of the various barrier technologies should be given further analysis and consideration for potential deployment at the various DOE sites is presented below. When reviewing the various barrier materials or technologies, if they could not meet these criteria, they were dropped from further consideration. The criteria presented below are related to DOE environmental or programmatic requirements.

- Barrier system is technically feasible 
- Is applicable to other DOE sites

- Can be applied to one or more USTs

- Will not require manned excavations near a tank (within a few feet)

- Will be able to contain present or future leaks from tanks during remediation (tank material retrieval) activities

- Will not mobilize contaminants already present in the soils

- Will not limit or reduce permanent closure options for DOE

The results of applying the above initial screening criteria to the list-of subsurface barrier systems identified is presented in table 2.4.5.1.

\subsubsection{Performance Criteria}

Performance criteria that will likely be important in determining the performance of subsurface barriers are identified below. They will be important in evaluating the performance of full scale demonstration tests of the selected barrier systems.

- Perform under local geologic/hydrologic conditions

- Perform for design life of 1 to 25 years

- Stable with time under increased temperature and radiation conditions

- Durable - resistant to chemical, radiological, biological, and physical attacks

- Will retain radionuclides and other hazardous liquid contaminants

- Will be able to perform after moderate earthquake episodes

- Criteria that is important in determining the performance of subsurface barrier technologies were compiled

\subsection{Geologic/Hydrologic Criteria}

The following geologic criteria define the types, sources, nature and structure of materials that will have an impact on the performance of a barrier system.

- Material barrier will function in:

- Soils

- Unconsolidated sediments

- Consolidated sediments 
- Type of material (source rocks)

- Sedimentary

- Igneous

- Metamorphic

- Type of bedding

- Horizontal

- Foreset

- Choatic

- Geologic structure

- Anticlinal

- Synclinal

- Flat

- Monoclinal

- Grain Size

- Range, mm

- distribution

- median ( $50 \%$ finer by weight)

- $\quad$ Accessory Minerals

- Clays

- Heavy minerals

\subsection{Hydrologic Criteria}

The following hydraulic properties of materials at a site will determine their ability to accommodate the installation and function of a subsurface barrier:

- Hydraulic Conductivity $(\mathrm{k}) \mathrm{cm} / \mathrm{sec} ; \mathrm{m} /$ day

- Material Porosity ( $\phi$ ) - pore space as percent of bulk volume

- $\quad$ Saturation $\left(\mathrm{S}_{\mathrm{w}}\right)$ - percent of pore space filled by water

- Critical Water Saturation $\left(S_{w c}\right)$ - saturation value below which no continuous phase of water is able to flow (exclusive of vapor phase transport)

- Direction of Flow of Groundwater - (N,E,S,W etc)

- Groundwater Flow Gradient - $\mathrm{m} /$ day; $\mathrm{m} / \mathrm{yr}$

- Depth to Groundwater Table $-\left(S_{\mathrm{W}}=100 \%\right)$

- Thickness of Aquifer - $\mathrm{ft} . /$ or $\mathrm{m}$ 
- Depth to Capillary Fringe $\left(S_{w c}\right.$ to $\left.S_{W}=100 \%\right)$

- Thickness of Capillary Fringe

- Rate of Recharge of Aquifer

- Source of Recharge

\subsection{Climatic Criteria}

Climatic conditions that exist in the region of a site will affect the hydrologic properties of the site. Some barriers may not be able to be installed or function is areas where the soils are highly saturated with water (e.g. circulating air barrier). Other barriers will not function in areas that have low soil water saturations (e.g. freeze barrier). The following climatic types define the prominent range of climatic conditions that would impact subsurface functionality.

- $\quad$ Arid

- Semi-Arid

- Temperate

- $\quad$ Rain Forest

\subsection{Chemical Activity Criteria}

A selected barrier material must be able to withstand contact with caustic or abrasive chemicals which may leak from the storage tanks, therefore the material must be able to maintain its integrity although it remains in contact with the leaked contaminant material for months or years. The following criteria are important in defining the type of barrier material acceptable for use in the subsurface:

- Non-reactive to contaminant chemicals

- Inert or non-reactive to ground water or subsurface migrating waters

\subsection{Method of Deployment}

The method of deployment required by the material may impact the area in which it can be deployed. The following are possible deployment methods that should be considered in the selection of a barrier material:

- Surface

- Trenches

- Directional wells

- $\quad$ Subsurface 
- Vertical Wells

- Inclined Wells

- Horizontal Wells

\subsection{Barrier Deployment Costs - \$/sq meter}

The costs of deploying a particular barrier or barrier material will have a major impact on the potential for it's selection. The following are elements of cost that should be considered in the selection of a barrier or barrier material:

- Permit Application Costs

- Labor Costs

- Construction materials costs

\subsection{Maintenance Activity- Costs}

Maintenance activity costs are another important criteria by which the probability of installation should be weighed. These costs would have to be compared with the maintenance costs for other barriers. The selected criteria are relative to other barrier materials or systems.

- Low

- Moderate

- High

2.4.3.2.8 Secondary Waste Generated - cu. meter waste / cu. meter barrier installed

- Low

- $\quad$ Moderate

- High

\subsubsection{Barrier System Selection Criteria}

The technologies which passed thru the screening process were then tested against a set of selection criteria These criteria were the principal elements used in selecting the candidates with the best qualifications for application to one or more of the DOE facility $s$ which may be related to specific climatic conditions which may augment their chance for success.

Specific criteria applied to determine systems for additional testing were:

- Ability to function under site specific conditions 
- local soil and geologic conditions

- local climatic conditions

- tank design

- radiation effects

- Potential impact on USTs

- Waste minimization aspect

- Can overcome site constraints

- Degree of contamination control

- Amount of disturbance to UST on installation $i$

- $\quad$ Can meet Health \& Safety requirements

\subsubsection{Performance Criteria Development}

Performance criteria that will likely be important in determining the performance of subsurface barriers are identified below. They will be important in evaluating the performance of full scale demonstration tests of the selected barrier systems.

- Perform under local geologic/hydrologic conditions

- Perform for design life of 1 to 25 years

- Stable with time under increased temperature and radiation conditions

- Durable - resistant to chemical, radiological, biological, and physical attacks

- Will retain radionuclides and other hazardous liquid contaminants

- Will be able to perform after moderate earthquake episodes

\subsubsection{Selection Criteria Development}

A series of selection criteria were selected for use in reducing the total number of barrier technologies that should be considered for further research and development activities. These criteria were used in the selection of four technologies for additional consideration for research and development activities.

- Provides for public health and safety considerations

- Degree of stress induced on USTs during barrier installation 
- Can be permitted under current regulatory environment

- Degree to which barrier can be installed in limited spaces

- Degree of subsidence or upheaval created during operation

- Degree of contamination control

- Degree of success of mating horizontal to vertical barrier elements

- Volume of excavated sediments brought to surface

- Degree of accommodation of infrastructure support (pipelines)

- Degree to which emplacement can be verified

- Degree to which barrier can function under local conditions (soils, geohydrologic)

- Proximity of main element of barrier to USTs.

- Life cycle cost/benefit

- Degree of public acceptance

\subsubsection{Deployment Systems for Barrier Installation}

All of the barrier systems described thus far require the use of drilled boreholes, either vertical inclined, or horizontal for the deployment of one or more aspects of the barrier system. In The In-situ Vitrification system used cased boreholes to conduct electric current for development of the encapsulation barrier system. The freeze barrier uses slant wells to circulate the refrigerant that creates the ice barrier. The desiccant barrier, permeation barrier, and jet grout barrier system all require boreholes drilled to the depth the barrier is to be installed where the barrier material is to be injected. the only barrier that does not utilize boreholes for deployment is the mined barrier system. This system uses a longwall coal mining machine system, including the roof shields to install a geomembrane of rubber upon which the mined material is backstowed thus trapping any fluid contaminants.

\subsubsection{Evaluation and Ranking of Barrier Systems}

The screening criteria presented in section 2.4.3.1 was used to provide the initial screening of the various barrier systems identified. Table 2.4.5.1 presents the results of the screening operation using the selected criteria against the barrier systems.

As a result of the initial screening activity as shown in table 2.4.5.1, In-situ Vitrification is eliminated as a potential subsurface barrier system for additional screening and ranking consideration. In-Situ Vitrification is a stabilization technique as opposed to a barrier technique. 
Eight other barrier systems identified from government and public publication sources were approved for additional and more detailed screening.

\subsubsection{Application of Selection Criteria to Remaining Barrier systems}

The scoring and ranking of the remaining barrier systems are presented in table 2.4.5.2 and figure 2.5.2.1. The method of scoring was to utilize BDM engineers and scientists to examine and score each barrier system against the selection criteria developed. The evaluation was performed individually but in a group setting where each participant could be briefed about any aspect of the barrier system he or she was not familiar with by a staff member who was familiar with the system. An initial overview of each system was presented and each of the scoring criteria was reviewed. The individuals then proceeded to score each barrier system against the criteria. Some of the barrier systems under consideration have undergone field trial demonstrations while others have had either conceptual or feasibility studies completed. All of the information known was made available to the participants before the scoring was completed. ${ }^{i}$

The Desiccant Barrier (CAB), the Permeation Grout (Cone Grout) Barrier, the Freeze Barrier, and the Direct-Coupled Barrier Systems were the highest scoring barrier systems. The CAB and Cone Grout Barrier were the highest scoring barriers, and recommendations for research to support the potential application these barriers will be presented.

\subsubsection{Identification of Key Problem Areas Needing Additional Evaluation}

Key problems that may arise in the actual field demonstration of the ranked barrier systems have been identified. Some specific aspects of the deployment or functioning of the identified barrier systems are defined as areas where additional investigations should be performed to increase the effectiveness of the barrier, or to better project the potential application of the system under specific requirements.

\subsubsection{Desiccant Barrier System Additional Evaluation Needs}

The air drying process is controlled by the formation porosity, permeability, and water saturation and the carrying capacity of the circulating gas to be used in the desiccation process. The rate of vapor phase transport is a function of the humidity and temperature of the input air (gas) and the barrier system reservoir temperature. Because of the potential for reaction of some contaminants with oxygen in the air, the use of nitrogen gas needs to be examined to determine if the vapor phase transport properties are very similar to that of air.

A primary issue for the Desiccant Barrier system is its ability to function at DOE sites located in temperate climates. The Barrier was designed to function in semi-arid climates where the soil saturation is at or below the mobile water saturation initially, therefore determining the optimum saturation levels as a function of grain size and grain size distribution, porosity, permeability, and clay content are issues that must be settled before it can be determined if the barrier is applicable to all DOE sites.

Baseline equilibrium moisture content curves should be developed for a specific grain size. Relative humidity should be determine for a specific temperature. The relationship of equilibrium 
humidity as a function of water saturation should be determined. The reservoir saturation percent at which air (gas) saturation is less than $100 \%$ should be determined The effects on flow and sweep efficiency for the fixed grain size reservoir as the dried air (gas) flow temperature is increased above ambient reservoir temperature should be determined to evaluate the desiccation process at elevated temperatures. Intuitively, it is believed elevated temperatures will allow adsorption of additional water that will be dropped out of the vapor phase as the temperature comes to equilibrium within the reservoir which is being processed. This could lead to by-passing of accumulations of water in some areas of the reservoir by the dry air vaporizing the water. It would be a process of remobilizing the water a number of times before being produced and also increasing the probability of producing some contaminants.

After this data has been obtained for a fixed grain size (for instance medium grain size 0.25 to $0.50 \mathrm{~mm}$ ) of for example $0.43 \mathrm{~mm}$ which is the size of a 40 mesh per inch sieve, then a second larger grain size should be used such as $1.0 \mathrm{~mm}$ or 20 mesh per inch serve. The final series of tests should be run with a mixed grain size distribution that resembles the sediments at Hanford site. Collection of this data will allow evaluation the highest water saturation in which it would be prudent and economical to establish a desiccant barrier

These test runs should be made with nitrogen gas from bottles which will already be dry gas, and will not require any treatment except to reduce the gas to 55 degrees which is the nominal reservoir temperature at most sites in the U S. In addition, the benefits of using air with higher levels of either nitrogen or carbon dioxide should be examined to provide guidelines for the types of gases that are not only safe to use, but to examine the drying efficiency of the gases as well. The most efficient non-reactive gas (relative to contaminants) should be determined.

The effects of localized radiogenic heating ( +2 to 5 degrees above ambient) of the reservoir as a result of leaked contaminants should be investigated to determine the potential effects on an otherwise nearly isothermal desiccation process.

\subsubsection{Permeation Grout Barrier Identified Research Needs}

The permeation grout barrier concept as defined was associated with the cone grout process where inclined wells were drilled and the spacing between the wells is determined by the distance of penetration of the grout material with allowances for overlap to assure bonding. The distance of penetration is controlled in turn by the viscosity and setting time of the grout. That in turn is dependent upon the specific grout material selected for the particular application. There have been a number of materials that have been identified as potential grouts for application at the Hanford site. Four such materials are a microfine cement with $1 \%$ latex, montan wax, sodium silicate, and hydrophobic polyurethane foam. The first three materials have been field tested, but the polyurethane foam has not been tested.

Bodocsi 15 and Bowers, 1991, tested hydrophilic polyurethane formulas and the permeability to 14 different chemicals. The results indicate that hydrophilic polyurethanes are attached and become more permeable when exposed to 10 and $20 \% \mathrm{NaOH}$ solutions. 
A key issue to be determined is whether a hydrophobic polyurethane formulation will be attached and made more permeable to $20 \% \mathrm{NaOH}$ solution. Most of the liquid wastes stored in the single shell tanks at Hanford contain $\mathrm{NaOH}$ and $\mathrm{NaNO}_{3}$ solutions.

Analysis of the deployment and operation of a cone grout barrier system revealed that a strong possibility exists that a cone grout barrier constructed of microfine cement with its cone shaped geometry would be subject to movement downward in the event of a 4.5 or larger, Richter scale, earthquake. The utilization of a lighter grout material such as polyurethane foam would likely not be cracked or move downward in the event of an earthquake, thus the rationale for testing a lighter, non-toxic barrier material is well grounded. Urethane chemistry is complex and many different formulations can be generated, therefore a review of current commercial products that have undergone tests should be conducted and testing should be confined to those

formulations that produce products close to that required. The following are physical and chemical properties required of a urethane (chemical) grout material that can be successfully deployed as a subsurface barrier:

1. The material should be nearly impervious to basic chemical contaminants such as $\mathrm{NaOH}$ for a period of years.

2. The material should be flexible and able to withstand small scale earthquakes.

3. The material should be light with a density close to that of water.

4. The material should have a viscosity that is low, ranging from 1 to 5 centipoise.

5. The material should have a set time of more than 1 hour and probably closer to 2 hours to allow for displacement of the grout up to 6 feet before initial set begins to retard flow.

6. The expansion of the polyurethane to form a flexible foam should be a controlled reaction, that is, a three to five fold increase in volume should occur over a matter of minutes rather than seconds to reduce expansion stresses that might be propagated upward to the overlying tanks.

7. The material should be resistant to radiation effects from gamma radiation and radiogenic heating.

\subsection{Discussion of Results}

\subsubsection{Screening Activities}

The results of the screening activities in which technical reviews of each barrier system was presented to a group of professionals and each scored the ability of each system reviewed to comply with the screening criteria element. The scoring and ranking table is presented in figure 2.5.1.1 while a graph of the numerical scores is presented in figure 2.5.1.2. The Desiccant Barrier (CAB), the Permeation Grout (Cone Grout) Barrier, the Freeze Barrier, and the Direct-Coupled Barrier Systems were the highest scoring barrier systems. 


\subsubsection{Selection Activities}

A review of the attributes of the highest scoring barrier under the screening system revealed that the freeze barrier has had one or more field demonstrations with varying degrees of success, and the Direct-Coupled barrier is a composite of two barrier systems, encapsulation and cone grout. The systems with perhaps the greatest potential for application as either a single barrier or part of a compound or combined system are the Circulating Air Barrier System, and The Permeation Chemical Grout System. These two remaining systems have been tested in some form but additional significant questions remain to be answered concerning deployment of chemical grouts, and rate of vapor phase transport. BDM recommends that these two systems undergo additional

The Permeation Grout (Cone Grout) Barrier and Desiccant Barrier (CAB) were the highest scoring barriers, and recommendations for research to support the potential application these barriers is recommended.

\subsection{Conclusions And Recommendations}

\subsubsection{Conclusions}

As a result of the literature review and analysis of several barrier systems, BDM believes that the systems used during the coming remediation efforts to be conducted on the single shell tanks at Hanford and other DOE sites should be as non-intrusive as possible, and should not foreclose on future potential remediation activities that might be desired or required at these sites. The circulating air barrier and the freeze barrier fits this description. The use of material which forms monolithic barriers in conjunction with the soils or rock materials will preclude any further activity in the area where the barrier is deployed.

The combination of the Freeze Barrier as the primary barrier with the Circulating Air Barrier as the second or backup barrier is a combination and approach that should be given serious consideration if DOE's decision is to continue the remediation process in the soils beneath the single shell tanks after the tanks have been emptied and removed. If however, DOE decides to abandon the material in place as landfills, then the permeation grout barrier in conjunction with the encapsulation barrier would appear to be the most adequate system to be considered.

It therefore seems prudent to continue to research in detail the unknowns that remain to be examined before these processes are to be cold tested at Hanford and eventually installed.

\subsubsection{Recommendations}

BDM recommends that additional research be conducted in support of the Circulating Air Barrier, and the Permeation (Cone Grout) Chemical Grout Barrier as key elements of potential barriers that may be installed at Hanford and other sites in support of remediation operations since these two systems will support the two options that DOE faces; complete remediation of contaminants or abandonment in place of contaminants. 


\subsection{List of References}

1. Siskind, Barry, and John Heiser, "Regulatory Issues and Assumptions Associated With Barriers in the Vadose Zone Surrounding Buried Waste", Brookhaven National Laboratory Informal Report BNL-48749, US DOE Contract No. DE-AC02-76CH00016, Feb. 1993

2. "DOE UST Interim Subsurface Barrier Technologies Workshop" Tuscon AZ., Feb. 25-27, 1992, Bovay Northwest Inc.

3. Harrington, R.A., "Subsurface Barrier Study for Tank 106-C and C Tank Farm", Kaiser Engineers, Jan. 10, 1993

4. Krieg, Ronald $\mathrm{K}$., Blaine, John $\mathrm{T}$., and Drumheller, Issawauh, "Closed Cryogenic Barrier for Containment of Hazardous Material Migration in the Earth", U S Patent No. 4,860,544, Aug. 29, 1989

5. Dash, J. G., "Frost Heave: Relevance to Underground Storage Tanks", RKK Inc. Technical Report, May 6, 1992

6. Bates, Steven O., "In Situ Vitrification of Buried Waste" E.\&G, Idaho, for DOE INEL, Contract No. DE-AC07-761001570, Waste Management 92 Proceedings, and EGG-WTD-9807, Aug., 1991

7. Luey, J \& T.D. Powell, "In Situ Vitrification of Buried Waste: Containment Issues and Suppression Systems, Pacific Northwest Laboratories, US DOE Contract DE-AC06-76RL01830, Waste Management 92, pp 1529-1533

8. Banno, Katsunori, and Hiroshi Yoshida, "Bottom Barrier by New Soil Improvement Method (Superjet) to Confine Vertical Plume of Contamination", Kajima Corporation, Tokyo, Japan, Waste Management 94 Conference proceedings, pp. 1063-1066

9. Pettit, Paul J. , and David Ridenour, Jeffrey Walker, Kent Saugier, "Demonstration of In SituConstructed Horizontal Soil Containment Barrier at Fernald", Waste Management 94 Proceedings, Vol. II, pp. 1053-1056.

10. Rezaiyan, A.J., T.A. Towers, H. R. Johnson, W.K. Overbey and S.P. Salamy, "Design of The Circulating Air Barrier For Cold Tests at Hanford", US DOE, Proceedings of Waste Management 94 Symposia, Vol. II, pp 845-851

11. Acheson, Willard P.,Terrie A. Towers, Kendrick W. Wentzel, Harry R. Johnson, and William $\mathrm{K}$. Overbey, "Evaluation of Alternative Drilling Technologies and Subsurface Confinement Barriers For Single Shell Tanks at Hanford, Proceedings of Waste Management 93 Symposia, Vol. II, pp. 1058-1063. 
12. Thomson, Bruce M., Carl E. Morris, John Stormont, Mark D. Ankeny, "Development of Dry Barriers for Containment and Remediation of Waste Sites", Proceedings of Waste Management 94 Symposium, Vol. III, pp. 2193-2198

13. Naudts, Alex, "Families of Grouts and Their Applications", Paper Presented at First International Grouting Conference, Toronto, Ontario, Canada, April, 1989

14. "Design of Cone Grouting Barrier System for Cold Test at Hanford" K\&M Engineering and Consulting Corp. \& BDM Federal Inc., Report to DOE Contract No. De-AC21-90MC27347, July 1994

15. Bodocsi, Andrew, Mark T. Bowers, "Permeability of Acralate, Urethane, and Silicate Grouted Sands With Chemicals", Journal of Geotechnical Engineering, Vol. 117, No. 8, pp. 12271245, August, 1991

16. Naudts, Alex, " Revolutionary Changes in the Grouting Industry Resulting From Polyurethane Injection Technology", Second International Grouting Conference, Toronto, Ontario, Canada, May, 1990

17. Heiser, J., H.P. Columbo, and J. Clinton, "Polymers for Subterranean Confinement Barriers for Underground Storage Tanks", CH321203, Brookhaven National Laboratory, Brookhaven, New York, 1992

18. Phillips, S.J., W.E. Stewart, R.G. Alexander, K.J. Cantrell, and T.J. McLaughlin, "Subsurface Barrier Design Alternatives for Confinement and Controlled Advection", Proceedings of Waste Management 94 Symposia, Tuscon Arizona, VVol. II pp. 1041-1046, 1994

19. Peng, S. S., and H.S. Chiang, Longwall Mining, Wiley, New York, NY, 1984

2.8 Figures And Tables For Chapter 2.0 


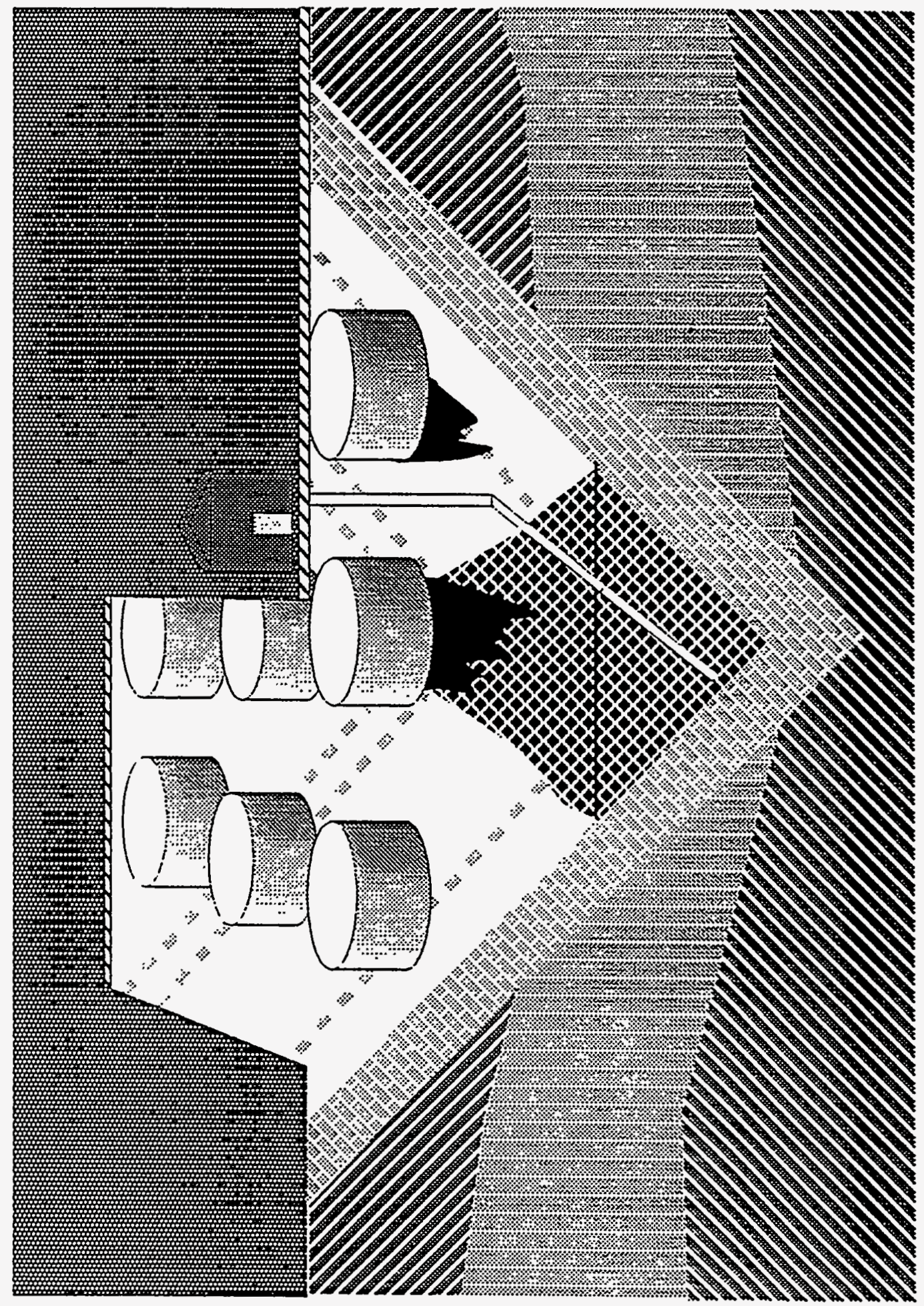

Figure 2.42.1 Freeze Grout Barrier 

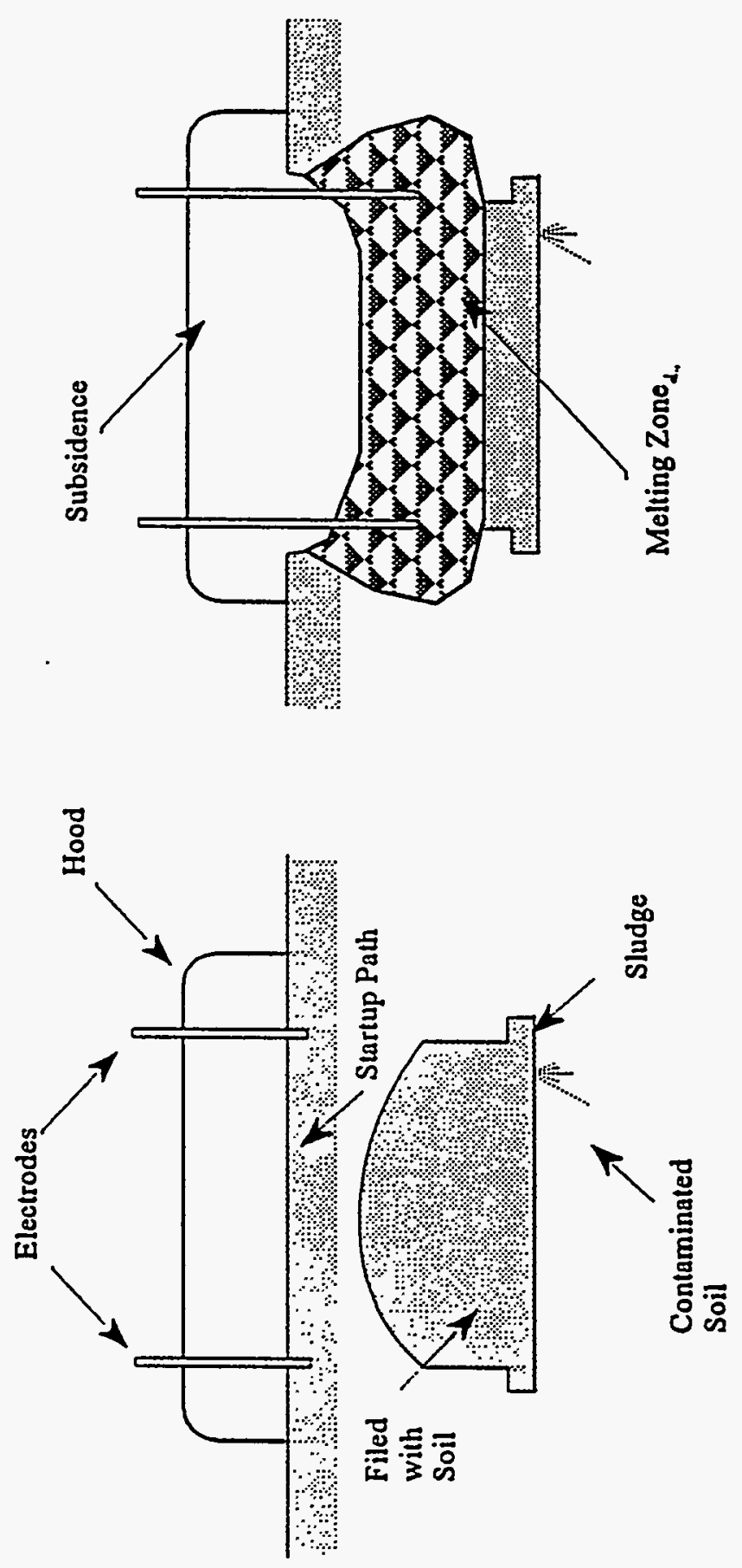

Figure 2.4.2.2 Underground Tank In-Situ Vitrification 


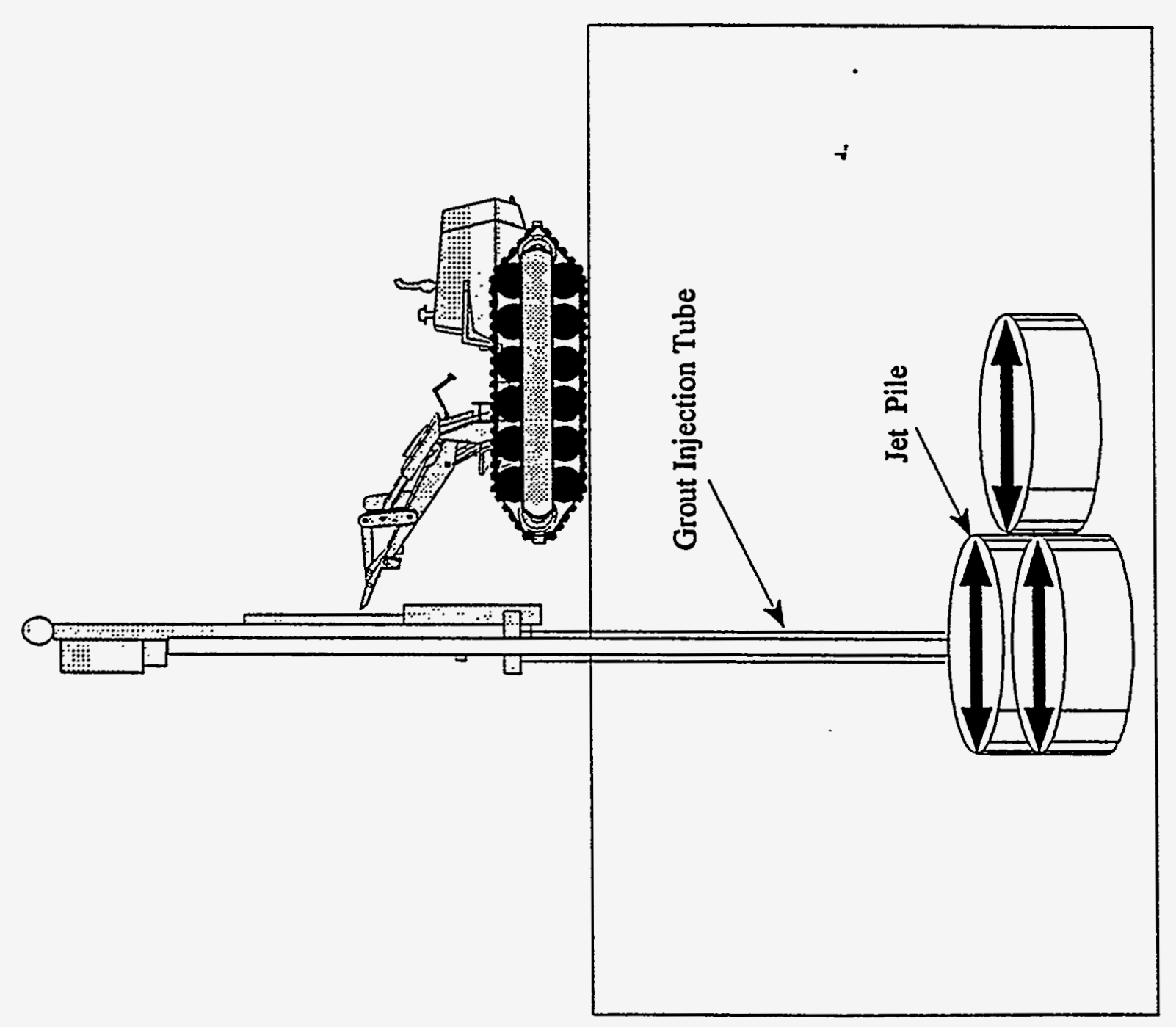

Figure 2.4.2.3 Jet Grout Barrier 

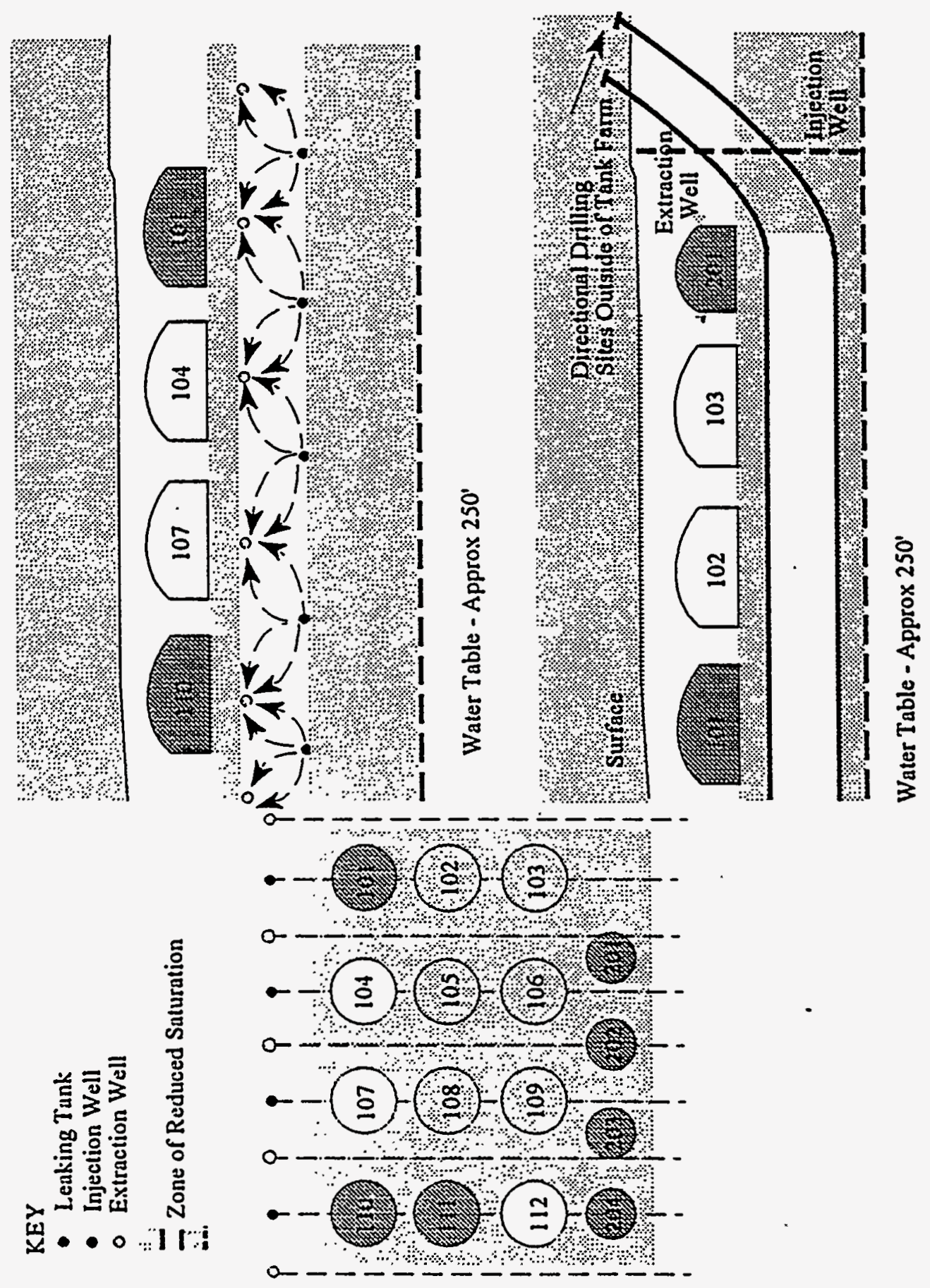

Figure 2.4.2.4 Circulating Air Barrier 


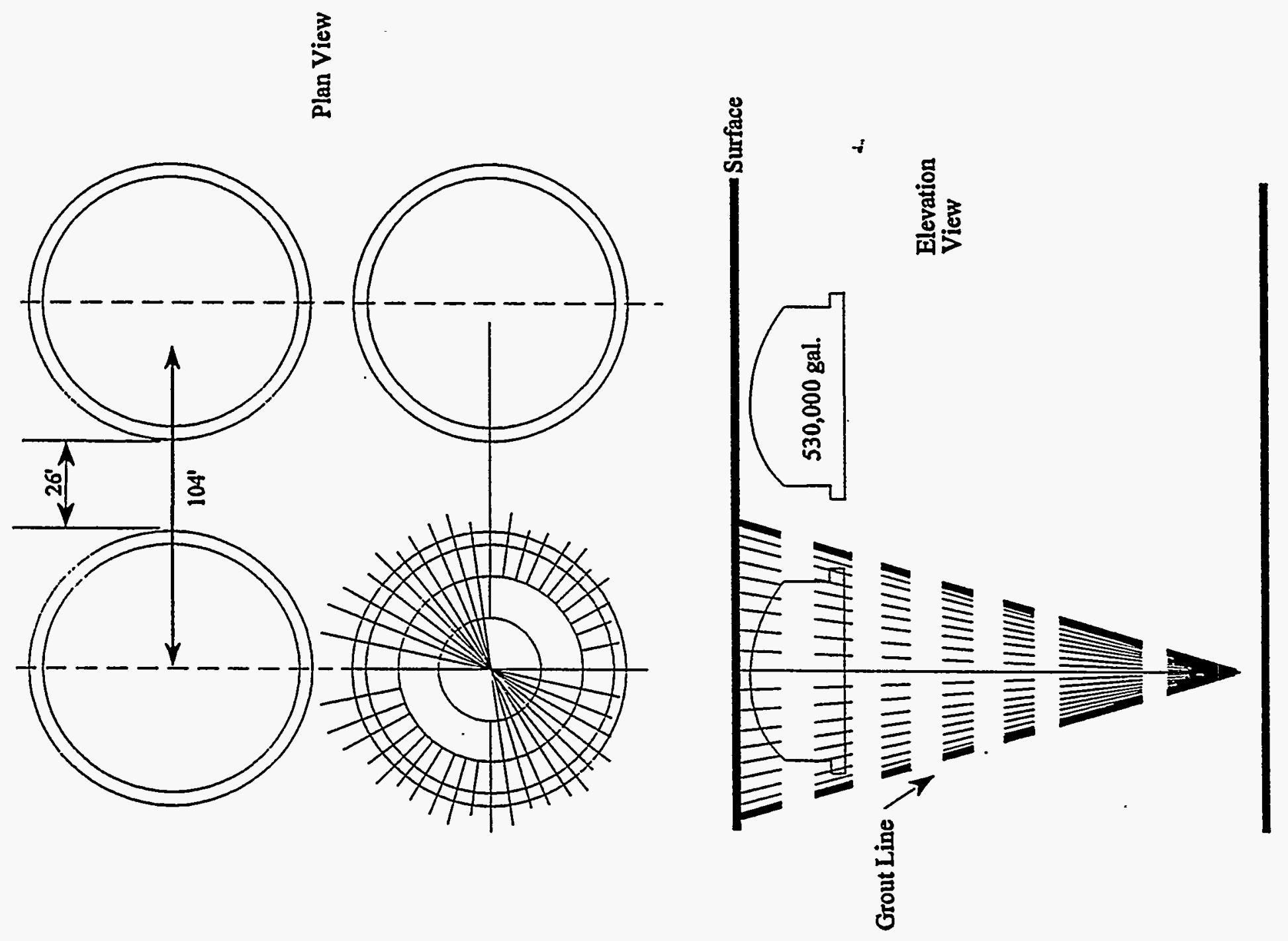

Figure 2.4.2.5 Permeation Grout Barrier 


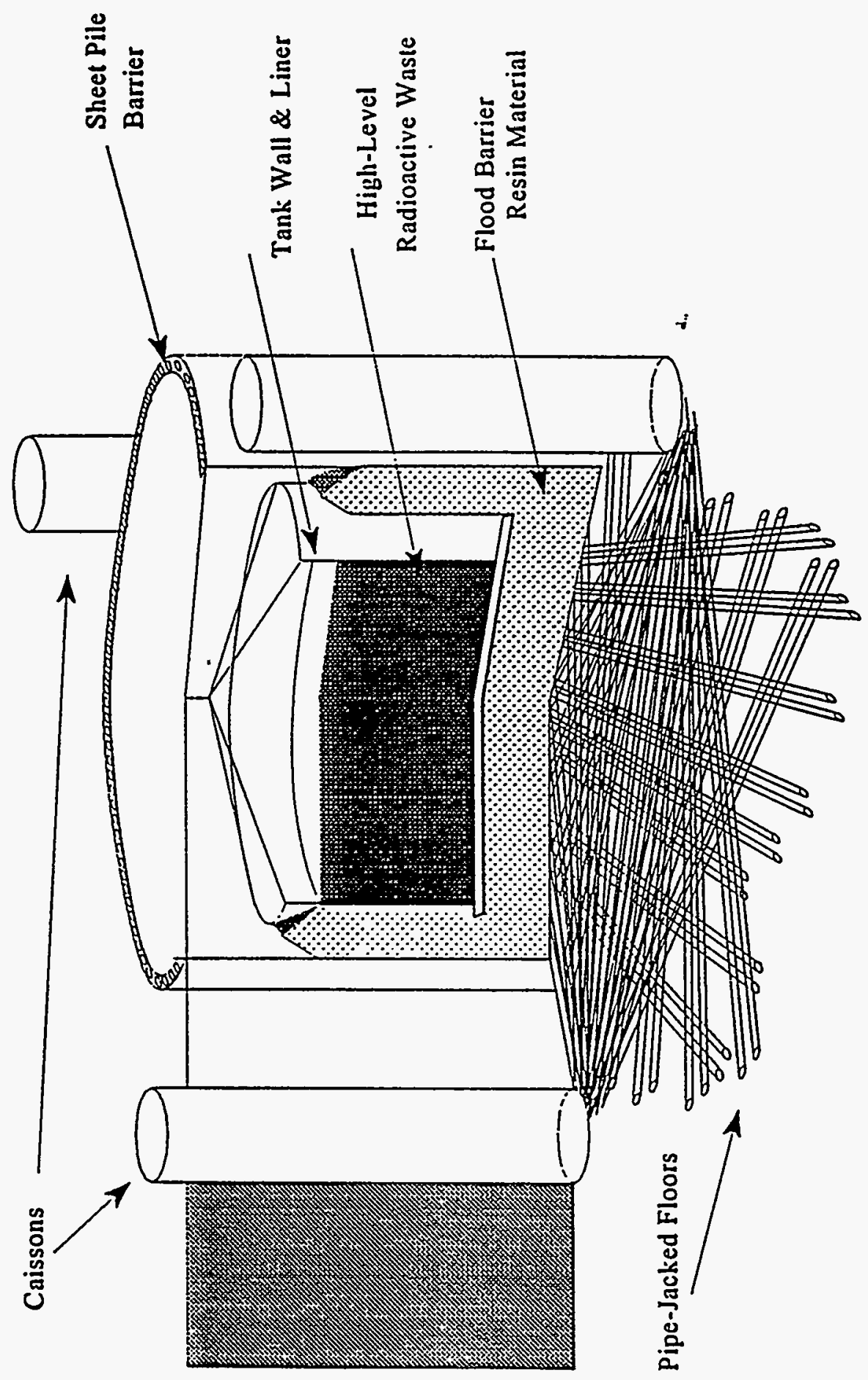

Figure 2.4.2.6 Encapsulation Barrier 


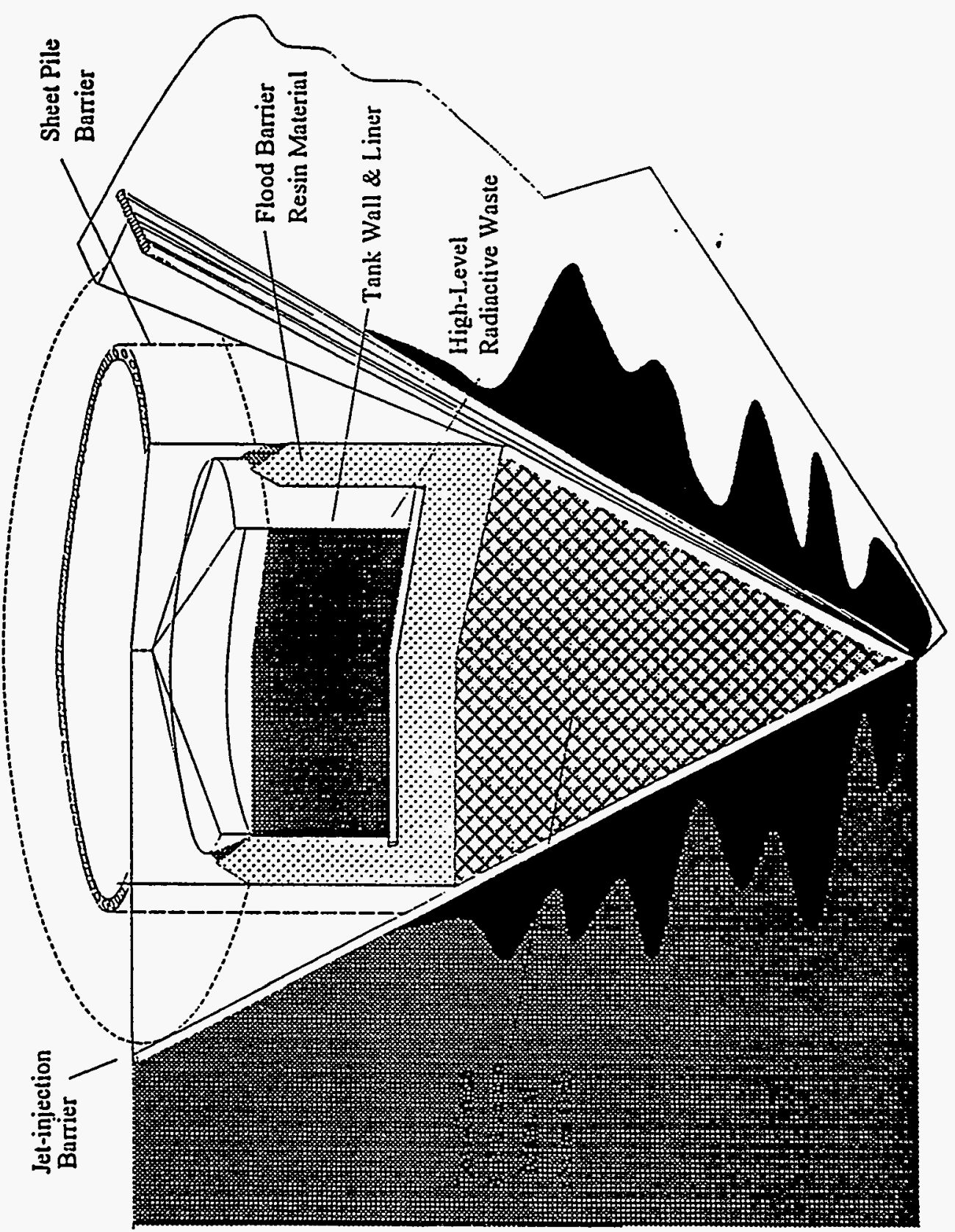

Figure 2.4.2.7 Direct-Coupled 


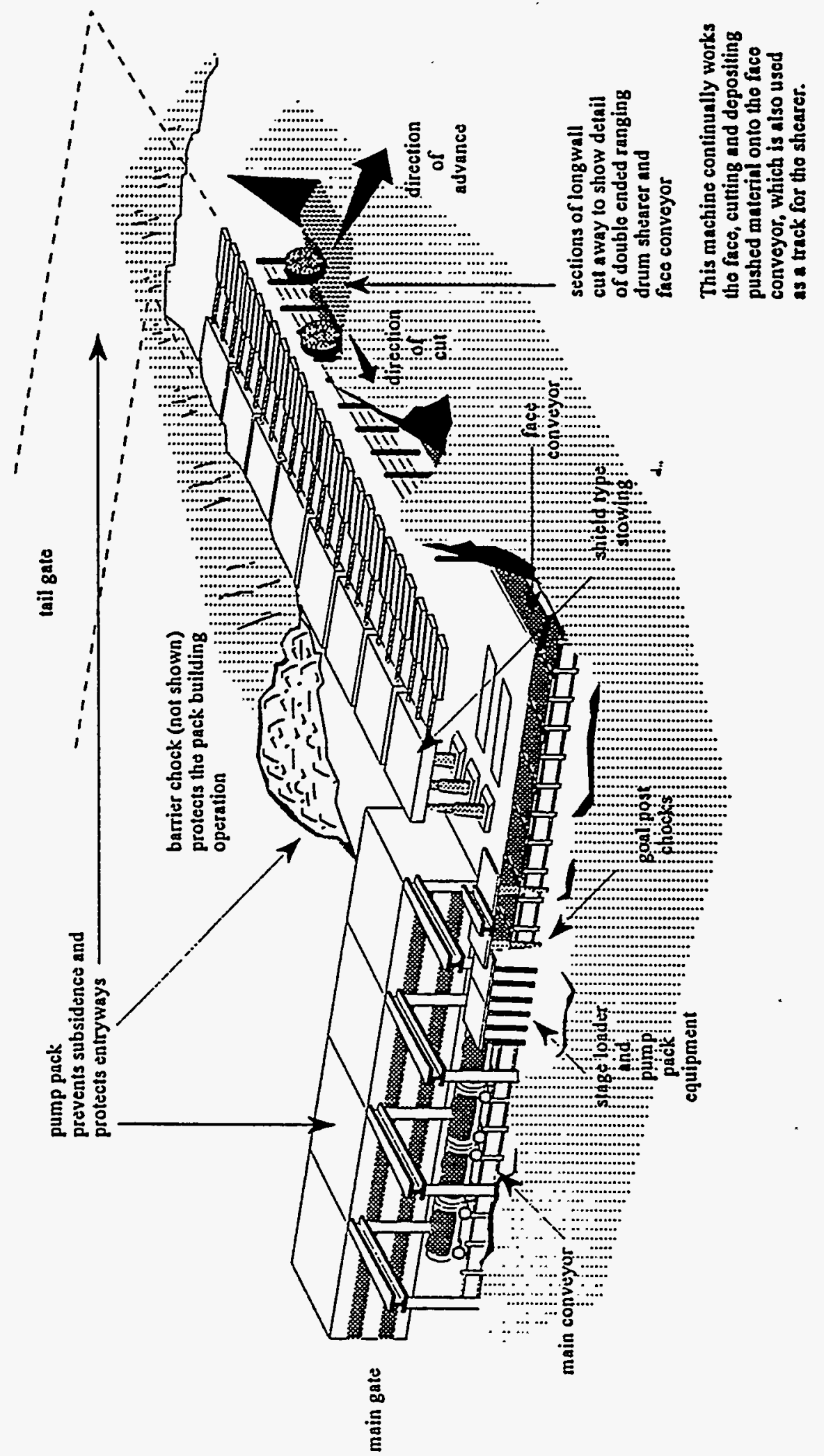

Figure 2.4.2.9 Schematic Diagram of a Robot Mined Barrier System 


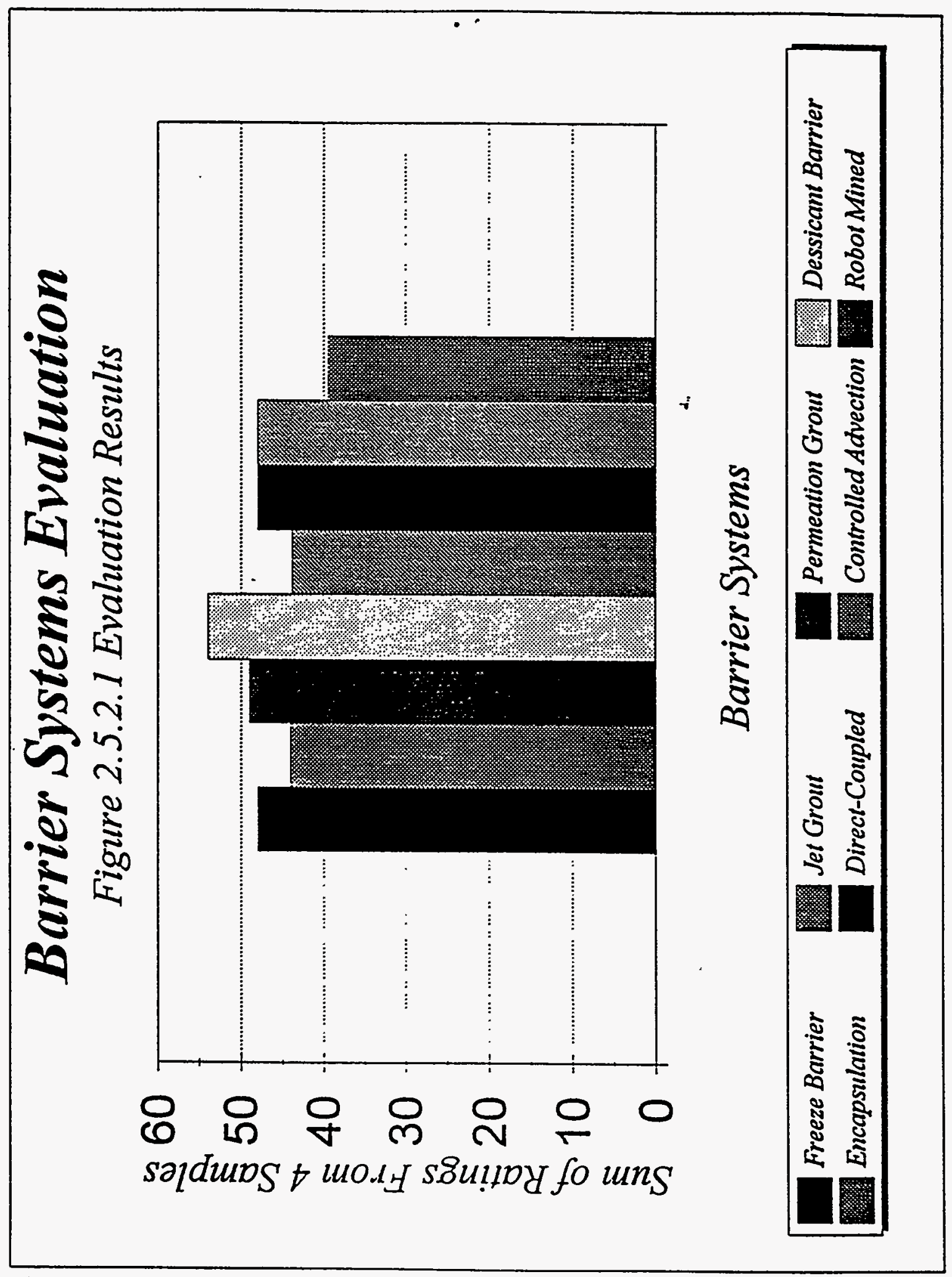

Figure 2.5.2.1 - Ranking of Barrier Systems Results 
$\operatorname{son} X=10 N=0-\operatorname{OION}$

\begin{tabular}{|c|c|c|c|c|c|c|c|c|c|}
\hline או1א & גו:א & או: & S:Is & S:ils & גוl & S:I & או:צי & ()$N$ & Cl:1.1.7);IIIIS \\
\hline 1 & 1 & 1 & 1 & I & 1 & 1 & 1 & 11 & 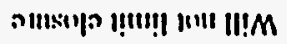 \\
\hline 1 & 1 & 1 & 1 & I & 1 & 1 & 1 & 1) & M!" \\
\hline 1 & 1 & 1 & 1 & $\mathbf{I}$ & 1 & 1 & 1 & 1 & (1) \\
\hline 1 & 1 & 1 & I & 1 & 1 & 1 & I & 1 & 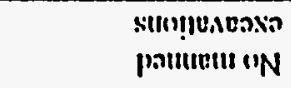 \\
\hline 1 & 1 & I & 1 & 1 & 1 & 1 & 1 & 1 & 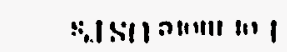 \\
\hline 1 & & 1 & & I & & 1 & 1 & 1) & | \\
\hline 1 & 1 & 1 & 1 & 1 & 1 & 1 & 1 & 0) & 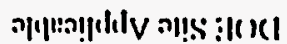 \\
\hline 1 & 1 & I & 1 & 1 & 1 & 1 & 1 & 1 & 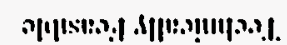 \\
\hline
\end{tabular}

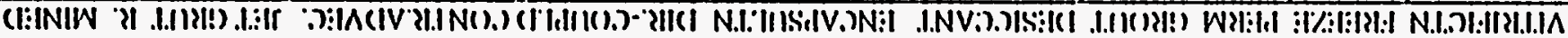

VII:I1.121:)

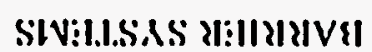

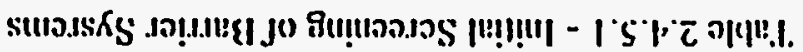




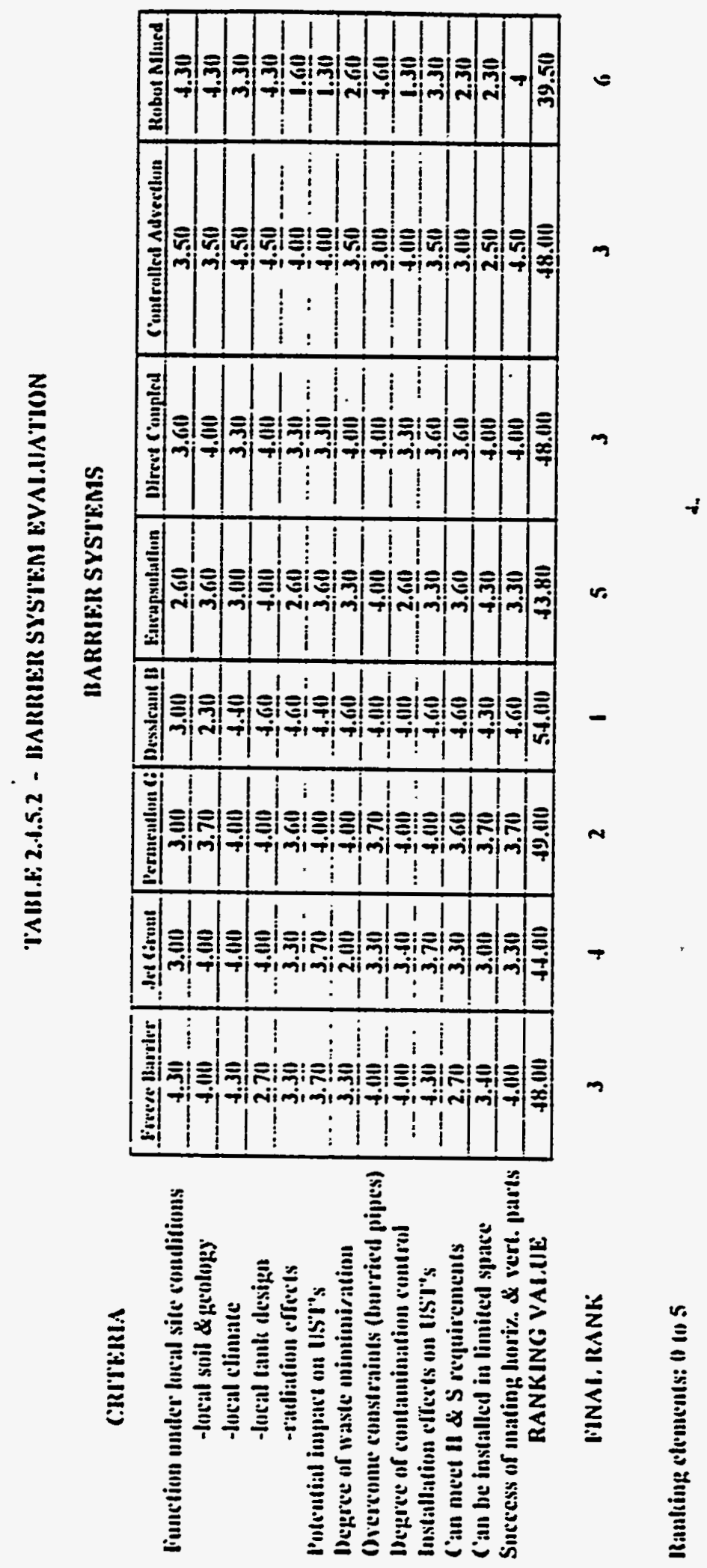

Table 2.4.5.2 - Barrier Systems Evaluation 


\subsection{REVIEW OF CHEMICAL GROUTS FOR USE WITH PERMEATION GROUT DEPLOYMENT SYSTEMS}

\subsection{Introduction}

There are a number of approaches to remediation that are used at contaminated sites. Examples are soil washing/flushing, in-situ bioremediation, vacuum or air stripping, and immobilization techniques. In the case of in-situ bioremediation, organic compound(s) are biochemically degraded within the contaminated subsurface. Air or steam stripping are feasible if the Henry's Law constant of the organic compound(s) is greater than $3 \times 10^{-3} \mathrm{~atm} / \mathrm{m}^{3} \mathrm{~mol}$. In the case of immobilization techniques, contaminants are tightly bounded within a solid matrix that minimizes their migration. Solidification, stabilization, and vitrification are the principal immobilization techniques. Contrary to immobilization, the soil washing/flushing approach promotes contaminant solubilization and migration in the liquid phase so that the contaminants can be easily flushed from the soil matrix.

In parallel to the remediation efforts, confinement and containment technologies are needed to retard, or even prevent, the advancement of the contamination plumes into the environment until the implementation of remediation efforts is completed. Research proposed herein aims at developing and investigating containment/confinement technology using Polyurethane foam and vinyl monomers for in situ formation of barriers. Polyurethane foam (PUF) is a foamed plastic that is manufactured based on the reaction process of isocyanate group with compounds containing active hydrogen groups to form substituted carbamic acid esters, or urethanes. Catalysts are used for control of the reaction rate with surface-active agents added for control of the foam bubble sizes.

The engineering and physical properties of PUF depend on the polymerization and cross linking reactions. Polyurethane foams react with water. Catalysts are used to control the reaction rate and the nature of the foaming process. PUF grout in its unreacted form usually has a viscosity slightly greater than water. Upon activation by water, a closed cell foam forms with gel time varying depending on the type of additives and catalysts.

Hazardous waste disposal sites have often employed simple unlined pits, underground storage tanks (USTs), and lagoons for the storage and disposal of wastes. Leakage from these sites has been a constant source of soil and water contamination. Bottom sealing of hazardous waste sites involves the injection or insertion of an inert impermeable and continuous horizontal barrier in soil below the source of contamination. This type of containment strategy could be used in conjunction with other technologies such as slurry walls, capping, and counter pumping to insure that contaminants do not migrate from the site into the surrounding soil and groundwater.

This literature review examines liquids which, when injected into the subsurface, produce chemically and biologically inert impermeable barriers through a very large increase in viscosity. Although cement, fly ash, and other pozpozalanicterials have been utilized for grouting, focus will be directed to the use of chemical grouts to develop bottom seals. Appropriate emplacement of 
these substances provides an effective containment of the contaminated zone by trapping and immobilizing both the contaminant and the plume. Methods of barrier placement will also be discussed.

\subsection{Chemical Grouts}

Chemical grouts are solutions that react to produce a gel or polymer that fills the pore space. The solutions typically have a low initial viscosity that increases rapidly during setting. Chemical grouts consist of compounds that are in solution and are generally made from liquid components. Blending of liquid ingredients in grouts can be done rapidly with little equipment and energy requirements. Chemical grouts can be batch mixed and injected or the components can be pumped together through a static in-line mixer.

Chemical grouts are used to penetrate low permeability soils such as silts and clays, small cavities, and where rapid hardening is needed. Disadvantages associated with chemical grouts include greater cost and potential toxicity (Boury 1994).

\subsubsection{Grout Mixing and Preparation Methods}

In some chemical grout systems, two components are pumped into the ground separately but through the same injection point. Two-solution processes allow for better penetration of the grout; but, the mixing of the reactants cannot be controlled in the soil and pockets of ungrouted soil may be produced (Littlejohn 1985).

In-line mixing is typically used where large volumes of one-solution chemical grout are being placed and short set times are needed to assure that the grout is properly placed. The uniformity of the mix depends on the quality of the metering pumps and the care taken in calibration (May et al. 1985).

Batch mixing involves combining all the components of the chemical grout in one container. The container is emptied by a pump which permeates the mixed grout into the soil being treated. Batch mixing allows the quantity of each grout component going into the mixer to be measured precisely. Batch mixing uses more time than in-line mixing and grouts injected this way are designed with longer set times to compensate for the delay in moving the grout to the injection point. Additionally, batch mixing permits samples to be taken to verify the setting time of each batch. In summary, this method allows for better quality control of the grout.

\subsubsection{Properties of Chemical Grouts}

The properties of chemical grouts vary considerably depending on the nature of its ingredients. Chemical grouts have been used to penetrate variable permeability soils such as silts and clays, small cavities, and where rapid hardening is required. Disadvantages associated with chemical grouts include greater cost and potential toxicity (Boury 1994). Karol (1983) identified the ideal properties of a chemical grout. He stated that basic materials should be:

1. A powder readily soluble in water (reduces transport and solvent costs)

2. Inexpensive and derived from chemicals in abundant supply 
3. Stable at all anticipated storage conditions

4. Nontoxic

5. Noncorrosive

6. Nonexplosive

The grout solution should be:
A. A low viscosity solution comparable to water
B. Stable under all normal temperatures
C. Nontoxic, noncorrosive, nonexplosive
D. Catalyzed with inexpensive chemicals, meeting the criteria of 8 and 9
E. Insensitive to salts normally found in groundwater
F. Of stable $\mathrm{pH}$ on the positive side
G. Readily controlled for varying gel times
$\mathrm{H}$. Able to withstand appreciable dilution with groundwater

And the end-product should be:

I. Permanent gel

J. Unaffected by chemicals found in the leaching fluid

K. Nontoxic, noncorrosive, nonexplosive

L. High strength

It may be visualized that no single grout will meet all of the above criteria thus making it important to determine which grout properties are critical to the success of the grouting project. In general, when selecting a grout for field use, the most important properties for determining their feasibility of use include:

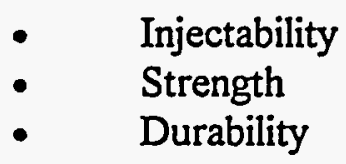

The advantages and disadvantages of commonly used chemical grouts can be found in Table 3.2.1.

\subsubsection{Urethanes/Polyurethanes}

Urethanes/polyurethanes are either hydrophobic or hydrophilic. Hydrophobic urethanes do not like water or are not water reactive. Hydrophilic urethanes/polyurethanes are resin solutions that are water reactive. Because they are water reactive, they can change from a free-flowing liquid to a water impermeable solid that bonds extremely well to wet surfaces.

Urethanes are designed to be mixed with water to initiate the formation of a flexible end-product. It has a moderate viscosity (20-60 cp), a formulation ph of 6.8-7.5, and a tensile strength of 2030 psi (Sherer 1986; Malone et al. 1985). It is prone to shrinkage in unsaturated and dehydrating conditions; however, with addition of moisture, $100 \%$ recovery can be expected. Additionally, in 
its cured form, the grout can be considered completely non-toxic (3M 1994). Urethane can be used for grouting sandy and silty soils.

Polyurethanes are formed by a chemical reaction between two components: an isocyanate and a pall resin. The pall component carries additives which determine the final cure characteristics of the grout (Micon 1994).

For both grouts, the resulting reaction with the active ingredient will release heat. For these grouts the mixing and preparation requirements are site specific and job-specific. One urethane based grout (Chemical Grout 5610 manufactured by $3 \mathrm{M}$ ) used for soil consolidation, typically would require in excess of eight gallons of water to one gallon of urethane, but when used for filling large fissures and cracks, it required a less dilute mixture (3M 1994).

These grouts can be injected in two forms: (a) foam or (b) gel. The foam structure itself is produced by a blowing agent, reacting chemically to produce carbon dioxide (Karol 1983). Foams are used to fill large void spaces such as cracking pipes and fractures in rock formations. They cannot feasibly be employed for sealing fine cracks and soil voids. Gels, on the other hand, have been applied to consolidate soils and fill hairline cracks and fissures making it of interest for bottom sealing at hazardous waste sites. In some instances, it may be appropriate to utilize both forms to develop a totally impermeable seal.

The single most important factor for the proper functioning grout barrier is its ability to maintain a low permeability over the design life span, even if it is exposed to chemical attack. The chemical resistance of polyurethanes/urethanes and many other grouts is well documented in past studies (Sherer 1986; Bodocsi et al. 1988; and Carson 1988). This compound was found to perform extremely well with 100\% acetone, reagent grade aniline, 100\% ethylene glycol, reagent grade xylene, and $1 \mathrm{~N}$ hydrochloric acid. Carson (1988) reported unreliable and variable results with exposure to $100 \%$ methanol. Detrimental affects were observed when the urethane was subjected to cupric sulfate, $4 \mathrm{~N}$ hydrochloric acid, and $10 \%$ and $25 \%$ sodium hydroxide. Additionally, Sherer (1986) reported no variance in permeability due to a two fold increase in confining pressure for a selected number of urethane grouts.

The use of urethane/polyurethane grouts are limited due to their excessive cost and short gel times. Although inhibitors are available, which can extend the gel time to 9-11 minutes, the injection window is extremely small and allows no room for error. A possibility to further increase the gel time is to use a chilled water $\left(7^{\circ} \mathrm{C}\right)$ in the mixing procedure. The $3 \mathrm{M}$ urethane grout is $\$ 314$ per five gallons in pure form and approximately $\$ 7.5$ per gallon when mixed with water. Additionally, all equipment after the point of mixing of the components will be unsalvageable and considered dispensable.

\subsubsection{Sodium Silicates}

Sodium silicate $\left(\mathrm{SiO}_{2}-\mathrm{Na}_{2} \mathrm{O}\right)$ is a commercially available compound as an aqueous (colloidal) suspension. In industry, it is used as an adhesive, catalyst, deflocculant, and as a detergent bleach. When sodium silicate solution and a concentrated solution of the appropriate salt are mixed, a gel is formed almost instantaneously. 
The first successful method for injecting this grout is called the Joosten Process (Karol 1983). This process results in a strong gel which can develop unconfined compressive strengths above $500 \mathrm{psi}$. However, due to the solutions high viscosities $(40-260 \mathrm{cp}$, the process is limited to soil media and necessitates close spacing of grout holes.

Due to the limited applicability of the Joosten Method, research and development aimed at formulating or modifying a silicate-based grout with gel time control and to eliminate any disadvantages of the prior injection process. Sherer (1986) evaluated two modified sodium silicate grout formulations: glyoxal-modified and sodium aluminate-modified. Both the glyoxalmodified and sodium aluminate-modified solutions yielded tremendous control over gel times (450 minutes), resulted in a variable viscosity of 1.5 to $50 \mathrm{cP}$ with a strength of $1-50 \mathrm{gm} / \mathrm{cm}^{2}$. Although both are inexpensive and were found to have low shrinkage, each is prone to extreme syneresis (degradation) in a harsh environment and involves the utilization of caustic raw materials.

\subsubsection{Acrylates}

Acrylates are a resin solution grout. An acrylate grout mixture is a combination of water, the acrylate constituent, triethanolamine (TEA, a catalyst), ammonium persulfate (initiator), and potassium ferricyanide (inhibitor). The inhibitor is capable of extending the gel time from the normal 30 seconds to approximately 40 minutes. The resulting gel is white and flexible with $\mathrm{pH}$ of 7.5 -9.5. Other properties include a viscosity of $1.2-2.0 \mathrm{cP}$ and a tensile strength of $20-200$ $\mathrm{gm} / \mathrm{cm}^{2}$.

This grout had been extensively studied for resistivity to various chemicals (Sherer 1986; Carson 1988; Bodocsi and Bowers 1991). In these studies, the permeability behavior of acrylate grouts in comparison to the urethane grout, was not as resistant. It yielded consistently low permeabilities to solutions of sodium hydroxide, cupric sulfate, acetone, methanol, and for $100 \%$ ethylene glycol and reagent grade xylene. However, increasing the concentration to $100 \%$ for the first four solutions increased the permeabilities well over five orders of magnitude. In addition, reagent grade aniline, and $1 \mathrm{~N}$ and $4 \mathrm{~N}$ hydrochloric acid significantly increased the permeability of the grout.

Advantages of using this grout for containment of hazardous wastes are its low toxicity and moderate strength. With the viscosity being approximately that of water, acrylate would be capable of injection into sand and/or silt. Disadvantages associated with utilizing acrylate grout are cost of application and the possible need for a two tank mix.

\subsubsection{Acrylamides}

Acrylamide grouts were formulated in 1951, making them one of the oldest classes of chemical grouts. It is a mixture of organic monomers, which could be polymerized at ambient temperatures, with setting time a direct function of catalyst percentage (Karol 1983). The viscosity and density of the grout solutions are close to that of water. 
Acrylamide in solution or powder form is neurotoxic. The gel is nontoxic. It can be used safely in the field when certain basic safety and handling precautions are observed. Nevertheless, when acrylamide grouts are employed in a saturated environment, a fraction of the compound will exist in its unreacted form. This unreacted portion could pose a contamination threat to a water supply (Bodocsi 1994).

This grout has been widely used for a number of years and exhibits properties desired for bottom sealing. However, its production has been severely reduced and the U.S. Environmental Protection Agency is considering a complete ban on its manufacture (Bergeson 1992).

\subsubsection{Vinyl Ester Grouts}

The literature identified one product referred to as DUROSEAL GELS which is comprised of these compounds. This product is based on water-swelling vinyl ester and oligomer. Water molecules are absorbed and held in the prepolymer matrix that results in swelling of the gel. The gel times are variable from minutes to hours by addition of a catalyst solution. There are two components in the grout solution:

1. A powder catalyst mixed with water, and

2. An accelerator mixed with the DURASEAL GEL.

The components are combined in equal proportions and injected into the soil. The resulting reaction of mixing the constituents is exothermic and produces a low viscosity solution (20-100 $\mathrm{cp}$ ) which requires low injection pressures. Both the components and the cured material are nonflammable, nontoxic, and noncorrosive. Equipment utilized (i.e., static mixers, pumps, hoses, etc) in the injection process can be washed and reused.

Limited data is available on the grouts resistance to various chemicals. The manufacturers information sheet shows excellent resistance to a broad class of chemicals. The most widely observed affect is a swelling of the gel, which should only reduce the permeability. A $100 \%$ ethylene glycol solution results in fragmentation of grout. Additional information is needed on the durability of this grout when exposed to concentrated acids, bases, and salts.

The largest disadvantage of the vinyl ester grout is its cost. The estimated cost for one gallon in a pure form is $\$ 61$. In summary, additional literature reviewing and research is required on this grout to establish it's feasible for use as a barrier to contaminant migration.

\subsubsection{Other Grouts}

\subsection{Lignosulfonate Grouts}

Lignosulfonates are the waste liquor by-products of the wood processing industries (such as pulp and paper mills) making them relatively inexpensive. Since the product is not controlled, it is widely variable in content from plant to plant. These grouts always consist of a lignosulfonates and a hexavalent chromium compound-hence the name chrome-lignins. 
The major drawback to the use of these grouts lies in its toxicity. A dichromate salt $\left(\mathrm{Cr}^{+6}\right)$ is used as a catalyst in all lignosulfonates which is highly toxic with a $0.05 \mathrm{ppm}$ limit in drinking water (Karol 1983).

\subsection{Phenoplast Grouts}

Phenoplasts resins are polycondensates resulting from the reaction of a phenol on an aldehyde. They are set under heat over a wide $\mathrm{pH}$ range at elevated temperatures. At ambient temperatures, the reaction for most phenols requires an acid medium. Since most soils are neutral or slightly basic, a grout requiring acidic conditions is undesirable (Karol 1983).

Phenoplasts always contain a phenol, a formaldehyde, and an alkaline base. All three components are health hazards and potential environmental pollutants. Resistance to wet-dry cycles is poor and can lead to complete disintegration.

\subsection{Aminoplast Grouts}

Aminoplasts are grouts in which the major ingredients are urea and formaldehyde. The formation of a resin requires the addition of heat and an acidic environment. They can only be used when it is known that the ground and groundwater $\mathrm{pH}$ is below 7. Grouts using urea solutions are toxic and corrosive due to the formaldehyde and acid (catalyst) content.

\subsection{Types of Grouting}

If a natural impervious clay layer or rock formation at a moderate depth exists under a waste site, then the containment should use this clay or rock for a bottom seal; that is, no bottom seal should be built. To achieve full containment only slurry walls need to be placed. However, when there is no underlying strata suitable for containing a contaminant plume, the use of chemically grouted barriers may be an alternative. There are two main types of grouting techniques that can be used in placing grouts : (1) injection grouting, (2) jet grouting. Four types of drilling can be used for both methods: vertical drilling, horizontal drilling, inclined drilling, and directional drilling. The methods of grouting mentioned above and other technologies for installing bottom barriers are discussed in the following sections of this report.

\subsubsection{Injection Grouting}

Injection (or permeation) grouting is defined as the process of filling small interstitial voids and fissures in rock or soil. The injection pressures must exceed the pressure of the water in order to displace it, but must not be high enough to expand or create fissures in the ground. In a laboratory study conducted by Sherer (1986), sands were grouted with various grouts at pressures of approximately $10 \mathrm{psi}(69.0 \mathrm{kPa})$. This form of grouting may be used for blanket or curtain grouting. Fig. 1 shows a schematic of a typical grout injection system. Common applications include: seepage control in granular soils and shattered rock, air and fire control in underground mining, seepage control in excavations, increasing bearing capacity of granular soils and shattered rock, slope stability improvements, and strengthening brick and masonry structures (Boury 1994). 


\subsubsection{Containment Methods}

Various methods of injection grouting to develop a bottom seal under hazardous waste sites will be discussed in this section.

\subsection{Injection Grouting With Different Drilling Methods}

A bottom barrier or floor below a body of waste can be created by injection grouting, using either vertical or horizontal drilling. Vertical drilling would involve drilling through the waste and grouting below it. Vertical drilling can be used to a maximum depth of approximately 120 feet, beyond this depth, the hole location can not be ensured. The grouted barrier must be of sufficient thickness to ensure adequate water tightness (Rumer and Ryan 1993).

Horizontal drilling techniques can be utilized by using trenches or grouting galleries in conjunction with a tube-a-manchette (sleeve grouting). The horizontal drilling method would not involve drilling through the waste, but it may involve drilling through the contaminated soils or contaminated groundwater below the waste. This method will cost more than vertical drilling due to excavation costs and the possibility of working below the groundwater table with the associated cost of dewatering. Additionally, working conditions in the horizontal drilling method are more constrained and may require the personnel to wear personal protective equipment in the confined space (Rumer and Ryan 1993).

Using inclined drilling, along with injection grouting is another method that could be used to contain buried waste. This method involves choosing a single, common point below the waste and forming an impermeable cone (Fig. 2). The success of this method relies on the accuracy of the drilling and the alignment of the grout holes (Rumer and Ryan 1993).

A variation of the grout cone involves placing two slanted grout planes under the waste (Fig. 3). Each plane is drilled from opposite sides of the waste towards a common line below the waste. The ungrouted sides of the containment structure would be created by two vertical walls (perhaps a slurry wall or sheet piling). This form of containment would be simpler to construct than the grouted cone barrier, due to it being easier to maintain the accuracy of the drilling (Rumer and Ryan 1993).

\subsection{Microtunneling and Injection Grouting}

The use of microtunneling involves pushing steel tubes into the soil from excavated trenches on the side of the waste site. These tubes can be pushed as far as 450 feet, are accessible to personnel, and spaced depending on the grout ability of the soil. Once the tubes are in place, injection rods are pushed from their sides towards adjacent tubes which are used to grout a barrier between the tubes.

\subsection{Rectangular Microtubes Pushed Side-by-Side}

In this system rectangular steel tubes are pushed horizontally from a clean open trench on either side of the waste. The tubes are positioned side-by-side in the soil below the waste to provide a watertight bottom barrier. The tubes can be interlocking (like sheetpiles), or the space between them can be filled by injection grouting. 


\subsubsection{Jet Grouting}

Jet grouting is a technique for excavating a cavity in the subsurface using a high-pressure fluid jet. The jetting fluid can be water, water with entrained air, or a water bentonite suspension. The cavity made by the jet is held open with water pressure or air pressure maintained in the cavity. If a cavity is being cut in porous media such as sand or silt, bentonite is added to the cutting fluid to form a water- and gas-tight "mud cake" on the inside wall of the cavity. The bentonite suspension prevents the loss of fluid to the media and assists in the removal of cuttings. The bentonite suspension makes it possible to jet in a sand where water without bentonite would normally be forced out of the cavity and into the sand. The pressure applied to the cavity is also used to remove the cuttings from the boring. After the cavity has been excavated, grout is introduced to fill the cavity and form an impermeable mass. Jet grouting is capable of utilizing a wide variety of grouts (e.g. particulate grouts) (May et al. 1985).

\subsubsection{Jetting Equipment}

Brunsing (1983) developed the equipment and procedures for jet grouting. The jetting system (Fig. 4) consisted of a high-pressure (240 psi at $200 \mathrm{gal} / \mathrm{min}$ ) positive displacement piston pump that delivers cutting fluid to a down hole jetting nozzle. The pressure and volume of fluid are controlled by changing the speed of the pump and opening or closing a by-pass line on the pump outlet. The cutting jet is mounted horizontally on a vertical 2 - in. pipe that fits down into a partly-cased hole through a gas tight well cap. The vertical high pressure pipe extends below the well casing, so that the jet nozzle is directed against the uncased boring wall. A swivel on the high pressure line above the drill hole casing allows the pipe and nozzle to be rotated so that the jet can be directed against the wall on all sides of the borehole to cut a disk-like notch. The cutting fluid is removed from the hole through a low-pressure return line that extends down into a sump at the bottom of the borehole. The plastic return line flexes enough to allow the jet to rotate 360 degrees. A compressor, regulator, and air line are used to maintain approximately 5 psi air pressure in the borehole and jetted cavity. The air pressure forces the jetting fluid and cuttings up the return line and into a settling tank and holding tank. The air pressure also maintains sufficient pressure in the cavity to prevent collapse as the jet cuts an opening. The suction line from the high-pressure pump recirculates cutting fluid from the holding tank. The grout injection line is connected to return line through a double action valve, it remains closed during the jetting activities. Once all the cutting had been removed, back-pressure valve closed, the grout injection starts. This cycle is repeated during the grouting operation (May et al. 1985).

\subsubsection{Case Histories}

May et al. (1985) utilized jet grouting and the previously mentioned apparatus to develop bottom seals in various soils. The jetting equipment performed well in creating a cavity in either silt or sand. However, it was not possible to determine the size or shape of the cavity prior to the introduction of the grout (a Portland cement, sand, and bentonite mixture). The grout bulbs created were not always the size or shape needed to provide an impermeable barrier.

\subsection{Jet Grouting in Loess}


In loess, the grout bulbs varied in size and shape and did not overlap to produce a seal or barrier at the center of the cluster of borings. Smaller auger holes used at other borings had indicated that approximately 20 minutes of jetting should produce approximately 30 in. penetration in loess. This was proved not to be the case, the maximum depth of jet penetration was approximately 8 in. for the smallest bulb. The rate of cutting was so variable that elapsed time could not be relied upon to indicate cavity size. Additionally, increasing jet size had no effect and yielded the same results.

\subsection{Jet Grouting in Compacted Silt}

Cavities of useful size were produced in the compacted silt; but again there was no accurate technique for determining the size and shape of the cavity. Contact between the grout bulbs up to distances of 5 feet apart was observed. However, the cavities were not of a uniform radius.

\subsection{Jet Grouting in Sand}

The sand washed out in more even disk-like cavities. This phenomenon can be explained by the noncohesive properties of the sand. A continuous seal did form in the area inside the cluster of the injection points with grouted bulb diameters up to approximately 4 feet. The minimum thickness was in the central area where the disk-like masses overlapped only 1.25 inch. The jet grouting in a sand media was able to develop overlapping grout masses that produced a useful seal in the sand.

\subsubsection{Containment Methods}

Vertical drilling and jet grouting may be used to create both vertical and bottom barriers around and under hazardous waste sites. In order to construct a bottom barrier, one would have to use a column pattern like that illustrated in Fig. 5. Proper precautions would need to be undertaken to maintain the accuracy of the borings/grout columns.

Constructing an impervious cone barrier or two impervious slanted plane barriers under a body of waste is impractical using jet grouting. Jet grouted columns are not usually angled in excess of 30 degrees from vertical. Therefore, the grouted columns used under a large site would have to be very deep in order for the columns to join at a common point or line.

\subsection{Jet Grouting and Horizontal Drilling}

Jet grouting can be performed using horizontal drilling. Horizontal drilling for the purpose of creating an impervious horizontal barrier would be limited to lengths of approximately 50 feet. This length limitation is due to the lack of accuracy involved with horizontal drilling. Another limitation associated with horizontal jet grouting is due to the effects of gravity on the grout and the water (Welsh and Burke 1993). Also, if horizontal jet grouting is used to place a bottom barrier below a body of waste, trenches or grouting galleries would have to be excavated which would significantly affect the cost of the grouting project.

\subsection{Jet Grouting and Directional Drilling}

As mentioned in prior sections, directional drilling can be used in conjunction with both injection grouting and jet grouting. If injection grouting is used, sleeve grouting is preferred since it can 
provides multiple injections at the site. The drilling sequence had been described in the respective sections.

Another possible method of grouting for an impervious barrier by directional drilling uses a cutter/mixer (Murdoch 1992). The cutter/mixer is pulled through two previously drilled adjacent holes, and as it is pulled it mixes the soil in front of it with a grout. This method would require only one row of holes to obtain impermeability.

A special jet grouting method combined with directional drilling has also been developed. In this method the jet grouting equipment contains a large number of static jets positioned so that they cut a rectangular path to form a slab-shaped grouted body (Rumer and Ryan 1993).

The main advantages of placing an impervious horizontal barrier by directional drilling and grouting under a body of waste are: (1) the waste would not have to drilled through; (2) no excavation would be necessary; (3) the locations of the holes can be tracked accurately, ensuring complete coverage of the area.

\subsubsection{Hydrofracturing}

Hydrofracturing for a barrier is the intentional fracturing of a soil formation using liquid which is pumped into the ground under pressure (similar to the method used in the petroleum industry). The first step in hydrofracturing is to drill a hole into the ground to the desired elevation of the hydrofracture, then to cut a small horizontal slot at the bottom of the hole using a jet. The slot gives the fracture a point of origin. Next, grout is pumped into the borehole under pressure. The pressure and the volume of the grout are increased until the pressure suddenly decreases and the grout uptake increases, indicating that hydrofracture has occurred. The grout pumping is continued which forces the soil fracture to propagate and be filled with grout. The grout in the fracture forces the fracture to remain open. Upon the setting of the grout, The fracture becomes impervious (Fig. 6).

Fractures have thicknesses of approximately 0.2 to 0.4 inches and often radiate from the borehole uncontrollably to distances of 20 to 35 feet. Due to these traits, hydrofracturing is a poor choice for constructing a bottom barrier. Also, because horizontal hydrofracturing can only be effectively applied in over-consolidated soils, the sites where it can be employed are severely limited (Rumer and Ryan 1993).

\subsubsection{Block Displacement Method}

A variation of the hydrofracture method is the Block Displacement Method, or BDM. Instead of injecting one borehole at a time with grout, in the BDM a whole series of boreholes are injected simultaneously to lift a large block of waste and the surrounding soil and to place an impervious grout bottom barrier under the block (Fig. 7).

\subsubsection{Case History}

A BDM test was actually conducted in Whitehouse, Florida by Foster-Miller, Inc. A 60 - foot wide block was lifted, and an impermeable seal placed below at a depth of 23 feet. This was 
accomplished using 32 perimeter holes and 7 interior injection holes. After lifting, exploratory borings were to determine the consistency and thickness of the bottom seal. It was discovered to vary in thickness from 3 to 12 inches.

\subsection{Field Grouting}

In order to effectively implement a grouting project in the field, instead of a controllable laboratory setting, data must be gathered on the site characteristics where the operation will take place.

\subsubsection{Site Characteristics}

The success of any grouting project depends on thorough investigation and characterization of the site in question, and selection of a grout that is suitable to the particular site. The following is the type of geotechnical information required to plan a grouting project.

\subsubsection{Soil and Rock Characteristics}

The sites soil and rock characteristics will influence greatly the type of grout to be used. If soil materials are to be grouted, the characteristics that must be determined include (Spooner et al. 1984):
- Permeability
- Porosity
- $\quad$ Particle size distribution

Permeability will influence the selection of the grout type (particulate or chemical) to be used, the allowable viscosity, and the required injection pressure. The porosity, or voids ratio, will give an indication of the amount of grout a unit volume of soil will "absorb," and how rapidly grout may be injected. The particle size distribution indicates the presence of large particles which could interfere with grout injection.

Karol (1983) identified the permeability requirements for grouting to be feasible:
a. $k=10^{-6}$ or less: ungroutable
b. $k=10^{-5}$ to $10^{-6}$ : groutable with difficulty by grouts with under $5 \mathrm{cP}$ viscosity and ungroutable at higher viscosities.
c. $k=10^{-3}$ to $10^{-5}$ : groutable by low viscosity grouts but with difficulty when viscosity is more than $10 \mathrm{cP}$. d. $k=10^{-1}$ to $10^{-3}$ : groutable with all commonly used chemical grouts.
e. $k=10^{-1}$ or more: use a suspended solids grout or chemical grout with filler.

\subsubsection{Geochemical Characteristics}


The geochemistry of a site, including that caused by waste disposal, can be extremely important. Among some of the geochemical data that should be determined during the site investigation are the nature and extent of wastes and leachates at the site, and the presence of soil or rock layers (such as salt deposits) that may significantly impact grout solution chemistry. Compatibility of the chemical grouts with different soils had been discussed in the subsequent parts of this report.

\subsubsection{Grouting Pressures}

The rate of grout flow into a formation is a function of pumping pressure; i.e., the higher the pressure, the faster a grout can be placed. From an economics point of view, it is therefore desirable to pump at the highest possible pressure. However, the possibility of damage to the formation limits the values of the pumping pressure. None of the literature yielded typical pressures in field grouting operations. However, when damage to the formation is not of concern, it has become common practice to grout at a pressure less than 1 psi per foot of depth below ground surface (Karol, 1983). One corporation's procedures states that the grouting pressure for any one pipe shall not be more than 2 psi per foot of burden (Hayward Baker, 1991).

\subsection{Chemical Compatibility of Grouts}

\subsubsection{Chemical Compatibility of Selected Grouts}

If grouting is to be used in the containment of a hazardous waste site, the interaction between the chemical(s) in the leachate and the grouting material must be ascertained. An exhaustive study was conducted by researchers from the University of Cincinnati in conjunction with the US Environmental Protection Agency to determine the effect of hazardous chemicals on the ability of grouting materials to prevent leachate water movement. Several synthetic chemical formulations and two actual leachates were investigated. In the following paragraphs, the results from these studies are summarized. Because the grouting material of interest in this research is urethane, emphasis will be placed on results from experiments in which urethane products were used.

Bodocsi and Bowers (1990) conducted an extensive laboratory-scale experiments using the following six grouts: 1) AC-400 - acrylate based grout from Geochemical Corp., 2) CR360 urethane based grout from 3M Company, 3) Pene-grout - urethane based grout from Pene-grout of North America, 4) SIROC \#132 - sodium silicate grout from Diamond Shamrock Corp., 5) glyoxal-modified sodium silicate grout from $\mathrm{PQ}$ Corp., and 6) sodium aluminate-modified sodium silicate grout from PQ Corp. A medium-fine silica sand (minimum and maximum void ratio of 0.52 and 0.68 , respectively) was used as the study soil for the acrylate and urethane based grouts (grouts 1,2 , and 3 ) while a medium mason sand (minimum and maximum void ratio of 0.5 and 0.7 , respectively) was used for the sodium-silicate-based grouts.

Following grouting and curing (at least 7 days at $98 \%$ humidity and $20^{\circ} \mathrm{C}$ ), the grouted-soil underwent testing in a flexible-wall Permeameter (typical sample dimensions: $7.6 \mathrm{~cm}$ inner diameter, $30.5 \mathrm{~cm}$ long). Column experiments lasted approximately 20 days. Deionized water was used to determine baseline hydraulic conductivities. The effect of various chemicals on the hydraulic conductivity of the soil-grout mixture was assessed using the chemicals listed in Table 2. Acetone was used to represent aldehydes and ketones. Aniline represented amines and amides. 
Heavy metals and metal complexes were represented by cupric sulfate. Ethylene gyglycolnd methanol were used to represent gycols and alcohols, respectively. Hydrochloric acid and sodium hydroxide were used to represent inorganic acid and bases, respectively. Xylenes were used to represent aliphatic and aromatic hydrocarbons. Finally, two leachates from a paint waste and refinery site were employed. Both leachates were collected from full-scale lysimeter tests conducted by Kinman et al. (1986) and were used at full strength.

Baseline hydraulic conductivities $\left(\mathrm{K}_{\mathrm{h}} \mathrm{W}\right)$ for each soil-grout mixture are presented in Table 3 . The acrylate-based grout (AC-400) had the lowest hydraulic conductivity followed by the urethanebased grouts and the sodium silicate-based grouts. If a permeability of $10^{-7} \mathrm{~cm} / \mathrm{s}$ is used as a threshold, the sodium silicate-based grouts would be eliminated. While the acrylate-based grout produced the lowest hydraulic permeability, its use in the field has been substantially reduced because of environmental concerns (Berry and Magill 1992).

In Table 4, the hydraulic conductivity at the end of the chemical compatibility permeability test $\left(K_{h} f\right)$ is presented for the acrylate- and urethane-based grouts for each chemical investigated. Also included in Table 3 is the ratio $\mathrm{K}_{\mathrm{h}} \mathrm{f} / \mathrm{K}_{\mathrm{h}} \mathrm{w}$. The acrylate-based grout was most affected by acetone $(100 \%)$, methanol $(100 \%)$, and aniline. The actual leachates (paint and refinery wastes) had little affect on the permeability of AC-400. The urethane grouts were most affected by sodium hydroxide while the hydraulic conductivity of Grout CR360 was not substantially reduced by the presence of the paint and refinery wastes. It appears that urethane-based grouts are most affected by high $\mathrm{pH}$ wastes. Thus, the focus of the chemical compatibility portion of the present research will focus on the behavior of the study grouts using high $\mathrm{pH}$ leachates.

\subsubsection{Selected Case Studies on the Use of Grouting as a Confinement Technique}

Spalding et al. (1985) conducted a two-level study on the feasibility of using grouts to reduce the hydraulic conductivity of shallow trenches used for low-level radioactive waste burial. Seven grouts and four soils ( 3 from Oak Ridge, TN and 1 from Maxey Flats, KY) underwent laboratoryscale testing. In Table 5, the types of grouts investigated and selected soil properties are presented. In laboratory-scale experiments, between 50 and 75 grams of moist soil were placed in a $1.85 \mathrm{~cm}$ inner diameter mold and the saturated hydraulic conductivity was determined. Grout $(150 \mathrm{ml})$ was applied to the top of the soil column and allowed to infiltrate. Following infiltration, the grout-soil mixture was allowed to cure for $48 \mathrm{hr}$ at which point the hydraulic conductivity was determined. The lowest hydraulic conductivity that could be accurately determined was approximately $10^{-7} \mathrm{~cm} / \mathrm{s}$. The cement-bentonite-fly ash, lime-fly ash, and the bentonite slurry were not able to infiltrate into the soil system thus, no further tests were conducted using these grouts. Hydraulic conductivities before and after grouting are presented in Table 6 for the four grouts that were able to infiltrate the soil specimen. Hydraulic conductivities for the sodium silicate and urea-formaldehyde grouted soils were reduced by three and two orders of magnitude, respectively. For all samples tested, the hydraulic conductivities of acrylamide and resorcinolformaldehyde samples were reduced to below the lowest measurable value $\left(10^{-7} \mathrm{~cm} / \mathrm{s}\right)$.

In the second-level of work conducted by Spalding et al. (1985) a field-scale demonstration was conducted at Oak Ridge National Laboratory, TN. Three trenches (designated as Trenches 349, 350 , and 351 ) measuring $3.1 \mathrm{~m}$ by $3.1 \mathrm{~m}$ by $1.5 \mathrm{~m}$ deep were constructed. The grout injection 
well was located in the center of the trench and 9 monitoring wells were placed on the trench perimeter. The trenches were filled with waste material (e.g., cement blocks, tires, scrap metal, etc.) and were backfilled with soil to grade using the Oak Ridge soils that underwent testing in lab-scale experiments. Trench 349 received 5,300 L of sodium silicate, Trench 350 received $7,900 \mathrm{~L}$ of sodium silicate and Trench 351 received 7,200 L of the acrylamide grout. Hydraulic conductivity of the waste/backfill was determined before and after grouting using a constant head pump-in test as described by Hvorslev (1951). In Table 7, the mean hydraulic conductivity of the nine monitoring wells before and after grouting are presented for Trenches 349,350 , and 351 . Grouting of Trench 349 did not substantially reduce the hydraulic conductivity of the waste/backfill and was considered a failure. The authors attributed the poor performance of Trench 349 to dilution of the sodium silicate grout by a high water table. Grouting of Trenches 350 and 351 was more successful, with the hydraulic conductivity decreasing by more than two orders of magnitude for the sodium silicate grout and by about 4 orders of magnitude for the acrylamide grout. For Trench 351, 8 of the 9 monitoring wells had hydraulic conductivities less than $10.7 \mathrm{~cm} / \mathrm{s}$.

Ackman and Jones (1991) conducted a field-scale study in which the feasibility of grouting a stream bed for the reduction of stream flow losses into an underground mine was investigated. The stream, located in Frostburg, Maryland, overlies an abandoned underground coal mine. Infiltration from the stream into the coal mine was a major factor in the production of acid mine drainage. Grouting the stream bed could reduce the volume of streamflow losses and decrease acid mine drainage production. A polyurethane grout was mechanically injected into a $70 \mathrm{ft}$ section if the stream bed in $10 \mathrm{ft}$ intervals using grout rods that were $3 \mathrm{ft}$ in length and $3 / 4$ inch in diameter. The rods were driven into the sediment bed to a depth of $2 \mathrm{ft}$ using a sledge hammer. A total of 5 gallons of grout were injected using pressures that varied between 400 and 1,200 $\mathrm{lb} / \mathrm{in}^{2}$.

Grouting was delayed when a surface leak was detected but was continued after the leak had sealed itself. The effectiveness of the grouting operation was determined by measuring the streamflow before and after grouting at gaging stations up and downstream of the grouted area. Before grouting, this section of the stream experienced a 25 percent loss in streamflow ( 800 $\mathrm{gal} / \mathrm{min}$ to $600 \mathrm{gal} / \mathrm{min}$ ). After grouting the authors reported a net gain in discharge at the downstream gaging station. As the dry season approach, streamflow decreased and eventually reached zero. No information on the performance of the grouted area during high stream flows was presented. Based on the these preliminary results the authors reported that the grout injection procedure reduced the amount of infiltration into the underground mine.

\subsubsection{Characteristics of Selected Grouts}

Characteristics of selected chemical grouts are presented in Appendix -B.

\subsection{Specimen Preparation Techniques}

The research effort in the past had concentrated on preparation of sand samples using different deposition techniques at variable target densities. Kolbuszewky (1950) pioneered the area of sample preparation using sand deposition. Using this method of sample preparation, the void ratio 
of a bedding formation prepared by vertical deposition of sand will be predominately governed by the intensity and velocity of deposition. Intensity is defined as the weight of sand passing in a unit of time per unit area. The velocity will be determined by the distance the sand will fall in a given time. The required density of the sand is produced when sand falls from a height that allows the dispersion of the sand. As the volume of sand increases with a decrease in fall height, an increase in density takes place.

Walker and Whitaker (1967) developed a sand rain device (SRD) for preparing beds of sands in circular containers to perform testing on model pile foundations. A soil sample is formed from thin layers of sand deposited by a hopper which is driven forward and backward on horizontal rails. The hopper has an opening above the roller which allows the sand to diffuse from the hopper. The sand is deflected by a deflector located in front of the roller to produce vertical movement of the particles. The density of the sand is determined from the height of fall and the speed of the rollers. This device produces fairly homogeneous deposits except for interference caused by the air currents.

Another type of sand raining device (SRD) was designed by Suarez (1984).The SRD consisted of a large cylinder which stored the sand. The bottom of the cylinder consisted of two perforated plates, the top one is fixed while the bottom plate is movable. As the bottom plate is rotated, the perforations in the two plates match hole patterns. This allows the sand discharge intensity to be adjusted. As the sand leaves the perforations in jets, the sand discharges through a diffuser. The diffuser consists of two mesh screens oriented 45 degrees with respect to each other. This disperses the sand allowing for a uniform deposition. The diffuser ascends as the sand is deposited, maintaining uniform destiny through out the sample.

Three different types of sand raining devices (SRD) had been reported in the literature; a rotating SRD, a single hose SRD, and a circular perforated plate SRD. The rotating SRD consists of a sand reservoir which feeds twenty-eight flexible hoses. The sand discharges through the hoses to a diffuser plate depositing the sand in a uniform manner. Density is controlled by the height of fall and variations in hole sizes on the diffuser plate. Non homogeneous deposits were observed with the use of this method. The single hose SRD also consists of a sand reservoir which feeds one hose that discharges onto a screen which distributes the sand evenly. It was observed that medium to dense sand specimens could be obtained using this type of device. The circular SRD consists of a circular sand reservoir having a perforated bottom. The reservoir is mobile allowing a variation in density by regulating the fall height. It had been reported that samples with wide range of densities could be prepared using circular SRD.

In order to use large scale grouting chamber to simulate in-situ conditions, sand rain device is currently being designed and manufactured. Extended review of the literature and various forms of sand rain devices will be presented in the next report.

\subsection{Computer Simulation of Grout Injection}

Numerical simulators have found wide use in the engineering and science community. Uses for these simulators cover a broad range of topics and include: geothermal reservoir engineering, 
petroleum engineering, geologic disposal of nuclear waste, unsaturated zone hydrology, and design and analysis of two and three-phase flow experiments. Many of the more practical and usable models are modified versions of more general programs. These code modifications have resulted in greater versatility, improved speed and efficiency of computations, and a more comprehensive description of multi-phase flow processes (Pruess 1990).

With the advent of grout injection as a means to confine underground waste by retarding the advancement of plumes, a suitable computer model was sought to facilitate the design implementation of such "grout curtains". These curtains would serve as either a temporary or permanent barrier while various remediation efforts took place.

Several models were previously evaluated by Sawyer (1994) for use as a grout injection simulator. The models investigated included BGROUT, MSTS, TOUGH2, BEST-GEL, and GPGAS2. Based on information publicly available, MSTS, TOUGH2, and BEST-GEL were deemed unsuitable for modeling cone grouting (Sawyer 1994).

The models evaluated in this report include BGROUT, PC-GEL, and GPGAS2. Information was readily available for both BGROUT and PC-GEL, but due to the private nature of GPGAS2, very little information was available for review.

\subsubsection{BGROUT}

In reviewing literature on the use of grouting for containment of underground leakage, a modified version of the BOAST3 code called BGROUT was investigated. BOAST3 is a modified version of previous BOAST models used to simulate oil/gas reservoir production. Relatively few modifications were required to convert BOAST3 from a "black oil simulator" used in petroleum reservoir engineering to an effective grouting model (Sawyer 1994).

\subsubsection{Boast: An Overview}

A Three-Dimensional, Three-Phase Black Oil Applied Simulation Tool (Version 1.1) was released by the Department of Energy in the fall of 1982. This program has been extensively used by various research, academic, and industry organizations. BOAST has been a popular choice due mainly to its ease of use and lack of burdensome and seldom-used features which complicate and slow the execution of the program. In spite of its wide-scale use, complications have developed in some applications. Most of the problems have occurred when the program was used for fieldscale conditions where it was not suitable in its original form (Fanchi et al. 1987).

BOAST II, released in 1987, was designed to overcome some of the limitations of the original BOAST. The main emphasis has been to keep the program simple and easy to use, yet add features which would improve its versatility (Fanchi et al. 1987).

BOAST3 is a modified version of BOAST II. BOAST3 is more efficient than its predecessors and designed to run in a 386/486 PC-based environment. As a result of streamlining the source code and using a 32-bit Fortran compiler, BOAST3 is about 3.7 times quicker than BOAST II (Stapp and Allison 1989). 


\subsubsection{BGROUT Parameters}

BOAST3 was converted to a grout simulation model by simply incorporating five new input parameters into the source code. These new parameters were required to control a viscosity versus time function and are explained below (Sawyer 1994).

SWCRIT: Critical "grout" saturation fraction. This parameter identifies when an individual grid block within the model has reached a critical grout saturation fraction. Once this percent saturation has been reached, initial setup of the grout begins to occur (typically set to $20 \%$ ).

VWMULT: Grout viscosity multiplier. This parameter controls the viscosity increase during initial setup time. This value is typically set at 2.0 to allow the initial viscosity (VWINIT) to double over the indicated time period (SET1). This increase in viscosity is assumed to be linear and increases up to the value V1, determined as follows: VI $=$ VWINIT * VWMULT.

VWMAX: Maximum grout viscosity at final setup time (typically set to $500 \mathrm{cp}$ ). After the initial setup time is reached, the viscosity begins to increase much more rapidly up to VWMAX. This increase is also linear based on the slope, V2, determined as follows:

$\mathrm{V} 2=(\mathrm{VWMAX}-\mathrm{V} 1) /(\mathrm{SET} 1-\mathrm{SET} 2)$.

SET1: Initial setup time of grout. This parameter controls the time required for the grout viscosity to increase from its initial value (VWINIT) to a defined value (VWMULT). SET1 is typically set to 215 minutes.

SET2: Final setup time of grout. This parameter controls the time required for the grout viscosity to increase from VWMULT to the maximum grout viscosity at setup, VWMAX. SET2 is typically set to 290 minutes.

With the use of these five new input variables, the viscosity versus time function of the injected grout can be easily controlled and modified. This allows for easy simulation of models where either rapidly setting or slow setting grout is used.

\subsubsection{BOAST3 Parameters}

Other parameters required for the simulation of grout injection are already incorporated into the BOAST3 code. All input data for the simulator are contained in a single file. These data can be divided into two groups: (1) initialization data and (2) recurrent data. The initialization data include reservoir geometry, rock porosity and permeability, initial pressure and saturation data, relative permeability and capillary pressure tables, fluid PVT data, and the additional viscosity versus time parameters (Chang and Gao 1993).

The recurrent data include the location and initial specifications of wells in the model, time step control information for advancing the simulation through time, a schedule of individual well rates and/or pressure performance, changes in well completions and operations over time, and controls on the type and frequency of printout information provided by the simulator. 


\subsection{Initialization Data}

The initialization data for BOAST3 are as follows (Fanchi et al. 1987):

Grid Dimensions (see example input files): The system investigated can be defined as a grid with $x, y$, and $z$ coordinates and composed of individual grid blocks. These grid blocks can have uniform dimensions throughout, or modified by layer or individually to simulate complex systems.

Porosity (see example input files): The porosity within the grid model can be distributed uniformly throughout the system, defined for each layer, or modified for each individual grid block. This allows for calculations of complex systems where heterogeneous soil conditions exist.

Permeability (see example input files): The permeability is defined for the $x, y$, and $z$ directions and can also be modified for individual grid blocks.

Transmissibility Modifications (see example input files): This function accounts for flow changes across a given boundary. Boundary conditions can be defined for either the $x, y$, or $z$ direction and for any number of grid blocks.

Rock and PVT Regions (see example input files): Up to five distinct rock and pressureviscosity-temperature (PVT) regions can be defined with each region having separate saturation and pressure dependent data.

Relative Permeability and Capillary Pressure Tables: This parameter is used only in connection with changes in "rock regions". A table is set up for each region where the relative permeability and capillary pressure changes. The variables that can be modified are: the phase saturation value; the oil phase relative permeability; the gas phase relative permeability; the oil phase relative permeability for gas-oil system; the oil/water capillary pressure; and the gas/oil capillary pressure.

Fluid PVT Data Tables: This parameter is used in connection with changes in "PVT regions" and is also set up in tables. One set of data is used for each defined PVT region. This parameter takes into account the initial oil bubble pressure, under saturated oil properties, oil PVT data, water PVT data, gas properties, rock compressibility, and stock tank fluid densities. When modeling grout injection, the initial viscosity of the grout is recorded as part of the water PVT data (see example input files).

Pressure and Saturation Initialization: Two options are available for pressure and saturation initialization. With the first option, the program calculates the initial pressure distribution for steady-state conditions given the location of the gas/oil and oil/water contacts and their respective pressures. In this case, saturations are read as constant values over the entire grid. The second option applies towards systems that are not in equilibrium. With the second option, the initial pressure distribution can be read on a block-by-block basis.

Aquifer Model: This parameter is not used during simulations of grout injection. When used for reservoir engineering, this option defines the type of aquifer model used for simulation. The aquifer models that the program can simulate include a POT aquifer, steady-state aquifer, and a Carter-Tracy aquifer. 


\subsection{Recurrent Data}

Fanchi et al. (1987) also suggest two types of recurrent data for BOAST3. The input information for the recurrent data are:

Well Information (see example input files): Input into this parameter controls the number of wells used and their locations, water (grout) injection rate, gas and oil rate, and injection pressure.

Time Step and Output Control: Input into this parameter controls the time-step and output method codes, frequency of output for well and summary report, elapsed times when output is to be printed, and map control codes. The map control codes govern the printing of the map of grid block pressures, oil saturations, water saturations, gas saturations, and saturation pressures.

The example input files given in this report show that the dimensions for this particular model were approximately $10 \mathrm{ft}$. by $10 \mathrm{ft}$. $(19 * 0.5$ by $19 * 0.5)$. The porosity; is 0.30 and the permeability is 2000,2000 , and 667 millidarcies (md) in the $x, y$, and $z$ directions, respectively. The viscosity versus time parameters are set to their typical values and the grout viscosity is set to $5.0 \mathrm{cp}$. There is one well node (injection well), the injection rate is $-100 \mathrm{stb} / \mathrm{day}$, and the injection pressure is 53 psi. The input file is presented in Appendix-2 (Sawyer 1994).

\subsubsection{Program Output Evaluation}

There are several output files created by BGROUT to facilitate the interpretation of the simulation results. The file B.CGR is probably the most usable output file. This file is the water (grout) viscosity map that was added when BOAST 3 was modified to BGROUT. With this file, results of a run can quickly be analyzed by looking at several maps of grout viscosity and grout saturation. By viewing the grout saturation map, penetration distance may easily be determined as a function of time (Sawyer 1994).

The file B.WEL lists time-step output of rates and saturations for each injection well (Stapp and Allison 1989). This file may easily be imported into spreadsheets and sorted into individual well nodes if more than one well is used. In this manner, high quality graphs can be created.

The file B.OUT is the normal output listing showing each time-step iteration (Stapp and Allison 1989). This file does not help facilitate interpretation of the results.

The file B.SCR is an image of all screen output and the time-step summary table (Stapp and Allison 1989).

The file B.TAB is a time-step summary report of total field production and injection, aquifer influx information, time step and material balance information, and a determination of where maximum pressure and saturation changes are occurring in the reservoir model (Fanchi et al. 1987). This output file is used extensively when simulating oil reservoir models. 


\subsubsection{Assumptions}

The BGROUT program simulates isothermal, darcy flow in three dimensions (Fanchi et al. 1987). It assumes reservoir fluids can be described by three fluid phases (oil, gas, and water (or grout)) of constant composition with physical properties that depend on pressure only. BGROUT also assumes that the viscosity versus time function is linear. A constant viscosity is maintained until the first set point is reached then the slope (rate of change) is increased to final set time.

\subsubsection{Summary}

The BGROUT program seems suitable to effectively model grout injection for containment of underground leakage. One, two, and three dimensional models can be simulated using one or more well nodes (injection wells). BGROUT offers modifications for permeability, porosity, grout viscosity, injection rate and pressure, and grout setup time along with other variables. The output of these simulations can be transferred to spreadsheet programs to produce high quality tables and graphs.

\subsubsection{PC-GEL}

PC-GEL is a three-dimensional, three-phase (oil, water, and gas) permeability modification simulator. It was developed by incorporating an in-situ gelation model into the BOAST source code. The features found in PC-GEL include: transport of each chemical species of the polymer/crosslinker system in porous media, gelation reaction kinetics of the polymer with crosslinking agents, theology of the polymer and gel, inaccessible pore volume to macromolecules, adsorption of chemical species on rock surfaces, retention of gel on the rock matrix, and permeability reduction caused by the adsorption of polymer and gel (Chang and Gao 1993). This program has been validated against data reported in the literature. The PC-GEL simulator is capable of simulating and optimizing any combination of primary production, water flooding, polymer flooding, and permeability modification treatments (Chang and Gao 1993).

Gelled polymers have been the focus on much of the previous permeability modification work. Two types of these polymers are available, either in-situ polymer gels or crosslinked polymers. In-situ polymer gels can be formed by one of several processes (Chang and Gao 1993). These processes involve mixing two or more reactants, often in the presence of a catalyst. Mixture can take place prior to injection, or the reactants can be injected in alternating slugs, depending on the process and chemicals used (Chang and Gao 1993).

Crosslinked polymer gels are created by combining polymers with crosslinkers. Traditionally, polyacrylamide or biopolymer polymers have been used to react with metallic crosslinking agents (Chang and Gao 1993). This combination forms a three-dimensional network of crosslinked polymers where the crosslinking sites are the $-\mathrm{COO}$ groups for both types of polymers. Crosslinked polymer gels are formed by ionic bonding of metal ions at carboxyl groups. Factors that effect the crosslinker condition, gelation time, and gel strength include: the type of polymer used, type of crosslinker, polymer and crosslinker concentration, temperature, $\mathrm{pH}$, total dissolved salts, and shear. In addition, polyacrylamide gel times are effected by hydrolysis. Generally, crosslinked polymer gels are formed in-situ, as opposed to being prepared on the surface prior to injection (Chang and Gao 1993). 


\subsubsection{Mathematical Modeling of In-Situ Gelation}

In the PC-GEL simulation study, a dichromate/thiourea redox system was chosen to model the kinetics. In the chromium redox process, $\mathrm{Cr}^{6+}$ is reduced to $\mathrm{Cr}^{3+}$ enabling it to react with a polymer to form a three-dimensional network of gel structure. This network of gel resists flow and is not eluted to readily (Chang and Gao 1993). The chemical reaction governing this gelation is as follows:

$$
\mathrm{Cr}_{2} \mathrm{O}_{7}{ }^{2-}+6 \mathrm{CSN}_{2} \mathrm{H}_{4}+8 \mathrm{H}^{+} 2 \mathrm{Cr}^{3+}+3\left[\mathrm{CSN}_{2} \mathrm{H}_{3}\right]_{2}+7 \mathrm{H}_{2} \mathrm{O} \text { and } \mathrm{nCr}^{3+}+\text { polymer gel. }
$$

The physical properties and characteristics of the gel and polymer that are accounted for in the simulator include viscosity, adsorption-retention on the rock matrix, permeability reduction, and inaccessible pore volume (IPV) to macromolecules (Chang and Gao 1993).

These parameters are the only major modifications to the BOAST3 code and are what separate PC-GEL from BGROUT.

\subsubsection{Input Parameters}

Because PC-GEL runs off of BOAST's source code, nearly all input parameters are identical to BOAST3 except for the addition of the Chemical Data for Gel System. This parameter contains the transport data of the gel chemical system. The following variables are controlled within this input parameter (Chang and Gao 1993).

Dispersion Coefficients: This variable controls the dispersion rate in $x, y$, and $z$ directions. The values are entered in $\mathrm{ft}^{2} /$ day.

$$
\begin{gathered}
\frac{d\left[\mathrm{Cr}_{2} \mathrm{O}_{7}^{2-}\right]}{d t}=\frac{d\left[\mathrm{CSN}_{2} \mathrm{H}_{4}\right]}{6 d t}=-k_{1}\left[\mathrm{Cr}_{2} \mathrm{O}_{7}^{2-}\right]\left[\mathrm{CSN}_{2} \mathrm{H}_{4}\right] \\
\frac{d\left[\mathrm{Cr}^{3+}\right]}{d t}=2 k_{1}\left[\mathrm{Cr}_{2} \mathrm{O}_{7}^{2-}\right]\left[\mathrm{CSN}_{2} \mathrm{H}_{4}\right]-k_{2} n\left[\mathrm{Cr}^{3+}\right]^{2}[\text { polymer }]^{2} \\
\text { and } \\
\frac{d[\text { polymer }]}{d t}=\frac{d[\mathrm{gel}]}{d t}=k_{2}\left[\mathrm{Cr}^{3+}\right]^{2}[\text { polymer }]^{2}
\end{gathered}
$$

Reaction Rate Constants: This variable controls the reaction rate and is entered in $\mathrm{ppm}^{-1}$ day $^{-1}$ for $\mathrm{K} 1$ and $\mathrm{ppm}^{-3}$ day $^{-1}$ for $\mathrm{K} 2$. The equations are as follows: 
Adsorption/Retention on Rock Matrix: The adsorption isotherms for all chemical components are assumed to follow the Langmuir equation.

$$
C_{i r}=\frac{B B(I) x C_{i}}{1+A A(I) x C_{i}}
$$

where $I=1$ to 5 , and $A A(I)$ and $B B(I)$ are adsorption parameters determined from laboratory for component $\mathrm{I}$. The adsorption parameters are entered here for each chemical.

Permeability Reduction: The permeability reduction caused by adsorbed polymer and gel is defined as:

$\mathrm{K}=\mathrm{k} / \mathrm{RRF}$, i

where $\mathrm{k}=$ absolute permeability in $\mathrm{md}$ and $\mathrm{RRF}=$ residual resistance factor. $\mathrm{RRF}$ is a function of the amount of component $I$ adsorbed and its critical onset value.

Other parameters controlled in the Chemical Data section include: viscosity parameters for polymer solution; viscosity parameters for gel solution; inaccessible pore volume (IPV) parameters for macromolecules of the chemical components involved; and the maximum concentrations allowed for the chemical components involved.

\subsubsection{Assumptions}

PC-GEL simulates isothermal, darcy flow in three dimensions. It assumes reservoir fluids can be described by three fluid phases (oil, gas, and water (or grout)) of constant composition with physical properties that depend on pressure only. PC-GEL also assumes that the Langmuir adsorption isotherms are valid for all chemical components and that the given equations govern the reactions involved.

\subsubsection{Summary}

PC-GEL is a modified BOAST program suitable for simulating and optimizing any combination of primary production, water flooding, polymer flooding, and permeability modification treatments. PC-GEL may be a feasible option for modeling grout injection, although no specific examples are given in the literature. The primary concern is PC-GEL's limitation to the type of grout being used. The simulation model developed to test the program used a specific crosslinked polymer gel. For this reason, PC-GEL may not be usable as a general purpose, chemical grout injecting model. Further examination of the PC-GEL program should be pursued to investigate its possible uses.

\subsubsection{GPGAS2}

GPGAS2 (with the viscosity modification logic added) was specifically designed by Walter $\mathrm{K}$. Sawyer to test the accuracies of BGROUT (Sawyer December 1994). Thorough examination and comparison took place between the two programs by Sawyer (July, 1994) with the results showing BGROUT to be very accurate (as compared to GPGAS2). This program is available 


\subsubsection{Summary}

Few models were actually available for complete evaluation. Of those that were evaluated, BGROUT, PC-GEL, and GPGAS2 seem to be the only models available that will simulate cone grouting.

The BGROUT program and source code is readily available, and there has already been much work in preparing and running example input files for cone grouting simulations. Use of this program for facilitating the design and implementation of grout curtains seems to be the best option at the present time.

The PC-GEL program is also readily available for use. Many example input files are available, but none specific for the purpose of general cone grouting. There are doubts that this program may be suitable for use as a general, cone grout simulator, but further examination and testing should be done.

According to Sawyer (December 1994), GPGAS2 models grout injection with greater accuracies than BGROUT. This model was not available for evaluation, though, but may be an option for future study and use.

\subsection{References}

Ackman, T. E. and Jones, J.R.(1991). "Methods to Identify and Reduce Potential Surface Stream Water Losses into Abandoned Underground Mines," Envr. Geology and Water Science, Vol. 17, pp. 227-232.

Bergeson, L. L. (1992). "EPA Proposes Ban of Acrylamide and NMA Grouts." Pollution Engineering, Vol. 24, pp 31-32.

Berry, R. M., and Magill, F. D.(1984). "Chemical Grouting: What's New and What's Being Done this Decade", Public Works, May, 1984.

Bodocsi, A., Bowers, M. T., and Sherer, R. (1988). "Reactivity of various grouts to hazardous wastes and leachates." EPA/600/S2-88/021. U.S. EPA Cincinnati, OH.

Bodocsi, A., and Bowers, M. T.(1991). "Permeability of Acrylate, Urethane, and Silicate Grouted Sands with Chemicals", Journal of the Geotechnical Engineering Division, ASCE, Vol. 117, No. 8, pp. 1227-1243.

Bodocsi, A. (1994). Personal Interview, University of Cincinnati, Cincinnati, OH.

Boury, E. B., Jr. (1994). "Evaluation of Lime Sludge/Fly Ash Grout for Abatement of AMD," Thesis, West Virginia University Morgantown, WV.

Borden, R. H., Gabr, M. A., Hsu, C., and Lien, W.(1987). "Evaluation of Lateral Coefficient of Subgrade Reaction Using the Dilatometer Test" Center for Transportation Engineering Studies, Department of Civil Engineering, North Carolina State University at Raleigh, September, 1987. 
Carson, D. A. (1988). "Hydraulic Conductivity of Modified Cement and Polymer Based Grouted Soils when Exposed to Hazardous Chemicals," Master Thesis, University of Cincinnati, Cincinnati, $\mathrm{OH}$.

Chang, M. M., and Gao, H. W.( 1993). "User's guide and documentation manual for PC-GEL simulator," IIT Research Institute, National Institute for Petroleum and Energy Research.

Dakoulas, P., and Sun, Y.(1992). "Fine Ottawa Sand: Experimental Behavior and Theoretical Predictions," Journal of the Geotechnical Engineering Division, ASCE, Vol. 118, No. 12, pp. 1906-1923.

Daniel, D. E., and Benson, C. H.(1990) "Water Content-Density Criteria for Compacted Soil Liners", Journal of the Geotechnical Engineering Division, ASCE, Vol. 116, No, 12, pp. 18111830.

Dunn, R. J., and Mitchell, J. K.(1984). "Fluid Conductivity Testing of Fine-Grained Soils," Journal of the Geotechnical Engineering Division, ASCE, Vol. 110, No. 11, pp. 1648-1665.

Estornell, P., and Daniel, D., "Hydraulic Conductivity of Three Geosynthetic Clay Liners", Journal of the Geotechnical Engineering Division, ASCE, Vol. 118, No. 10 pp. 1592-1607.

Fanchi, J. R., Kennedy, J. E., and Dauben, D. L.(1987). " BOAST II: A Three-Dimensional, Three-Phase Black Oil Applied Simulation Tool," U.S. Department of Energy Report DOE/BC88/2/SP.

GKN Hayward-Baker (1991). "Guide Specifications for Chemical Grout Underpinning," Company Literature.

Houlsby, A. C.(1988) "Improvements in Grouting of Large Ground Anchors," Journal of the Geotechnical Engineering Division, ASCE. Vol. 114, No. 4. pp. 448-468.

IIT Research Institute( 1994). "User's guide and documentation manual for BEST-GEL," National Institute for Petroleum and Energy Research.

Juang, C. H., and Holtz, R. D., "Fabric, Pore Size Distribution, and Permeability of Sandy Soils," Journal of the Geotechnical Engineering Division, ASCE, Vol. 112, No 9, pp. 855-868.

Karol, R. H. (1983). "Chemical grouting," Marcel Dekker. Inc. New York, NY.

Krizek, R. J., and Perez, T.(1985). "Chemical Grouting In Soils Permeated by Water," Journal of the Geotechnical Engineering Division, ASCE, Vol. 111, No. 7, pp. 898-915. 
Littlejohn, G. S. (1985). "Chemical Grouting-1." Ground Engineering. Vol 18, No. 2, pp. 1315.

Malone, P. G., May, J. H., and Larson, R. J. (1985). "Development of methods for In-Situ Hazardous Waste Stabilization by Injection Grouting." Proc. Tenth Annual EPA Research Symposium: Land Disposal of Hazardous Waste, EPA-600/9-84-007, U.S. EPA, Cincinnati, OH.

May, J. H., Larson, R. J., Malone, P. G., Boa, J. A., Jr., and Bean, D. L. (1985). "Grouting Techniques in Bottom Sealing of Hazardous Waste Sites." Final Report, EPA 600/2-86-020. U.S.EPA, Cincinnati, OH.

Micon (1994). Product Bulletin, Glassport, PA.

Murdoch, L. (1992), "Some Recent Developments in the Delivery and Recovery: Hydraulic Fracturing and directional Drilling," Proceedings of the ETEX 1992 Second Annual Environmental Exposition and Conference, Washington D.C.

Pruess, K.(1990). "TOUGH2 - A General-Purpose Numerical Simulator for Multiphase Fluid and Heat Flow," Earth Science Division, Lawrence Berkeley Laboratory.

Rumer, R. R., and Ryan, M. E. (1993). "Review and Evaluation of containment Technologies for Remediation Applications-Draft". New York State Center for Hazardous Waste Management.

Sawyer, W. K.(1994). "BGROUT, Users Manual and Program", A Modified Version of BOAST3: A Modified Version of Handbook for PC Version of BOAST II: A Three-Dimensional, Three-Phase Black Oil Applied Simulation Tool.

Sawyer, W. K.(1994). Memorandum to William K. Overbey and C. David Locke of BDM. Sawyer, W. K., December 1994, Personal Communication.

Sherer, R. (1986). "Permeability Behavior of Grouted Soils Subjected to Hazardous Wastes," Master Thesis, University of Cincinnati, Cincinnati, $\mathrm{OH}$.

Spooner, P. A., Hunt, G. E., Hodge, V. E., and Wagner, P. M. (1984). "Compatibility of Grouts with Hazardous Wastes." Final Report, EPA-600/2-84-015, U.S.EPA, Cincinnati, OH.

Stapp, L. G., and Allison, E. C.(1989). "BOAST3: A Modified Version of Handbook for PC Version of BOAST II: A Three-Dimensional, Three-Phase Black Oil Applied Simulation Tool.

Suarez, E.(1984). "Design and Construction of Large Scale Triaxial Chamber", Special Report, Department of Civil Engineering, North Carolina State University at Raleigh, November, 1984.

3M (1994). "Chemical Grout 5610," Product Bulletin. Construction Markets Division, St. Paul, $\mathrm{MN}$.

Tarricone, P.(1994). "Jet Grouting Gains," Civil Engineering, December, 1994, pp. 40-43. 
Vaid, Y. P., and Negussey, D.(1988). "Preparation of Reconstituted Sand Specimens," Advanced Triaxial Testing of Soil and Rock, ASTM STP 977, Robert T. Donaghe, Ronald C. Chaney, and, Marshall L., Silver, Eds., ASTM, Philadelphia, 1988, pp. 405-417.

Welsh, J. P. and Burke, G. K. (1989). "Jet Grouting - Uses for Soil Improvement", Geotechnical News, Vol 7, No. 1.

\subsection{Tables And Figures For Chapter 3.0}

Table 3.1 Advantages and Disadvantages of Various Grouts

\begin{tabular}{|c|c|c|}
\hline Grout Type & Advantages & Disadvantages \\
\hline Urethanes/Polyurethanes & $\begin{array}{c}\text { Low Viscosity } \\
\text { Low Toxicity } \\
\text { Chemically Inert }\end{array}$ & $\begin{array}{c}\text { Cost } \\
\text { Short Gel Times }\end{array}$ \\
\hline Sodium Silicates & $\begin{array}{c}\text { Widely Used } \\
\text { Inexpensive } \\
\text { Low Shrinkage } \\
\text { Gel Time Control }\end{array}$ & $\begin{array}{c}\text { Subject to Syneresis } \\
\text { Caustic Raw Materials }\end{array}$ \\
\hline Acrylates & $\begin{array}{c}\text { Low Viscosity } \\
\text { Low Toxicity } \\
\text { Moderate Strength }\end{array}$ & $\begin{array}{c}\text { Cost } \\
\text { Mixing Method }\end{array}$ \\
\hline Acrylamides & $\begin{array}{c}\text { Widely Used } \\
\text { Low Viscosity }\end{array}$ & $\begin{array}{c}\text { Possible U.S. EPA Ban } \\
\text { High Toxicity }\end{array}$ \\
\hline Vinyl Esters & $\begin{array}{c}\text { Low Viscosity } \\
\text { Low Toxicity } \\
\text { Chemically Inert }\end{array}$ & $\begin{array}{c}\text { Cost } \\
\text { Limited Use }\end{array}$ \\
\hline Lignosulfonates & Inexpensive \\
& Waste-Product & High Toxicity \\
& Inexpensive & Variable Content \\
\hline Phenoplasts & High Toxicity \\
& Inexpensive & Requires Acidic Conditions \\
\hline Aminoplasts & Hequire Acidic Conditions \\
\hline
\end{tabular}


Table 3.2 Chemicals Used in Bodocsi and Bowers (1990) Experiments

\begin{tabular}{|c|c|}
\hline Chemical Type & Concentrations \\
\hline Acetone & $25 \%, 100 \%$ \\
\hline Aniline & $100 \%$ \\
\hline Cupric Sulfate & $10 \%, 20 \%$ \\
\hline Ethylene Glycol & $25 \%$ \\
\hline Methanol & $25 \%, 100 \%$ \\
\hline Hydrochloric Acid & $1 \mathrm{~N}, 4 \mathrm{~N}$ \\
\hline Sodium Hydroxide & $10 \%, 25 \%$ \\
\hline Xylenes & $100 \%$ \\
\hline Real-Site Paint Waste ${ }^{1}$ & Full Strength \\
\hline Real-Site Refinery Waste & Full Strength \\
\hline
\end{tabular}

1 Full Strength Leachate from Lysimeter Studies Conducted by Kinman et al. (1986). 
Table 3.3 Baseline Hydraulic conductivities for Each Soil-Grout Mixture Used in Bodocsi and Bowers (1990) Experiments

\begin{tabular}{|c|c|}
\hline Soil-Grout Mixture & $\mathbf{K}_{\mathbf{h}}{ }^{\mathbf{w}}, \mathbf{c m} / \mathbf{s}$ \\
\hline AC-400 & $5.1 \times 10^{-10}$ \\
\hline CR360 $^{2}$ & $3.6 \times 10^{-9}$ \\
\hline Pene-grout $^{2}$ & $5.0 \times 10^{-8}$ \\
\hline SIROC \#132 & $5.0 \times 10^{-5}$ \\
\hline glyoxal-sodium silicate $^{3}$ & $1.9 \times 10^{-5}$ \\
\hline aluminate-sodium silicate $^{3}$ & $9.2 \times 10^{-6}$ \\
\hline
\end{tabular}

1 acrylate-based grout

2 urethane-based grout

3 sodium silicate-based grout 
Table 3.4 Hydraulic Conductivities in the Presence of Selected Chemical From the Bodocsi and Bowers (1990) Experiments

\begin{tabular}{|c|c|c|c|c|c|c|c|c|c|c|c|c|c|c|c|}
\hline \multirow{3}{*}{$\frac{\text { GROUT }}{\text { Type }}$} & \multicolumn{15}{|c|}{ LEACHATE TYPE } \\
\hline & \multicolumn{2}{|c|}{ Acetone } & \multirow{2}{*}{$\begin{array}{l}\text { Aniline } \\
100 \%\end{array}$} & \multicolumn{2}{|c|}{ Cupric Sulfute } & \multirow{2}{*}{$\begin{array}{c}\begin{array}{c}\text { Ethylene } \\
\text { Glycol }\end{array} \\
25 \% \\
\end{array}$} & \multicolumn{2}{|c|}{ Methanol } & \multicolumn{2}{|c|}{$\mathrm{HCl}$} & \multicolumn{2}{|c|}{$\mathrm{NaOH}$} & \multirow{2}{*}{$\begin{array}{l}\text { Xylene } \\
100 \%\end{array}$} & \multirow{2}{*}{$\begin{array}{l}\begin{array}{c}\text { Paint } \\
\text { Waste }\end{array} \\
100 \% \\
\end{array}$} & \multirow{2}{*}{$\begin{array}{c}\begin{array}{c}\text { Refinery } \\
\text { Waste }\end{array} \\
100 \%\end{array}$} \\
\hline & $25 \%$ & $100 \%$ & & $10 \%$ & $20 \%$ & & $25 \%$ & $100 \%$ & $1 \mathrm{~N}$ & $4 N$ & $10 \%$ & $25 \%$ & & & \\
\hline \multicolumn{16}{|l|}{ AC-400 } \\
\hline $\mathrm{K}_{\mathrm{h}}{ }^{\mathrm{f}}, \mathrm{cm} / \mathrm{s}$ & $1 \mathrm{E}-8$ & $2 \mathrm{E}-4$ & $1 E-4$ & $1 \mathrm{E}-7$ & $4 \mathrm{E}-7$ & $4 \mathrm{E}-9$ & $3 E-9$ & $1 E-4$ & $8 \mathrm{E}-6$ & $9 E-6$ & $\cdots$ & $3 E-11$ & $3 \mathrm{E}-7$ & 1E-9 & $6 \mathrm{E}-10$ \\
\hline $\mathrm{K}_{\mathrm{h}}^{\mathrm{t}} / \mathrm{K}_{\mathrm{h}}{ }^{\mathrm{W}}$ & 56 & 274000 & 16,700 & 280 & 540 & 6 & 5 & 218000 & 11,000 & 13,400 & $\cdots$ & 0.05 & 540 & 2 & 1 \\
\hline \multicolumn{16}{|l|}{ CR360 } \\
\hline $\mathrm{K}_{\mathrm{h}} \mathrm{f}^{\mathrm{f}} \mathrm{cm} / \mathrm{s}$ & -- & $2 \mathrm{E}-8$ & $4 \mathrm{E}-10$ & $-\cdots$ & $2 \mathrm{E}-7$ & $2 \mathrm{E}-9$ & $\cdots$ & $8 \mathrm{E}-9$ & $6 \mathrm{E}-8$ & $4 \mathrm{E}-8$ & $2 E-4$ & $1 E-4$ & $8 \mathrm{E}-7$ & $1 \mathrm{E}-8$ & $1 E-8$ \\
\hline $\mathrm{K}_{\mathrm{h}} \mathrm{t} / \mathrm{K}_{\mathrm{h}} \mathrm{W}^{\mathrm{W}}$ & $-\cdots$ & 5 & 0.2 & $\cdots$ & 74 & 0.7 & $\cdots$ & 3 & 24 & 18 & 78640 & 71750 & 310 & 2 & 2 \\
\hline \multicolumn{16}{|l|}{ Pene-Grout } \\
\hline $\mathrm{K}_{\mathrm{h}}^{\mathrm{f}}, \mathrm{cm} / \mathrm{s}$ & --- & $3 E-6$ & $\ldots$ & $-\ldots$ & $6 \mathrm{E}-6$ & $9 \mathrm{E}-8$ & $-\cdots$ & -- & $5 \mathrm{E}-7$ & - & - & $8 \mathrm{E}-5$ & $9 \mathrm{E}-7$ & $\therefore$ & $\cdots$ \\
\hline $\mathrm{K}_{h} \mathrm{f} / \mathrm{K}_{\mathrm{h}}{ }^{\mathrm{W}}$ & -- & 92 & $\cdots$ & $-\cdots$ & 690 & 9 & $\cdots$ & - & 80 & - & -- & 3,940 & 21 & $\cdots$ & $=$ \\
\hline
\end{tabular}


Table 3.5 Summary of Grout Types and Soil Properties for Spalding et al. (1985) Lab-Scale

\begin{tabular}{|c|c|c|c|c|}
\hline \multicolumn{5}{|c|}{ Grouts Investigated } \\
\hline \multicolumn{5}{|c|}{ Sodium Silicate } \\
\hline \multicolumn{5}{|c|}{ Acrylamide } \\
\hline \multicolumn{5}{|c|}{ Resorcinol-Formaldehyde } \\
\hline \multicolumn{5}{|c|}{ Urea-Formaldehyde } \\
\hline \multicolumn{5}{|c|}{ Cement-Bentonite-Fly Ash } \\
\hline \multicolumn{5}{|c|}{ Lime-Fly Ash } \\
\hline \multicolumn{5}{|c|}{ Bentonite Slurry $i$} \\
\hline \multicolumn{5}{|c|}{ Selected Properties of Study Soils } \\
\hline Soil ID & $\%$ Sand & $\%$ Silt & \% Clay & $\mathrm{pH}$ \\
\hline Trench $350^{1}$ & 36 & 24 & 40 & 4.4 \\
\hline Trench 351 & 26 & 42 & 32 & 7.1 \\
\hline Trench 349 & 23 & 42 & 35 & 4.9 \\
\hline Maxey Flats & 17 & 51 & 32 & 4 \\
\hline
\end{tabular}

1 Designates Trench Location at Oak Ridge, TN 
Table 3.6. Hydraulic Conductivities Before and After Grouting for Lab- Scale Experiments Conducted by Spalding et al. (1985)

\begin{tabular}{|c|c|c|c|}
\hline \multirow[t]{2}{*}{ Soil } & \multirow[t]{2}{*}{ Grout } & \multicolumn{2}{|c|}{ Conductivity $-\mathrm{K}_{\mathrm{h}}, \mathrm{cm} / \mathrm{s}$} \\
\hline & & Before & After \\
\hline \multirow{4}{*}{$\begin{array}{l}\text { Trench } \\
\mathbf{3 5 0}\end{array}$} & Sodium Silicate & $7.9 \times 10^{-3}$ & $4 \times 10^{-6}$ \\
\hline & Acrylamide & $6.3 \times 10^{-3}$ & $<1 \times 10^{-7}$ \\
\hline & $\begin{array}{l}\text { Resorcinol- } \\
\text { Formaldehyde }\end{array}$ & $1.6 \times 10^{-2}$ & $<1 \times 10^{-7}$ \\
\hline & Urea-Formaldehyde & $1.2 \times 10^{-2}$ & $1.3 \times 10^{-3}$ \\
\hline \multirow{4}{*}{$\begin{array}{l}\text { Trench } \\
351\end{array}$} & Sodium Silicate & $3.2 \times 10^{-2}$ & $4.7 \times 10^{-7}$ \\
\hline & Acrylamide & $2.2 \times 10^{-2}$ & $<1 \times 10^{-7}$ \\
\hline & $\begin{array}{l}\text { Resorcinol- } \\
\text { Formaldehyde }\end{array}$ & $3.2 \times 10^{-2}$ & $<1 \times 10^{-7}$ \\
\hline & Urea-Formaldehyde & $2.8 \times 10^{-2}$ & $8.7 \times 10^{-3}$ \\
\hline \multirow{4}{*}{$\begin{array}{l}\text { Marey } \\
\text { Flats }\end{array}$} & Sodium Silicate & $6.3 \times 10^{-3}$ & $3.7 \times 10^{-6}$ \\
\hline & Acrylamide & $5 \times 10^{-3}$ & $<1 \times 10^{-7}$ \\
\hline & $\begin{array}{l}\text { Resorcinol- } \\
\text { Formaldehyde }\end{array}$ & $1.6 \times 10^{-2}$ & $<1 \times 10^{-7}$ \\
\hline & Urea-Formaldehyde & $1.2 \times 10^{-2}$ & $1.3 \times 10^{-3}$ \\
\hline
\end{tabular}

Table 3.7 - Hydraulic Conductivities Before and After Grouting For FieldStudies Conducted By Spaulding et al.(1985)

\begin{tabular}{|c|c|c|}
\hline Trench \#/Grout Type & \multicolumn{2}{|c|}{$\mathrm{K}_{\mathrm{h}, ~} \mathrm{~cm} / \mathrm{s}$} \\
& Before & After \\
\hline 349/Sodium Silicate & $2.4 \times 10^{-2}$ & $5.0 \times 10^{-3}$ \\
\hline 350/Sodium Silicate & $2.4 \times 10^{-2}$ & $8.8 \times 10-5$ \\
\hline 351/Acrylamide & $1.6 \times 10-2$ & $9.7 \times 10-7$ \\
\hline
\end{tabular}




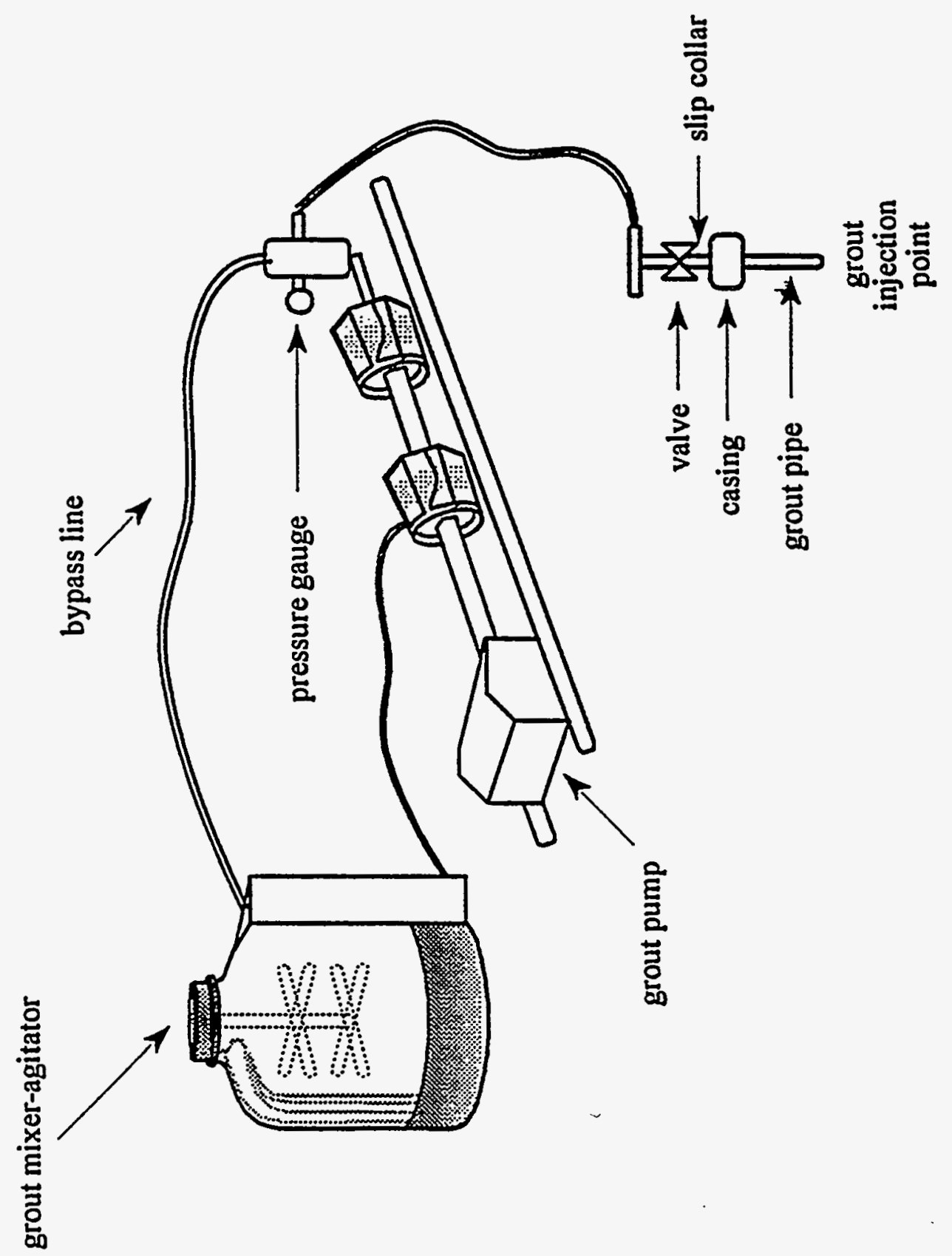

Figure 3.1 Schematic of Typical Grout Injection System 

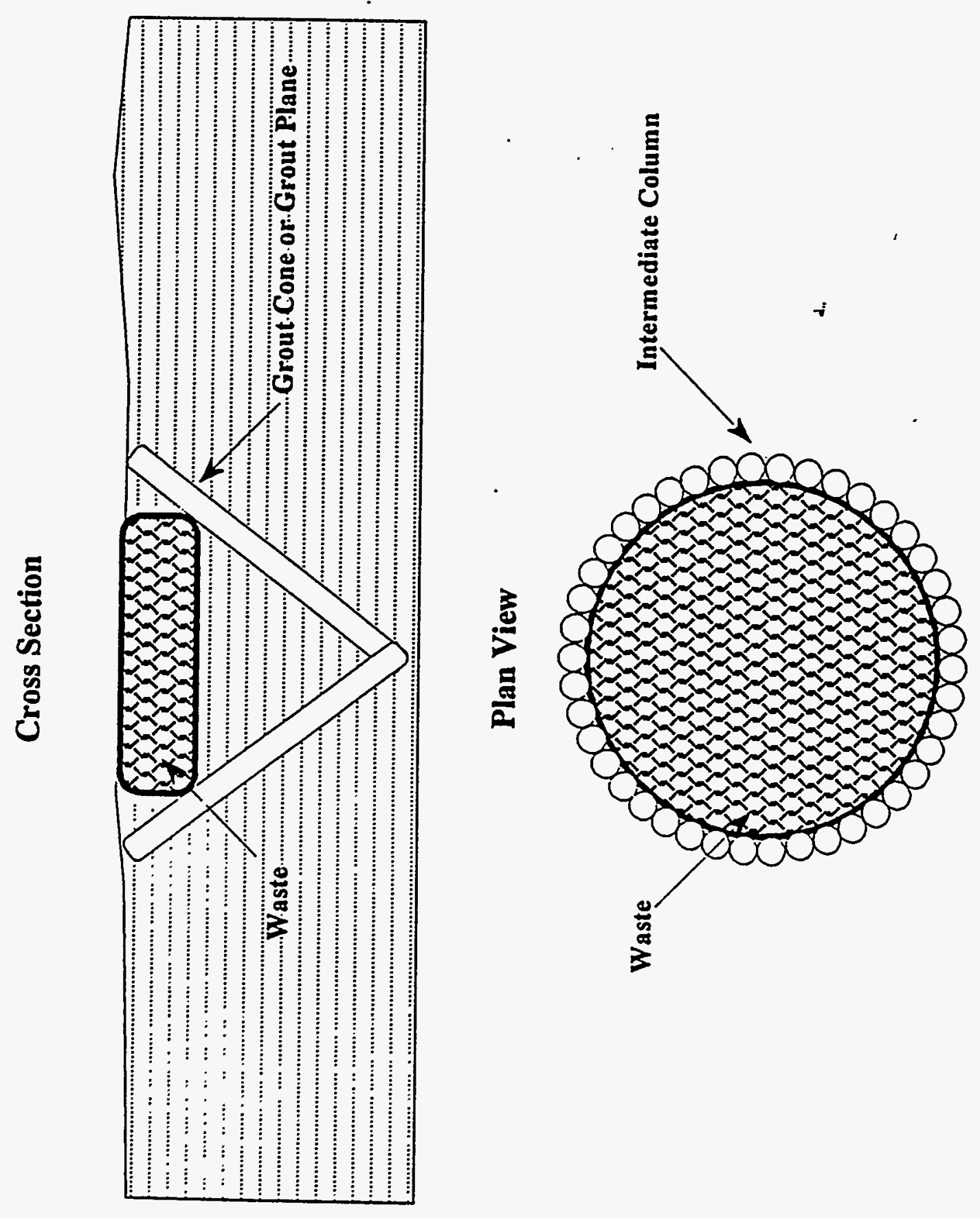

Figure 3.2 Grout Cone 

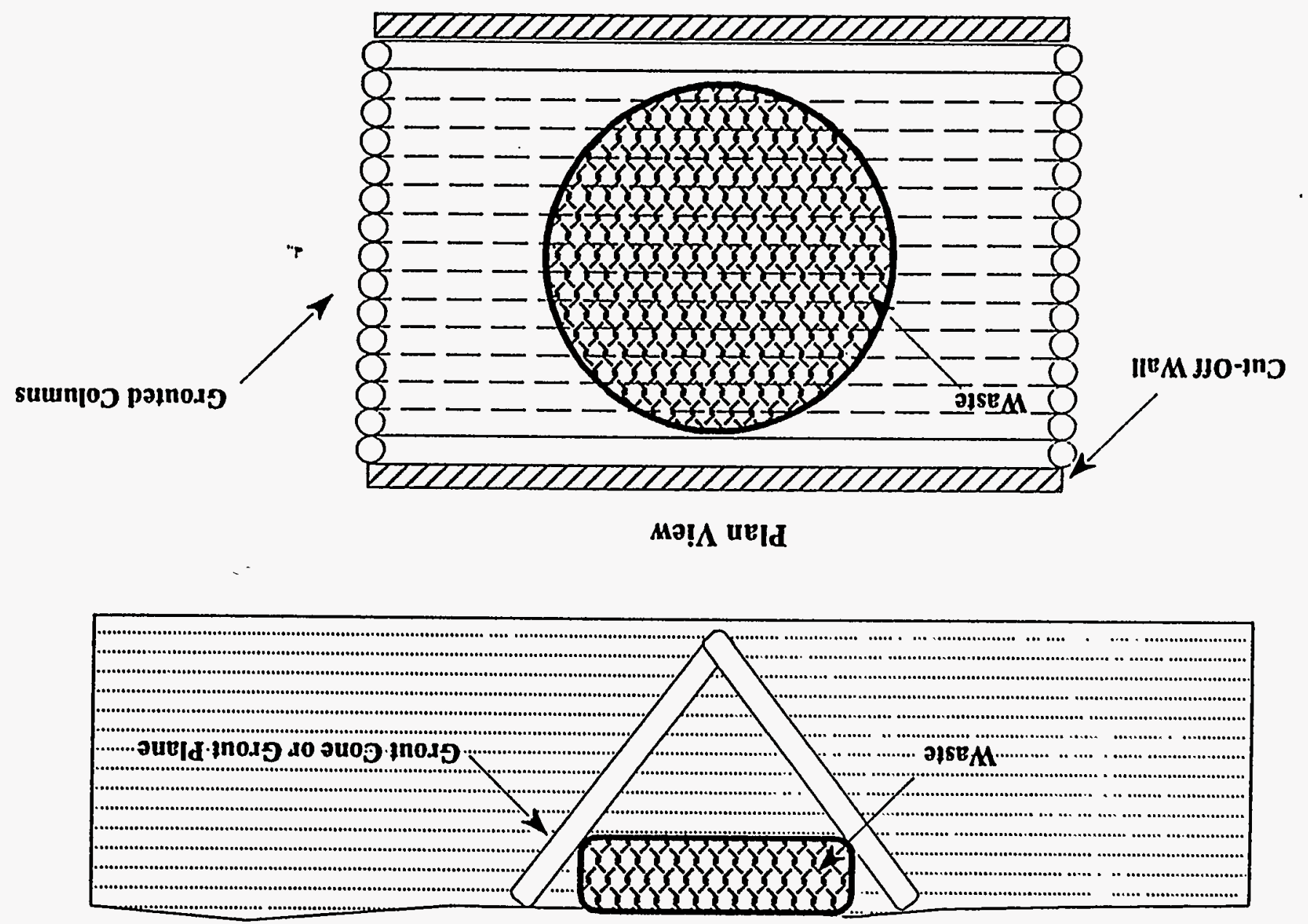

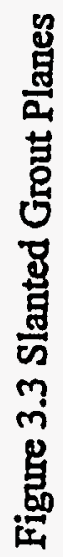

uo!̣วOS SSOגว 


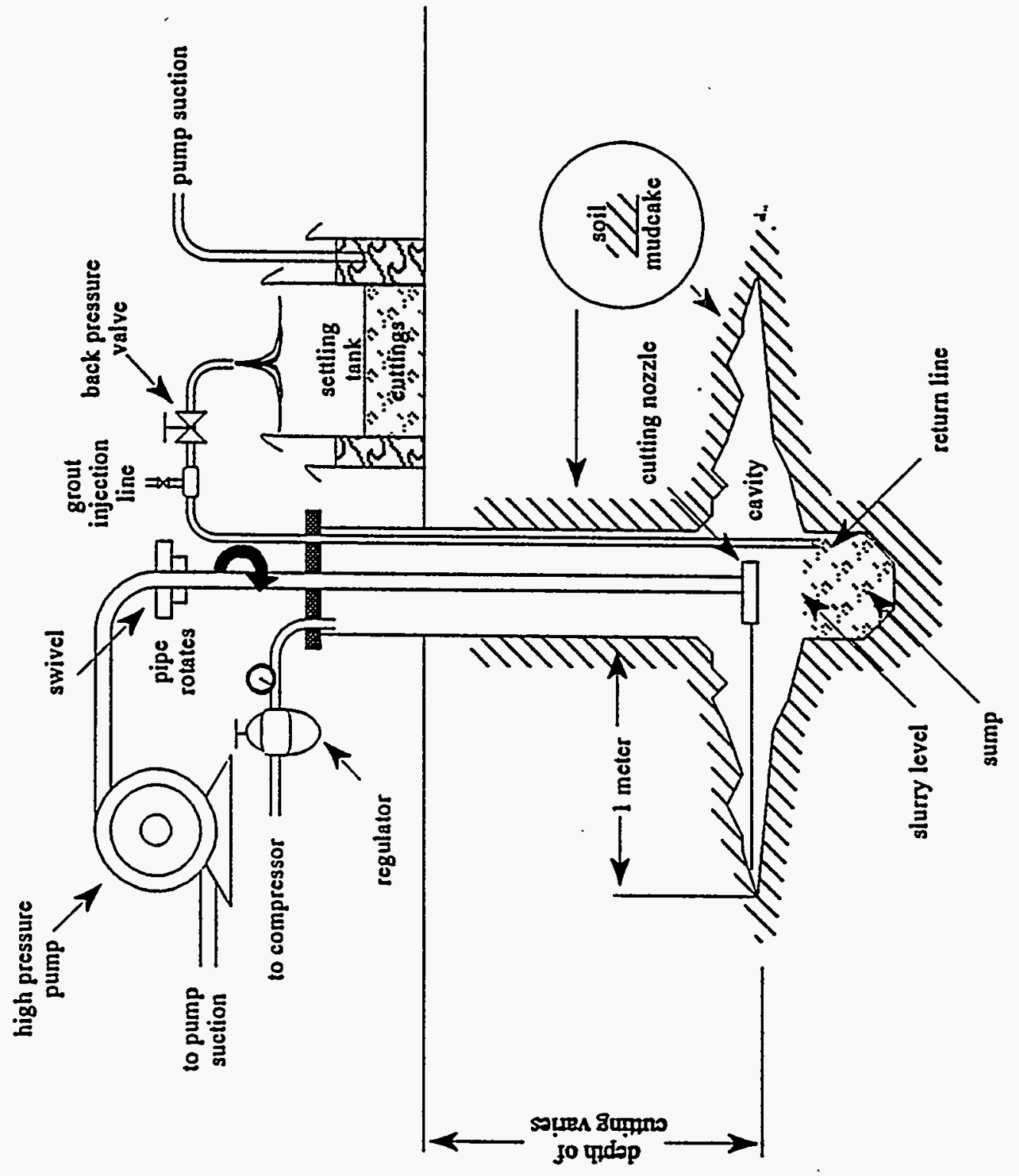

Figure 3.4 Jetting System 


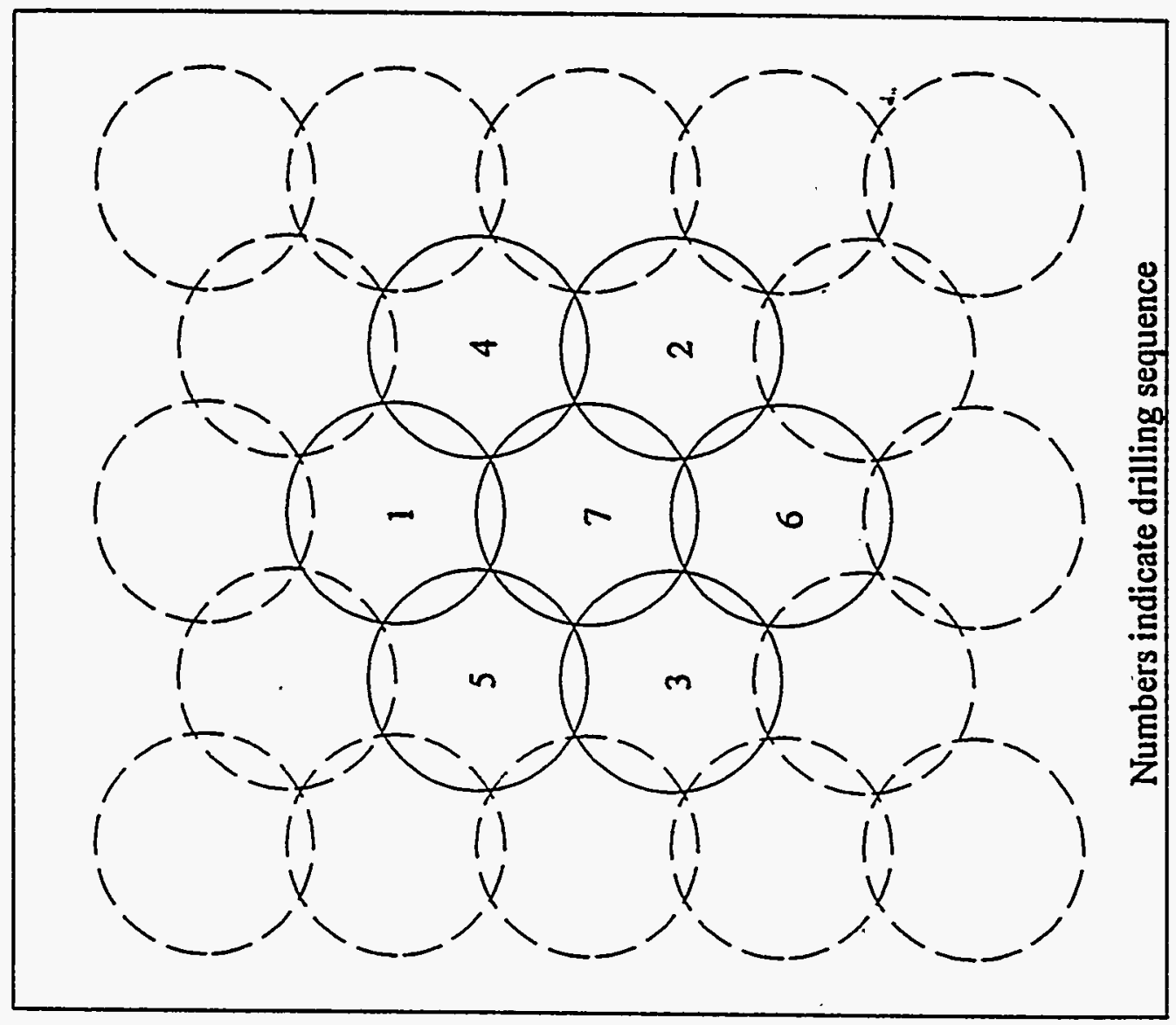

Figure 3.5 Geometric Layout for Jet Grouted Columns to Form a Horizontal Barrier 


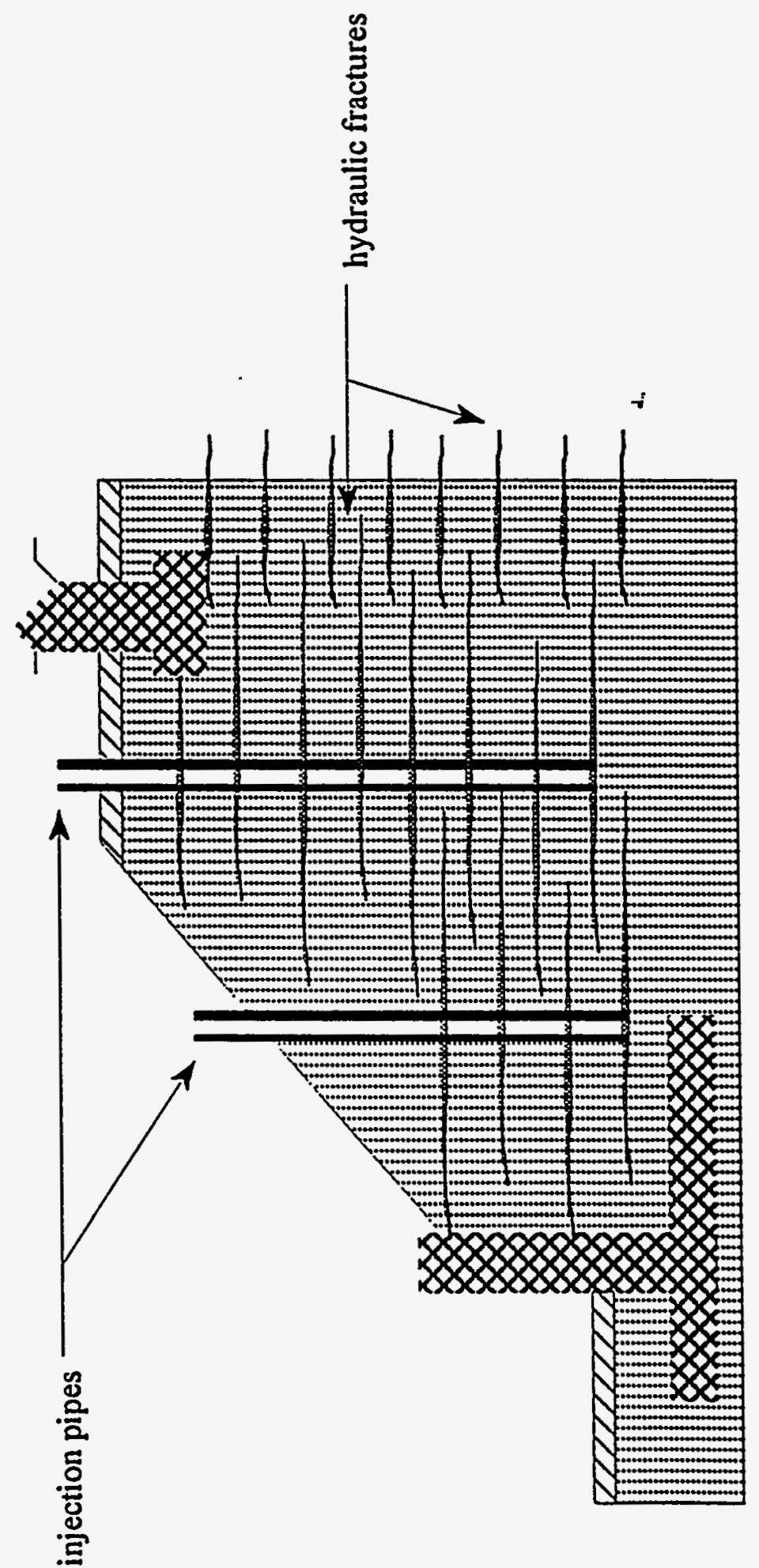

Figure 3.6 Hydrofracturing 


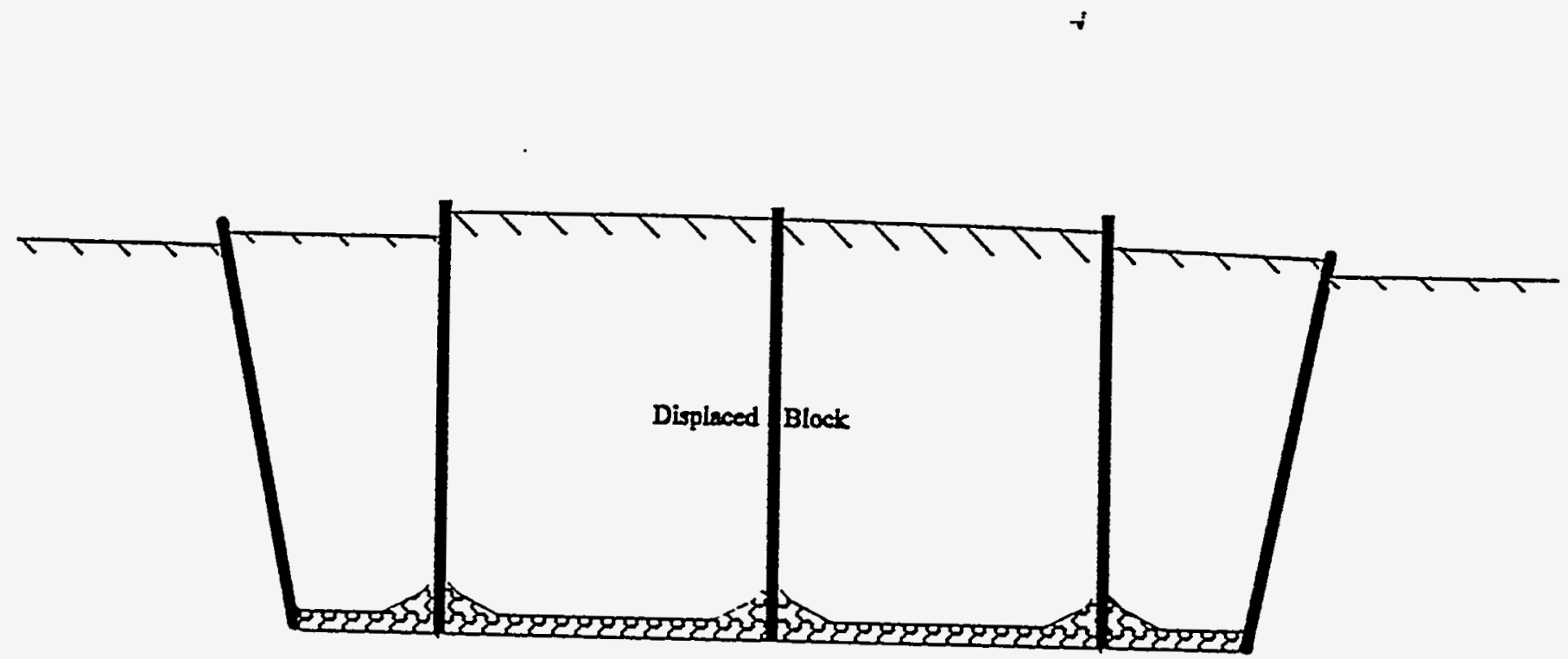

Figure 3.7 - Cross-Sectional View of Block Displacement Method Grouting 


\subsection{REVIEW OF DESICCANT BARRIER (CIRCULATING AIR BARRIER) SYSTEM}

A review of literature about Circulating Air Barrier (CAB) system was conducted. The literature review included the search of engineering and scientific journals and periodicals through both $C D$ -ROM databases of journals available at West Virginia University library and computerized search using a list of key words. The following discussion summarizes the results of the literature review.

\subsection{Circulating Air Barrier (CAB)}

The Circulating Air Barrier (CAB) system is a desiccant-type barrier designed to prevent the movement of liquid contaminants toward groundwater, using a gas (here, air) circulation and processing system to lower water saturation in a targeted subsurface zone below the saturation required for liquid flow through that zone. The concept of Circulating Air Barrier was conceived to solve the serious subsurface contamination problems at Hanford Site through applying directional and horizontal well drilling technology developed by petroleum industry (1).

The references to $C A B(1,2,3)$ are mainly related to $C A B$ as a concept and no field or laboratory data have been found in the literature. A study conducted by K\&M/BDM (1) included the evaluation of alternate drilling technologies and subsurface barriers for application at DOE's Hanford Site. A facet of this study included investigation of barrier systems that could be installed beneath and around the tank farms with a minimum of excavation. This barrier would be designed - to prevent the downward movement of the contaminant plume, preventing the liquid contaminants from reaching the ground water. The barrier concepts included existing, commercially available technologies that were suitable for the variety of soil conditions found beneath the Hanford tank farms. The barriers were also investigated for ability to withstand chemical attack and seismic deformations, and for their ability to have the barrier integrity verified remotely. The study culminated in development of seven integrated subsurface barrier systems. They were evaluated and ranked in qualitative terms for their suitability to the Hanford Site, their ability to meet environmental health and safety constraints and leak response capability, and in quantitative terms of installation/excavation requirements and estimated deployment times and costs.

The Hanford Site is semi-arid; water contained in soil matrix is low, averaging less than $20 \%$. The geology is complex; sediments vary rapidly, both vertically and horizontally. Average porosity is relatively high, about $40 \%$. The ground water table is found approximately 244 feet below the surface of the tank farm. This type of environment is well suited for application of the CAB technology that was ranked the highest. The $C A B$ concept introduced in this study (1) involves the circulation of air (or another gas) through a subsurface interval in order to lower and then maintain the water saturation required for liquids to flow. The barrier can be installed using either vertical or horizontal wells, establishing a pattern of air injection and production wells. The moving air vaporizes water in the zone and carries the water vapor to production (extraction) well. The production stream is then processed in a surface facility to remove the water and any contaminants or particulates. In time, circulation of the air reduces the water saturation in the 
swept interval, and continues to remove, by evaporation, liquids that move into the zone such as a leaked plume. No liquids can flow through this interval until a critical saturation is achieved, a saturation level that is well above the initial saturation. In the event that a leak occurs, the CAB system serves as a tool for early leak detection and provides a means to withdraw volatile contaminants for surface treatment. The study (1) concluded that $C A B$ system provided many advantages including non-physical confinement, active monitoring and leak detection, commercially available oil and gas technologies and equipments, emergency response and rapid deployment capability, and high potential for integration with other remediation technologies. However, the concept needs to be demonstrated to develop data needed for scale-up and regulatory acceptance.

A follow up study by $\mathrm{K} \& M / B D M(2)$ which addressed modeling, cold test design, and surface processing and control design for the $\mathrm{CAB}$ demonstration at Hanford concluded that several issues must be settled before it can be decided if $\mathrm{CAB}$ technology is applicable to all DOE sites. Key among these issues is the influence of the soil characteristics such as porosity, permeability, water saturation, grain size-distribution, and clay content on drying profile and $\mathrm{CAB}$ performance. This report further recommended a laboratory study to be undertaken to evaluate the soil characteristics influence on $\mathrm{CAB}$ performance and to find out the effects of flow and sweep efficiency for fixed grain-size and mixed grain-size soils. This would also serve to validate and/or improve model predictions of system behavior and drying profiles of different soil types. In addition, a range of geologic and climatic environment within which the $\mathrm{CAB}$ could successfully operate, baseline equilibrium moisture curve for a specific grain-size, and relative humidity for a specific temperature.

A different paper described a similar idea by introducing Dry (or sometimes tensiometric) barrier(3). The concept described in this paper includes dry air injection into unsaturated formation to lower the soil moisture content to reduce the hydraulic conductivity of unsaturated media to the point where liquid phase transport becomes negligible, by that achieving containment. The paper concludes that this concept could be applied in subsurface formation to provide containment from a leaking facility, or it could be incorporated as an additional component of a landfill cover system The air injection process could in principal be coupled with a vacuum extraction system to recover soil vapors, which would then provide a remediation process that would be appropriate if volatile organic compounds were present. Either application would require circulation of relatively dry air through the formation to achieve moisture removal. Drying a soil layer creates a barrier to water movement in three ways. First, the drying removes water from the system, intercepting the downward movement of water. Second, drying a soil layer increases its water storage capacity so the soil will tend to retain rather than transmit water. Third, as a soil layer dries, progressively smaller and smaller pores empty and hydraulic conductivity of the formation for liquid flow decreases. The analyses presented in this paper (3) suggest that there are no engineering obstacles to incorporating a dry barrier into either a landfill cover or as a subsurface barrier beneath a contaminant plume in the vadose zone. 


\subsection{Phase Equilibria and Mass Transfer in Porous Media}

The development of $C A B$ or Dry Barrier system involves evaporation of water from liquid phase into gas phase(air). The concept of drying has been extensively studied (4). Generally, the term drying refers to removal of moisture from solids(or liquids) by evaporation into a gas stream. In practice, the moisture is often water and gas is frequently air (4). The air-water equilibrium therefore plays a critical role in the drying process. While there are published data for air-water equilibrium, they are not obtained in the porous solid (media). Consequently, it is important to investigate the influence of porous media on both gas-water equilibrium and mass transfer from liquid phase to gas phase. A review of petroleum engineering literature suggests that the influence of porous media on phase equilibrium generally is ignored in practical reservoir engineering calculations. The typical examples are the use of oil PVT-data in material balance calculations (5) and the use of natural gas-water equilibrium data in determination of natural gas water content (6). Indeed, the natural gas-water equilibrium data are used in estimating the increase in water content of dry natural gas (pipeline quality) when it is removed from the underground storage reservoirs $(7,8)$. This confirms that porous media can be dried by injecting a dry gas. This lends validity to $C A B$ concept .

Generally, there are two competing factors when dealing with gas-liquid equilibrium and mass transfer in porous media. They are surface contact and surface tension. Generally, porous media increases the contact surface area between the phases when one or both are flowing and enhances the mass transfer between the phases. This is the fundamental concept in design and application of packed columns. Simultaneously, the surface forces tend to cause liquid to have lower vapor pressure than the pure liquid at the same temperature (bounded moisture). As a result, the driving force for mass transfer is lowered. Both factors are influenced by the internal surface area of the porous media. The internal surface area depends on grain-size, grain size-distribution and packing in porous media. Therefore, it appears that the proposed experiments with-sand packs should provide the fundamental data to assess the influence of porous media on air-water equilibrium and mass transfer.

\subsection{Sand-Pack Design}

To study the influence of porous media on air-water equilibrium and mass transfer representing the typical soil conditions, a series of tests in sand-pack has been proposed. This segment deals with the review of the literature relative to the design of the sand-pack. There are many publications available for determining soil properties. The ones referred to here are generally those published by American Society for Testing and Material (ASTM). The standard procedures that were investigated and reviewed included compaction $(9,10)$, moisture-density relations $(10,11)$, determination of soil water content (12), and permeability evaluation (13). These procedures form the basis for test design and development. These experiments are designed to investigate the repeatability of ASTM standard techniques and will be used to identify the most feasible method of determining sand-pack properties including permeability, porosity, and moisture content (water saturation). The influence of particle size and particle size-distribution on sand-pack properties will be also investigated. 
In addition to standard techniques relative to laboratory testing of soil properties, a number of papers have been published on modeling approach for determining the properties of porous media $(14,15,16)$. The modeling approach has been studied by many investigators and numerous papers are available on the subject. It is beyond the scope of this report to review these articles in detail. However, an excellent summary has been previously published (17). The modeling approach will complement the experimental results in the area of particle size and particle size-distribution influence on porosity and permeability. Attempts will be also made to model the influence of the particle size on the internal surface area. This approach, if successful, can be used to scale-up the experimental results.

\subsection{References}

1. K\&M/BDM :" Evaluation of Alternative Drilling Technologies. and Subsurface Barriers for Single Shell Tanks at Hanford" Report Prepared for USDOE/METC under Contract No.

DE-AC21-90MC27346, Phase I: feasibility assessment Jan. 1993 and Phase II: Implementation Plan Development Nov. 1993.

2. K\&M/BDM :" Design of Circulating Air Barrier System for Cold Tests At Hanford " Volume I - Draft Report Prepared for USDOE/METC under Contract No. DE-AC2190MC27346, Task 23, July 30,1994.

3. Thompson, B.M., C.E. Moriss, J. Stormont, M.D. Anesky : "Development of Dry Barrier for Containment and Remediation of Waste Sites", Proceedings of Waste Management 94 Symposia, Vol. III, pp. 2193-2198

4. Robert E. Treybal: Mass Transfer Operations, second edition, McGraw-Hill Book Company, 1968.

5. H.C. Slider: Worldwide Practical Petroleum Reservoir Engineering, PennWell Books, 1982.

6. C.H. Ikoku: Natural Gas Production Engineering, McGraw-Hill Book Company, 1983.

7. Katz and Coats: Underground Storage of Fluids, Ulrichs Books Inc., Ann Arbor, Mich. 1975.

8. Katz et al.: Handbook of Natural Gas Engineering, McGraw-Hill Book Company, 1959.

9. "Compaction Tests", Chapter 6:Manual of Soil Laboratory Testing, Vol.1, John Wiley and Sons, 1978.

10. ASTM Committee D-18: "Standard Test Methods for Moisture-Density Relations of Soil, Rock, and Soil-Aggregate Mixtures Using 5.5-Ib Rammer and 12-inch Drop", from Annual Book of ASTM Standards, Section 4, Vol 04.08, 1991. 
11. ASTM Committee D-18: " Test Methods for Moisture-Density Relations of Soil(D698)", Proceeding for Testing Soils, Fourth Edition, December 1964.

12. ASTM Committee D-18: "Standard Test Method for Laboratory Determination of Water (Moisture) Content of Soil, Rock, and Soil-Aggregate Mixtures", from Annual Book of ASTM Standards, Section 4, Vol 04.08, 1991.

13. ASTM Committee D-18: "Standard Test Method for Permeability of Granular Soils (Constant Head)", from Annual Book of ASTM Standards, Section 4, Vol 04.08, 1991.

14. Alsono, M., M. Satoh, and K. Miiynami: "Void-Size Distribution in Two-Dimensional Random Packings of Equal-Sized Disks", The Canadian Journal of Chemical Engineering, Vol.70, February 1992, pp. 28-32.

15. Ouchlyama, N.: "Porosity Estimation from Particle Size Distribution", Ind. Eng. Chem. Fundam., Vol. 25, No. 1, 1986, pp. 125-129.

16. Aberg, B. : "Hydraulic Conductivity of Noncohesive Soils", Journal of Geotechnical Engineering, Vol. 118, No. 9, September 1992, pp. 1335-1347.

17. Ameri, S., T.P. Meloy, and K. Aminian: "Permeable Rock Model Using An Array of Pores", Powder Technology, Vol. 75, 1993, pp. 107-112.

\section{APPENDIX A}

\section{A.1 BDM Literature Search}

\section{A.1.1 Technical Approach}

A list of key words and modifiers was compiled that described the key elements of subsurface barriers, potential barrier materials, or geologic condition. The first search was conducted at the Evansdale Branch of the West Virginia University Library. Subsurface barrier technology is an emerging technology so the literature search was limited to material published since 1985 . The second phase of the search was conducted at the Morgantown Energy Technology Center Library, where the key words associated with subsurface barriers was utilized in a search of Government reports, including the National Technical Information Service (NTIS) data base. Another source of reports utilized was the published papers presented at the national Nuclear Waste Management Symposia held each year in Tuscon, Arizona and sponsored by the DOE and University of Arizona.

\section{A.2 Results of Literature Review}




\section{A.2.1 Procedure}

Key words were entered into the library computer to determine the lists of articles which contained the groups of key words selected. The title and an abstract, if available, was copied to a disk for more detailed review to determine if a paper copy of the report would be required. Paper copies were then reviewed in detail for use in the evaluation of barrier types, materials, and deployment systems.

\section{A.2.2 Key Words Used For In Situ Barriers Search}

1. freeze wall barriers

- solidification

- coagulation

- crystallization

2. barriers

- desiccant barriers

- circulating air barriers

- jet grout barriers

- grout barriers

- engineered barriers (rubber, plastics)

- barriers (in vadose zone)

- chemical membrane barriers

- chemically reactive barriers

3. grout barriers

- polyfoams

- cements

- chemicals (Na silicate)

4. mining operation

- engineered barrier (mined-longwall machinery)

- mine roof bolting

- mine shaft lining

5. toxins

6. contamination

- hazardous materials

- toxic or hazardous liquids

7. waste

- hazardous wastes

- solid wastes

- waste disposal

- waste management

8. air flow

9. plastics foamed

- polyurethane foam

10. water

- ground water/artificial discharge

- waste water 
- underground water

- ground water pollution

- water pollution

- water pollution control federation (wpcf)

11. environment

- thermal

12. soil

- saturation

- adsorption

- conservation

- mechanics

- infiltration

- pollution

- leaching

13. tanks

- underground/installation/leakage

- plastic

- rubber lining

- double wall tanks

- leak detectors

- secondary containment

14. hazardous landfills

- design

- lining

- closure

- superfund sites

- pollution liability

- barriers

15. hazardous wastes/substances management

- storage

- disposal

- remediation

- closure

- on site treatment

- environmental aspects

- analysis

- cleanup

16. conservation

- soil conservation

- conservation

- environmental aspects 


\section{A.3. Literature Review For In Situ Barriers}

The following is a list of articles that were selected for more detailed review based on reading of the abstract:

1. Analysis of leak prevention technologies for underground storage tanks

2. Capping hazardous wastes landfill (Pitman, New Jersey)

3. Conference focuses on bioremediation and proposed rules for land disposal

4. Designing your underground storage tank system

5. Detection and monitoring systems for storage

6. Disposal of hazardous and special wastes

7. Elastomers for containment of hazardous waste

8. Five steps to effective secondary containment

9. Foam aids toxic cleanup

10. Grouting against hazwaste

11. Handling hazardous wastes and lining landfills; equipment guide

12. Hazardous waste migration in soil

13. Hydraulic fracturing may enhance in situ remediation

14. Impermeable landfill caps found suitable for arid environments

15. Innovative rock support system and radon gas barrier (MIROC Mineguard)

16. Innovative shaft lining method

17. Landfill-cover conflict

18. 1993 Landfill liner \& geotextile equipment guide

19. Liners keep Superfund waste in its place

20. Maximum saturated depth over landfill liner

21. Minimizing liability for LUST: countermeasures for leaking underground storage tanks

22. Monitoring for hazardous waste leaks

23. Monolithic linings and coatings for secondary containment structures

24. Permeability of acrylate, urethane, and silicate grouted sands with chemicals

25. Plan carefully--storage areas take an active role in pollution control

26. Polyurethane foam plugs leak in water tunnel

27. Polyurethane foam rescues tunnel

28. Polyurethanes

29. Prioritizing areas for statewide groundwater monitoring

30. Sand fill and compaction: getting them right

31. Shielding effects of concrete and urethane foam external pipeline barrier coatings

32. Simulation of chemical transport in unsaturated soil

33. Simultaneous groundwater and soil clean-up

34. Soil stability at landfills

35. Toxic waste deposits delay lock construction (Kanawha River, W. V. )

36. Use of liners for containment at hazardous waste landfills

37. Which polyurethane?--and where to use it

38. Polymer Containment Barriers for Underground Storage Tanks

39. Demonstration of In-Situ Constructed Horizontal Soil Containment Barrier at Fernald 
40. Bottom Barrier by New Soil Improvement Method to Confine Vertical Plume of Contamination

41. Subsurface Barrier Design Alternatives for Confinement and Controlled Advection

\section{APPENDIX - B}

\section{B. 1 Chemical Grouts Product Data}

In this research, two different grouts are tested and evaluated for, the suitability of subsurface grouting. The product information as supplied by the manufacturers is presented in the subsequent sections.

B. 1.1 3M Scotch-Seal ${ }^{\text {TM }}$ Chemical Grout 5610 (Gel)

B. 1.2 Manufacturer

$3 \mathrm{M}$ Construction Markets Division

3M Center, Building 225-4S-08

St. Paul, MN 55144-1000

(612) $713-1140$

\section{B. 1.3 Product Description}

3M Scotch Seal Chemical Grout 5610 is hydrophilic urethane, i.e. it is water reactive. It can change from a free-flowing liquid to a water-impermeable solid. It penetrates and consolidates soil to produce a water-impermeable grouted soil mass or grout membrane. The formation of chemical-grout barrier confining containment area is expected to retard, or even prevent the advancement of the contamination plumes into the environment until the implementation of remediation efforts is completed.

Chemical grout 5610 is hydrophilic urethane liquid that is designed to be mixed with water and applied through pumping equipment. It has a moderate viscosity and a sweet odor (ketone solvent). Chemical grout 5610 contains Toluene Diisocyanate (TDI) and Acetone.

The product should be stored in a cool, dry place where temperature does not exceed $80^{\circ} \mathrm{F}$. The useful life is one year if the compound is properly stored in original unopened containers. As application equipment, hose liners (butyl or polyethylene) are recommended. Nylon reinforcement should not be used. 
Use of chemical grout 5610 as a subsurface barrier for confining a contaminant zone is limited by soil permeability. Grout 5610 can be used up to the grain size larger than approximately 0.03 $\mathrm{mm}$, which is silt. In various environments, 5610 gel should be formulated with additives to increase resistance to shrinkage and degradation from biological agents, chemicals and solvents. Water used with 5610 should be within pH range from 5 to 9 . Chemical grout 5610 is supplied in 5 gallon (18.90 liters) buckets.

\section{B. 1.4 Technical Data}

Technical data for the urethane chemical grout 5610 is presented in Tables B1, B2, and B3.

\section{B. 1.5 Advantages}

As a grouting material for construction of a subsurface barrier, Chemical Grout 5610 is considered effective for the following reasons: (1) it is non-toxic when fully cured, thus it can be used safely as a subsurface containment treatment technology, (2) the subsurface barrier made from this grout (5610) is very durable and resistant to wet and dry cycles (refer to Table B2), (3) grout can be used in soils down to silt size due to its low viscosity, (4) viscosity of the grout can be varied by changing volume ratio of water $(5: 1$ to $15: 1)$ to suit project needs, (5) it is very resistant to attack of acids, bases, organic solvents, salts, and gases, which are found in typical industrial wastes.

\section{B. 2. Duroseal ${ }^{\mathrm{TM}} \mathrm{Gel}$}

\section{B. 2.1 Manufacturer}

BBZ AG/BBZ GmbH for: ABSOLUTE WATERPROOFING SYSTEMS INC., (AWS) 200 railroad Avenue

Greenwich, CT 06830

\section{B. 2.2 Product description}

It is a low viscosity Vinyl monomer liquid that forms insoluble, high strength, non-foaming, nontoxic gel upon the introduction of a catalyst. After curing, Duroseal Gel reacts with water in a controlled manner to provide and maintain a barrier against water intrusion and hydrostatic pressure, thus it can effectively prevent any further spreading of a contaminant plume in groundwater. Due to its extremely low viscosity (nearly equal to water), Duroseal Gel is wellsuited for penetrating the dense soil strata. For soil stabilization and grouting barriers, standard soil and rock injection practices are well suited for use with Duroseal Gel.

\section{B. 2.3. Technical Data}

Technical data is presented in Tables B4, B5 and B6.

\section{B 2.4. Mixing Procedure}

In order to achieve 70 minute gel time, following procedure is recommended by the manufacturers: 
Step 1. Mix a 100 grams bag of catalyst powder in 900 grams of clean water. This is called $10 \%$ catalyst solution.

Step 2. Mix half of the $10 \%$ catalyst solution in one 10 liter bottle of liquid Duroseal Gel.

Gel time can be reduced by the use of gel-time acceleration catalyst. The gel-time can be reduced to few seconds. However, in case of a subsurface barrier higher gel timings are beneficial since it allows grout to penetrate into the soil matrix. Gel times of a Duroseal Gel mixed with different concentration of catalyst solution is presented in Figure A1.

\section{B.2.5 Advantages}

Duroseal Gel is a low viscosity liquid that form insoluble, high strength, non-foaming. Non-toxic gel. Duroseal Gel reacts with water in a controlled manner to provide a barrier against water intrusion and hydrostatic pressure, thus it can effectively prevent spreading of contaminant plumes in groundwater.

Table B1. Typical Physical Properties of Uncured Materials of Chemical Grout 5610

\begin{tabular}{|c|c|c|}
\hline Properties & $\begin{array}{c}\text { Measuring Standards and } \\
\text { Conditions }\end{array}$ & Results \\
\hline Appearance & Visual & Blue Green \\
\hline Solids Content by Weight & ASTM D 1010 & $77-83 \%$ \\
\hline Viscosity & ASTM D 1638 @ 70F & $600-1200 \mathrm{cps}$ \\
\hline Weight Per Gallon & ASTM D 1638 +/-0.11bs/gal. & 8.5 lbs /gal. \\
\hline Flash Point & ASTM D 93 & $16^{\circ} \mathrm{F}$ \\
\hline Corosiveness & & Non-corrosive \\
\hline Shipping Classification & & $\begin{array}{c}\text { Flammable Liquids, NOS } \\
\text { (contains acetone) UN 1993 }\end{array}$ \\
\hline
\end{tabular}


Table B2. Typical Performance Properties of Cured Materials From Chemical Grout 5610

\begin{tabular}{|c|c|c|c|}
\hline Properties & $\begin{array}{l}\text { Measuring Standards } \\
\text { and Conditions }\end{array}$ & $\begin{array}{c}\text { Formulation } A^{i} \\
\text { Results }\end{array}$ & $\begin{array}{c}\text { Formulation B } \\
\text { Results }\end{array}$ \\
\hline $\begin{array}{l}\text { formulation } \\
\text { Composition }\end{array}$ & & $\begin{array}{l}40 \text { gal. water } \\
10 \text { gal. } 56121 \\
50 \text { lbs Filler } 2\end{array}$ & $\begin{array}{c}45 \text { gal. Water } \\
5 \text { gal. } 5612 \\
50 \mathrm{lbs} \text { Filler }\end{array}$ \\
\hline Specific Gravity & & 1.03 & 1.03 \\
\hline Viscosity & $\begin{array}{c}\text { Brookfield RVT } \\
\text { Spindle \#1@100 rpm }\end{array}$ & $60+/-5 \mathrm{cps}$ & $55+/-5 \mathrm{cps}$ \\
\hline Color & Visual & Milky Tan Dispersion & Milky Tan Dispersion \\
\hline $\mathrm{pH}$ & & $6.5-7.5$ & $6.8-7.5$ \\
\hline Tensile Strength & $\begin{array}{l}\text { ASTM D } 1564 \\
2 \mathrm{inch} / \mathrm{min}\end{array}$ & $25-45 \mathrm{psi}$ & $20-30 \mathrm{psi}$ \\
\hline Elongation & ASTM D 1564 & $200-300 \%$ & $150-250 \%$ \\
\hline Shrinkage & 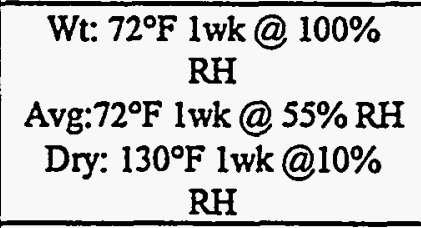 & $\begin{array}{c}0 \% \\
5 \% \\
15 \%\end{array}$ & $\begin{array}{c}0 \% \\
8 \% \\
25 \%\end{array}$ \\
\hline Compression Strength & $\begin{array}{l}\text { Wet (same as Above) } \\
\text { Avg.(Same as Above) } \\
\text { Dry (same as Above) }\end{array}$ & $\begin{array}{c}50-60 \mathrm{psi} \\
60-70 \mathrm{psi} \\
155-165 \mathrm{psi}\end{array}$ & $\begin{array}{l}40-50 \mathrm{psi} \\
45-55 \mathrm{psi} \\
80-90 \mathrm{psi}\end{array}$ \\
\hline $\begin{array}{l}\text { Recovery to Original } \\
\text { Volume }\end{array}$ & $\begin{array}{l}1 \text { wk } 100 \% \mathrm{RH} \\
2 \text { wk } 100 \% \mathrm{RH}\end{array}$ & $\begin{array}{c}98 \% \\
100 \% \\
\end{array}$ & $\begin{array}{l}100 \% \\
100 \% \\
\end{array}$ \\
\hline Toxicity & & $\begin{array}{l}\text { Non-Toxic in cured } \\
\text { form }\end{array}$ & $\begin{array}{l}\text { Non-Toxic in cured } \\
\text { form }\end{array}$ \\
\hline
\end{tabular}


Table B3. Chemical Resistance Data of Chemical Gout 5610

\begin{tabular}{|c|c|c|}
\hline Concentration in Water & Weeks & Results \\
\hline Acids & 26 & Slight Shrinkage \\
\hline Hydrochloric (2\%) & 26 & No Change \\
\hline Acetic (2\%) & 26 & No Change \\
\hline Sulfuric (2\%) & & Swells \\
\hline Bases & 26 & Swells \\
\hline Sodium Hydroxide (1\%) & 26 & Moderate Shrinkage \\
\hline Potassium Hydroxide(1\%) & & Slight Shrinkage \\
\hline Salts & 26 & Slight Shrinkage \\
\hline Sodium Chloride & 26 & \\
\hline Amonium Sulfate & 26 & Slight Shrinkage \\
\hline Potassium Chlorate & & Slight Swelling \\
\hline Organic Solvents & 26 & No Change \\
\hline Ethylene Glycol (100\%) & 26 & No Change \\
\hline Isoproponol (100\%) & 26 & \\
\hline Heptane (gasoline) & 26 & No Change \\
\hline Carbon Tetrachloride (100\%) & 26 & . \\
\hline Methyl Ethyl Keytone (100\%) & 26 & No Change \\
\hline Toluene (100\%) & & \\
\hline Gas & 9 & \\
\hline Hrdrogen Sulfide & & \\
\hline
\end{tabular}

Table B4. Typical Physical Properties of Uncured Material of Duroseal TM Gel

\begin{tabular}{|c|c|c|}
\hline Properties & $\begin{array}{c}\text { Measuring Standards and } \\
\text { Conditions }\end{array}$ & Results \\
\hline Residue by Evaporation & ASTM D 2939-78 & $41-47 \%$ \\
\hline Water Content & ASTM D 244-88 & $54-60 \%$ \\
\hline Viscosity & ASTM D 1638 @70 $70^{\circ} \mathrm{F}$ & $50-100 \mathrm{cps}$ \\
\hline Weight Per Gallon & ASTM D 2939-78 & $8-10 \mathrm{lbs} / \mathrm{gal}$. \\
\hline pH & & $7-8$ \\
\hline Flash Point & ASTM D 93-85 & Not Applicable \\
\hline Color & Visual & Purple Transparent Liquid \\
\hline Toxicity & & Non-Toxic \\
\hline Corrosiveness & & Non-Corossive \\
\hline Hazard Class & & $\begin{array}{c}\text { Not Considered Hazardous } \\
\text { Material }\end{array}$ \\
\hline
\end{tabular}


Table B5. Typical Performance Properties of Cured Materials from Duroseal TM Gel

\begin{tabular}{|c|c|c|}
\hline Density & ASTM D 3800-79 & $1.1-1.2 \mathrm{~g} / \mathrm{ml}\left(68^{\circ} \mathrm{F}\right)$ \\
\hline Toxicity & & Non-Toxic \\
\hline
\end{tabular}

Table B6. Chemical Resistance Data of Duroseal ${ }^{\mathrm{TM}}$ Gel

\begin{tabular}{|c|c|c|}
\hline Concentration in Water & Weeks & Results \\
\hline Acids & & \\
\hline Hydrochloric (2\%) & 3 & $20 \%$ Swelling \\
\hline Acetic (2\%) & 3 & $10 \%$ Swelling \\
\hline Sulfuric (2\%) & 3 & $10 \%$ Swelling \\
\hline Bases & 3 & Strong Swelling \\
\hline Sodium Hydroxide (1\%) & 3 & Strong Swelling \\
\hline Potassium Hydroxide(1\%) & & Swelling \\
\hline Salts & 3 & Swelling \\
\hline Sodium Chloride(salt water) & 3 & \\
\hline Amonium Sulfate & 3 & $30 \%$ Fragmentation \\
\hline Potassium Chlorate & & No Change \\
\hline Organic Solvents & 3 & Color Change \\
\hline Ethylene Glycol (100\%) & 3 & No Change \\
\hline Isoproponol (100\%) & & No Change \\
\hline Heptane (gasoline) & 3 & No Change \\
\hline Methanol (100\%) & 3 & No Change \\
\hline Diesel Fuel (100\%) & 3 & No Change \\
\hline $1,1,1-$ Trichlorethane (100\%) & & No Change \\
\hline Methyl Isobutyl Keytone & & Swelling \\
\hline (100\%) & 3 & \\
\hline Toluene (100\%) & 3 & $30 \%$ Fragmentation \\
\hline Xylene & 3 & \\
\hline Formaldehyde (40\%) & & \\
\hline
\end{tabular}




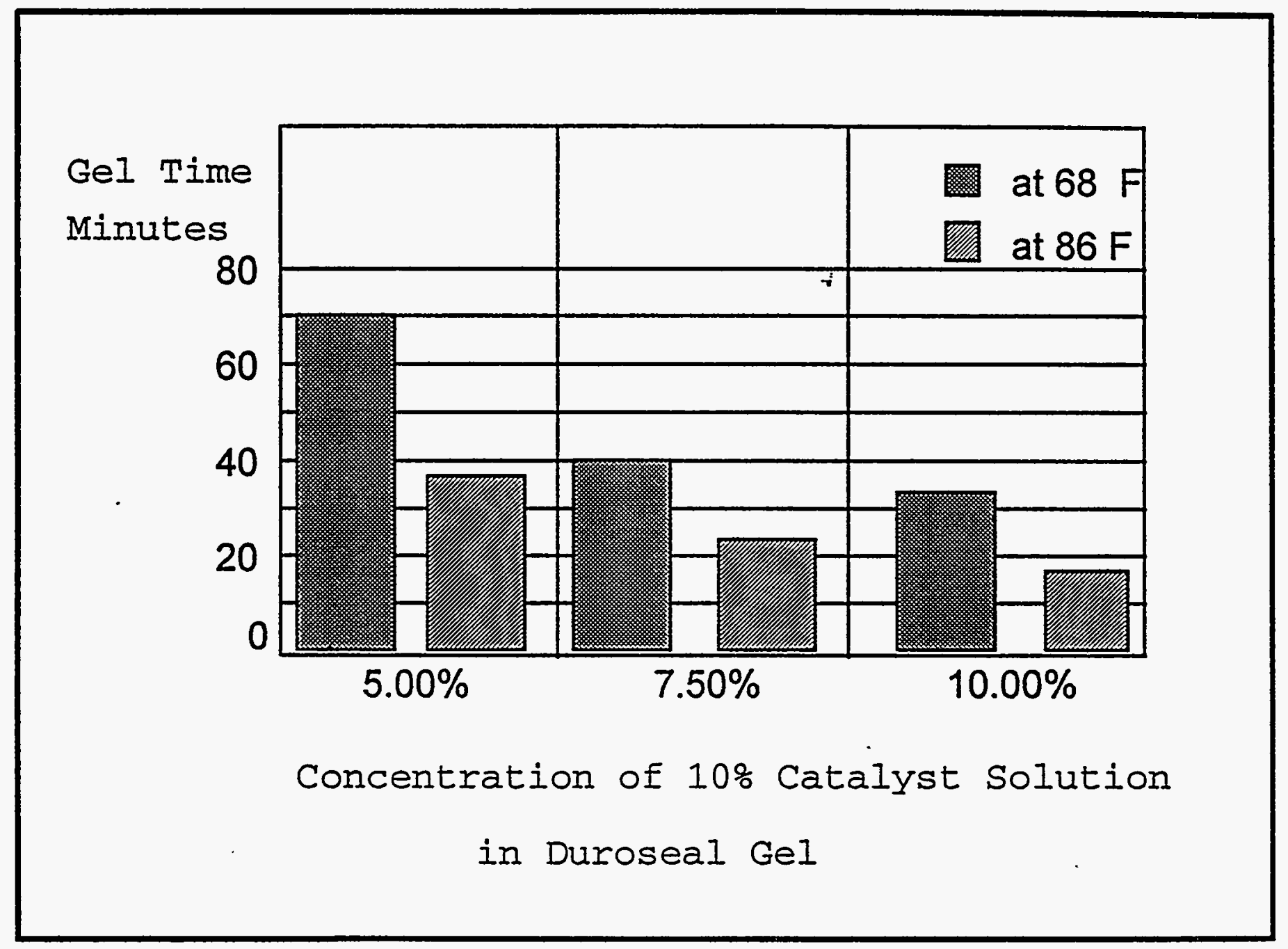

Figure B1. Gel Times of Duroseal Gel Mixed with a $10 \%$ Catalyst Solution 


\section{APPENDIX B-2}

Example Input Files for BGROUT Simulator

EXAMPLE INPUT FLLES (C:LGROUTNO5200053.SLM)

[05200053.SIM] 5 ep initial vis. $k=2000 \mathrm{md}$ Piaj $=53.0$ psia

ID2: setting times $=215$ \& $290 \mathrm{~min}$

ID3: TMAX $-300 \mathrm{~min}=0.2083333$ days

ID4:

IDS:

RESTART AND POST-PLOT CODES

10

GRID DATA

20201

GRID BLOCK LENGTHS

0000

$0.221519 * 0.5$ GRID DIMENSIONS

$0.221519 \cdot 0.5$

4.0

$4.0<1^{\prime} \times 4$ sinco now 2 quadram (injecting @ $1,1,1$ )

Grid block lengyh modifications

$0 \begin{array}{lllll}0 & 0 & 0 & 0 & \text { NUMDX NUMDY NUMDZ NUMDZN IDCODE }\end{array}$

Depth to top of upper sand zone

0.0 [KEL-Elevation code \& Dip angle (alpha)]

100

Porosity and permeability distributions

$\begin{array}{llllllll}0 & 0 & 0 & 0 & \text { [KPH KKX KKY KKZ] }\end{array}$

0.300 Phi $\quad$ POROSITY

$2000 \mathrm{Kx}$

$2000 \quad \mathrm{Ky}$

$667 \quad \mathrm{~K} 2$

NUMP NUMKX NUMKY NUMKZ KPHIMP KXMP KYMP KZMP

PERMEABILITY

$\begin{array}{lccccccc}1 & 0 & 0 & 0 & 1 & 1 & 1 & 0\end{array}$

TRANSMISSIBILITY MODIFICATIONS

0000

NROCK NPVT

1 < Changed NROCK to 2; added NUMROCK=3 \& TABLE 2 (09/14/93)

SAT KROW KRW KRG KROG PCOW PCGO < Begin TABLE\#I

$0.00 .00 .0 .0000 \quad 00.0000$

$\begin{array}{lllllllll}0.10 & 0.1111 & 0.000 & 0.1111 & 0 & 0 & 00.00\end{array}$

$0.90 \quad 1.0000 .88891 .0000000 .00$

1.01 .0001 .0001 .0000000 .00

ITHREE SWR

0.10

PBO PBODAT PBGRAD SWCRTT VWMULT VWMAX(cp) SETI(min) SET2(min) VIS va TIME

$\begin{array}{llllll}14.0 & 0.0 & 0.0 & 0.2 & 2.0 & \text { S00. 215. } 290 .\end{array}$

VSLOPE BSLOPE RSLOPE PMAX REPRS

PARAMETERS

$.0000-3.0 \mathrm{E}-06$ 0. 200

P MUO BO RSO

$0.001 .01 .000 \quad 0.0$

$200.0 \quad 1.0 \quad 0.999440 .0$

P MUW BW !!!!!!!!!NOW INJECTTNG WATER AS MICROFINE CEMENT (i.e. GROUT)

$0.005 .01 .0 \quad$ !!!!!!!!!06/1/94

$200.05 .0 \quad 0.99944$

GAS AND ROCK PROP

GROUT VISCOSITY, cP

0 < Gas Properties Option (if "1", use PSEUDO to cale gas properties)

P MUG BG PSI CR

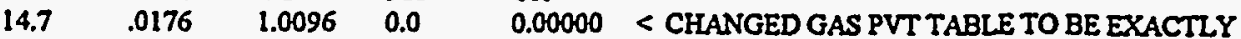

$\begin{array}{lllll}20.0 & .0176 & 0.7402 & 0.0 & 0 .\end{array}$

$\begin{array}{lllll}30.0 & .0176 & 0.4914 & 0.0 & 0 .\end{array}$

$\begin{array}{lllll}40.0 & .0176 & 0.3670 & 0.0 & 0 .\end{array}$

$\begin{array}{lllll}50.0 & .0176 & 0.2924 & 0.0 & 0 .\end{array}$

$\begin{array}{lllll}60.0 & .0176 & 0.2426 & 0.0 & 0 .\end{array}$

$\begin{array}{lllll}70.0 & .0176 & 0.2071 & 0.0 & 0 .\end{array}$

$\begin{array}{lllll}80.0 & .0176 & 0.1804 & 0.0 & 0 .\end{array}$

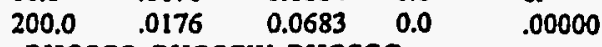

RHOSCO RHOSCW RHOSCG 
$62.462 .4 .0764<$ Injected "oil" is GROUT - correct density latter!!

Initialization Option Codes

220.00 .0 [KPL.KSI PDATUM GRAD]

NR Pwoc WOC Pgoc GOC Soi Swi Sgi [nitialization by Rock Region]

170.0 $<$ Not used since KPI=KSI=2

Initialization by Layer (NZ Records)

1 14.700 0.0 .10 0.90 [Pi Soi Swi Sgi]

KSNI KSMI KCOI KCOF KSCRN KOUT

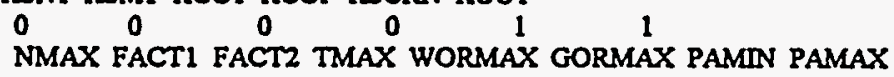

INITIAL PRESSURE (Pi)

NMAX FACT1 FACT2 TMAX WORMAX GORMAX
$99991.25 \quad 0.25 .2083333$ 20. 1.E12 .100010000.

KSOL MTR OMEGA TOL TOLI DSMAX DPMAX

22501.2 .0010 .00 .0 .050 200. < chid DSWMAX:.050 >.100 06/24/94

NUMDIS IRK THRUIN

00.5

AQUIFER DATA

0

WELL and NODE DATA

No. of Welis

Well Nodes WellName

$1171^{\circ}$

Well Node(L,J,K) DIR

11111

RECURRENT DATA

C DATA SET 1-201\& INITIAL. WATER SATURATION (Swi)

MAX STIMULATION TIME

011 [ICHANG IOMETH IWLCNG > NOTE: ICHANG not USed ifIOMETH>0]

0.000694444

201000

$\begin{array}{lllllll}1 & 0 & 0 & 1 & 0 \\ 0 & 1 & 0 & 0 & 0 & 0 & 0\end{array}$

$\begin{array}{lllllllll}0 & 1 & 0 & 0 & 0 & 0 & 0 & \text { [KROmap KRWmap KRGmap IRSOMP PCOWmap PCGOmap KPHImap] }\end{array}$ .00005 .00005 .00005 [DT,DTMLN,DTMAX] !!End of data read in main!!

INJ/PROD WELLS [Begin data read by NODES - if IWLCNG $=1$ ]

10 [NWELLN=No. of new wells, NWELLO=No. of old wells]

INJO1 1 l 1 I 1 l 1 [FORMATTED: AS,S13 - WELLID, IDWELL, I, J, PERFI, NLAYER]

1000. PID

00. PWF

INJO1 $12-000.0-100.00$ 0. 0. [AS,2L3,4F10.0 - WELLID IDWELL KIP QO QW QG QT]

091 [ICHANG IOMETH IWLCNG > NOTE: ICHANG not used if IOMETH>0]

0.00347222 .00694444 .0138888 .0208333 .0416666 .0833333 .125 .166666 .2083333

$2010000 \quad$ [IPMAP,ISOMAP,ISWMAP,ISGMAP,IPBMAP,IAQMAP]

$\begin{array}{lllllll}0 & 0 & 0 & 1\end{array}$ [KXMP,KYMP,KZMP,MUWMP]

$\begin{array}{lllllllll}0 & 1 & 0 & 0 & 0 & 0 & 0 & \text { [KROmap KRWmap KRGmap IRSOMP PCOWmap PCGOmap KPHImap] }\end{array}$

.00010 .00001 .000347222 [DT,DTMIN,DTMAX] !!End of data read in main!!

INJ/PROD WELLS [Begin data read by NODES - if IWLCNG $=1$ ]

10 [NWELLN=No. of new wells, NWELLO=No. of old wells]

INEW WELLS $=$ N=m.

INJO1 11111111 [FORMATTED: AS,S13 - WELLID, IDWELL, I, J, PERFI, NLAYER]

SOO. PID

53. PWF

INJOI $1-12-000.0-0000$ 0. 0. [AS,213,4F10.0 - WELLID IDWELL KIP QO QW QG QT]

INJECTION RATE, STENAY

WELL INFORMATION

$+$

INJECTION RATE, STBDAY

\section{APPENDIX C - SELECTED LITERATURE FOR REFERENCES}

The following reports are included in this report because they were key references used in the literature review. The reports are compiled here in the order in which they were referenced.

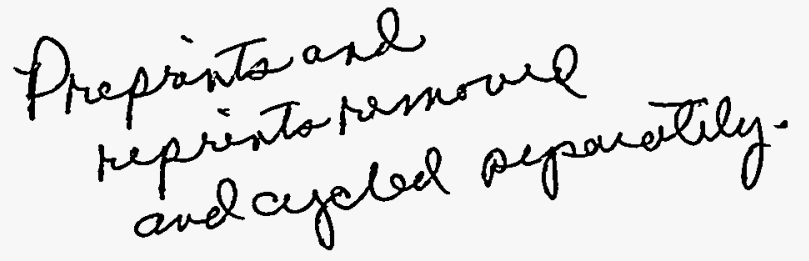




\section{LIST OF ATTACHMENTS}

ATTACHMENT 1 SCOPE STATEMENT SHEET

ATTACHMENT 2 ACTION PLAN

ATTACHMENT 3 KEH ENGINEERING AND ESTIMATE DETAILS

ATTACHMENT 4 ALTERNATIVE AND CRITERIA MATRIXES

ATTACHMENT 5 ASSUMPTIONS AND

UNKNOWNS/UNCERTAINTIES

ATTACHMENT 6 REQUIREMENTS

ATTACHMENT $7 \cdot$ INTERFERENCES

ATTACHMENT 8 FAST DIAGRAM

ATTACHMENT 9 TUCSON WORKSHOP - SAS NOTES

ATTACHMENT $10 \quad K \& M: 1: B D M$ ENGINEERING STUDY - SAS NOTES

ATTACHMENT 11 SUPPIEMENTAL INFORMATION

ATTACHMENT 12 AGE:IDA, GUIDELINES, AND EXPECTATIONS

ATTACHMENT 13 DRY Y IVELL RADIATION LEVELS FOR TANKS 103-C, 105-C, AND 106-C 
ATTACHMENT 1

SCOPE STATEMENT SHEET 
Print Date: January 10, 1993

PROJECT SCOPE STATEMENT SHEET

Project Title:SUBSURFACE BARRIER STUDY FOR TANK C-106 AND C TANK FARM No. 001 Location of SAS Session: Kaiser Commerical Office, 292 Torbett Dates: $12 / 15-17 / 92$ Team Briefing Meeting: N/A Date:

TEAM MEMBERS

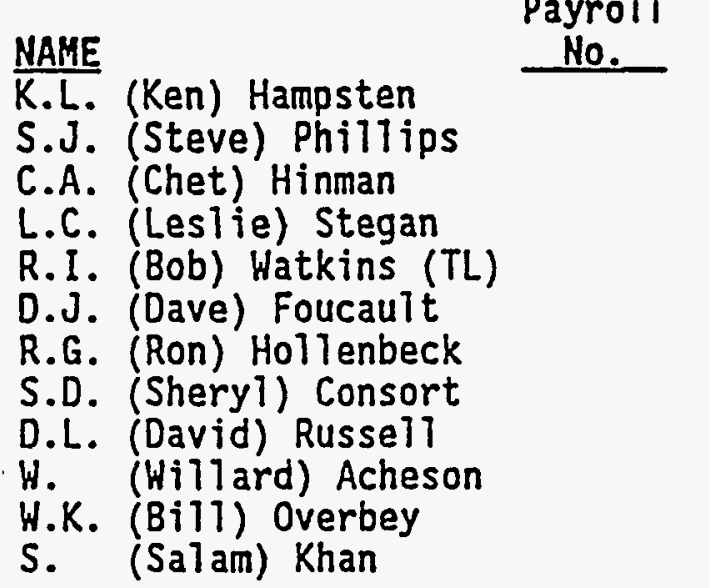

NAME

S.J. (Steve) Phillips

C.A. (Chet) Hinman

L.C. (Lestie) Stegan

R.I. (Bob) Watkins (TL)

R.G. (Ron) Holl lenbeck

S.D. (Sheryl) Consort

D.L. (David) Russell

W.K. (Biil) Overbey

S. (Salam) Khan

$\begin{array}{lc}\frac{\text { PHONE }}{6-3127} & \text { MISN } \\ 6-1720 & \text { L4-71 } \\ 6-3260 & H 0-34 \\ 2-1824 & S 4-58 \\ 6-3383 & E 6-41 \\ 2-1680 & E 2-11 \\ 6-0513 & E 6-42 \\ 6-2838 & E 6-40 \\ (404) & 923-4408 \\ (304) & 598-2666\end{array}$

\section{FLOATERS}

K.L. (Kurt) Kehler

K.D. (Kevin) Elliot -

G.D. (Gerry) Bazinet

J.M. (Mark) Henderson

C.E. (Chuck) Hilson

S.S. (Steve) Lowe

B.W. (Ben) Volk

L.E. (Larry) Efferding

C. (Chris) Haecker

R.J. (Jerry) Alexander

F.R. (Fred) Reich

E.J. (Ed) Renkey

G.H. (Greg) McLell and

Team Leader (TL)

$\begin{array}{lc}6-1632 & E 6-21 \\ 2-2121 & E 2-20 \\ 6-3059 & L 4-71 \\ 2-0377 & 54-55 \\ 6-6202 & H 5-27 \\ 6-2023 & H 5-49 \\ 6-2418 & N 3-05 \\ 6-5377 & H 0-33 \\ (509) & 783-9651 \\ 2-2112 & N 4-14 \\ 5-4063 & L 5-63 \\ 6-0186 & H 5-49 \\ 6-2260 & N 3-05\end{array}$

Project Management

Estimating

Retrieval Engineering

Program Management

Projects

Central Engineering

Horizontal Drilling

EA/CE

Systems Engineering

Tech. and Development

Tank Closure Plan

Central Engineering

RR/Env.

CO.
WHC
WHC
WHC
WHC
XEH
KEH
KEH
XEH
X\&M
K\&M
BDH
K\&M

KEH

KEH

WHC

WHC

WHC

WHC

WHC

WHC

LATA

WHC

WHC

WHC

WHC

\section{FACILITATOR}

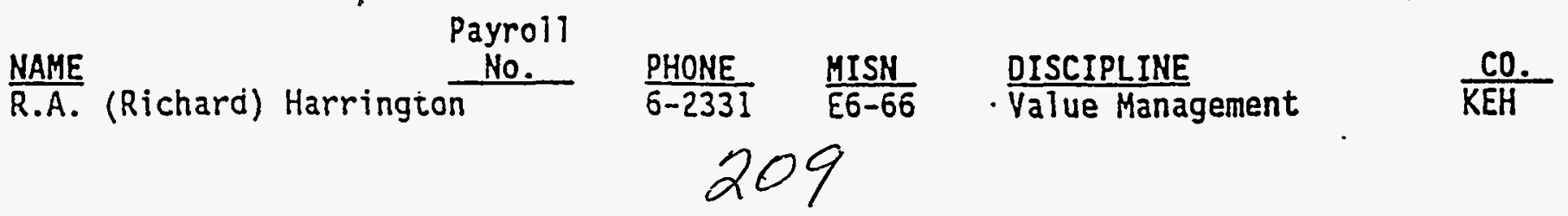




\section{ATTACHMENT 2}

\section{ACTION PLAN -}

1

210 


\section{SCOPE}

- Subsurface Barrier Technologies

- Interim Subsurface Barrier Technologies Horkshop Report

- BDM/K\&M Study Report on Subsurface Barriers

- Direction/request from HDOE

\section{OBJECTIVES}

- Review and identify barrier concepts in the Workshop and BDM/K\&M Study Reports.

- Understand request from WDOE

- Develop basis for further engineering study by:

- Identifying functions and requirements

- Identifying regulatory requirements

- Identifying interfaces

- Identifying issues/concerns

- Identifying assumptions amd unknowns/uncertainties

- Develop F.A.S.T. (Function Analys is System Technique) diagram

- Develop Mission Statement

- Develop evaluation/acceptance criteria and rank all options for further development.

- Select top two subsurface barrier options for further engineering study.

\section{DELIVERABLES}

- Action Plan in support of the follow-on engineering study and issuance of the SAS study report. 


\section{ATTACHMENT 3}

\section{KEH ENGINEERING AND ESTIMATE DETAILS}


ACTION PLAN

MART

who Wtiol

1. SEVO LEAKAEREROT KEN IR/21/92 TO KEA

- ck. clearaver ON MONITORING: OATA

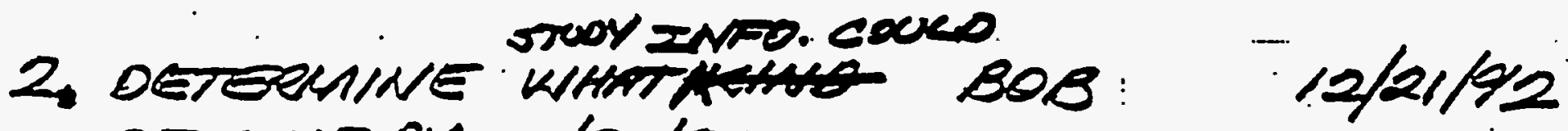
BE DONEBY 1/30/93

3. COAPLETE PURUNING SHEES, BOB $12 / 29 / 92$ STUOY ETTMATE \& S.0.W. F ZSSUE TO UUHC.

4. COUPCERE PRELM. DATA BOB ON ER STUby Rescet के ISSUE TO WHE.

5. zOSUE SRS eEPORT RICK $1 / 8 / 9$

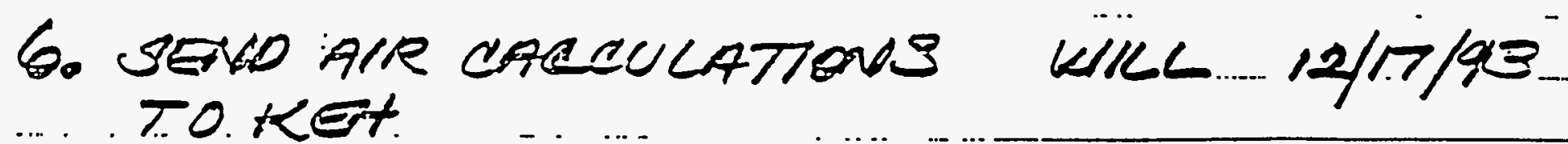

$2 / 3$ 
KEH ENG. STUDY

- INCLUDES:

= INBTHLCATTON CONCEPT (DESTRIPTION)

- stetehs for ench caviept.

- TOTAL scheodile for ench converpt

- ESTIRATE Fol onch concept

WRTTE-UPS WILC IUCLUDE; INTER FEREN EES, RISKS, UNCOETINTIES, UnVNOWNS, ZNTEO=ACES; AOVANTABSES है DBAOUMTASES, ASUUAPTIONO.

- SCOPE OF ESTINATE UILL IRLLVDE:

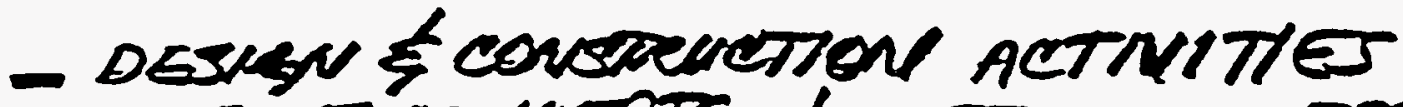

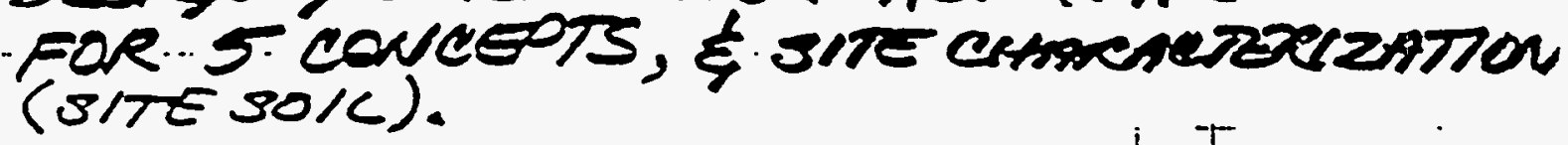

NOTE: ESTIRATTE WILC NOT FNCLUTD:

* COST FOR DENO. TEST

- " "INFRAMRULTURE

- "I" ODESATNW EDST-POST

- " " sTOENSEG\%R. INUSTJCATION

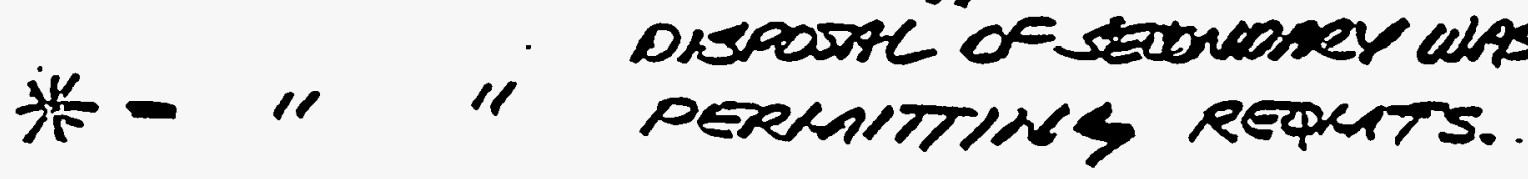

* InCCUDE... IN SCHEDULE.

214 
ESTIMATE

- BYTTANR - CAB CONE GROCTINS PIRECTIOVAL

$\because$ BY TRVK EREV - cAE s cone greortints

215 


\section{ATTACHMENT 4}

\section{ALTERNATIVE AND CRITERIA MATRIXES}




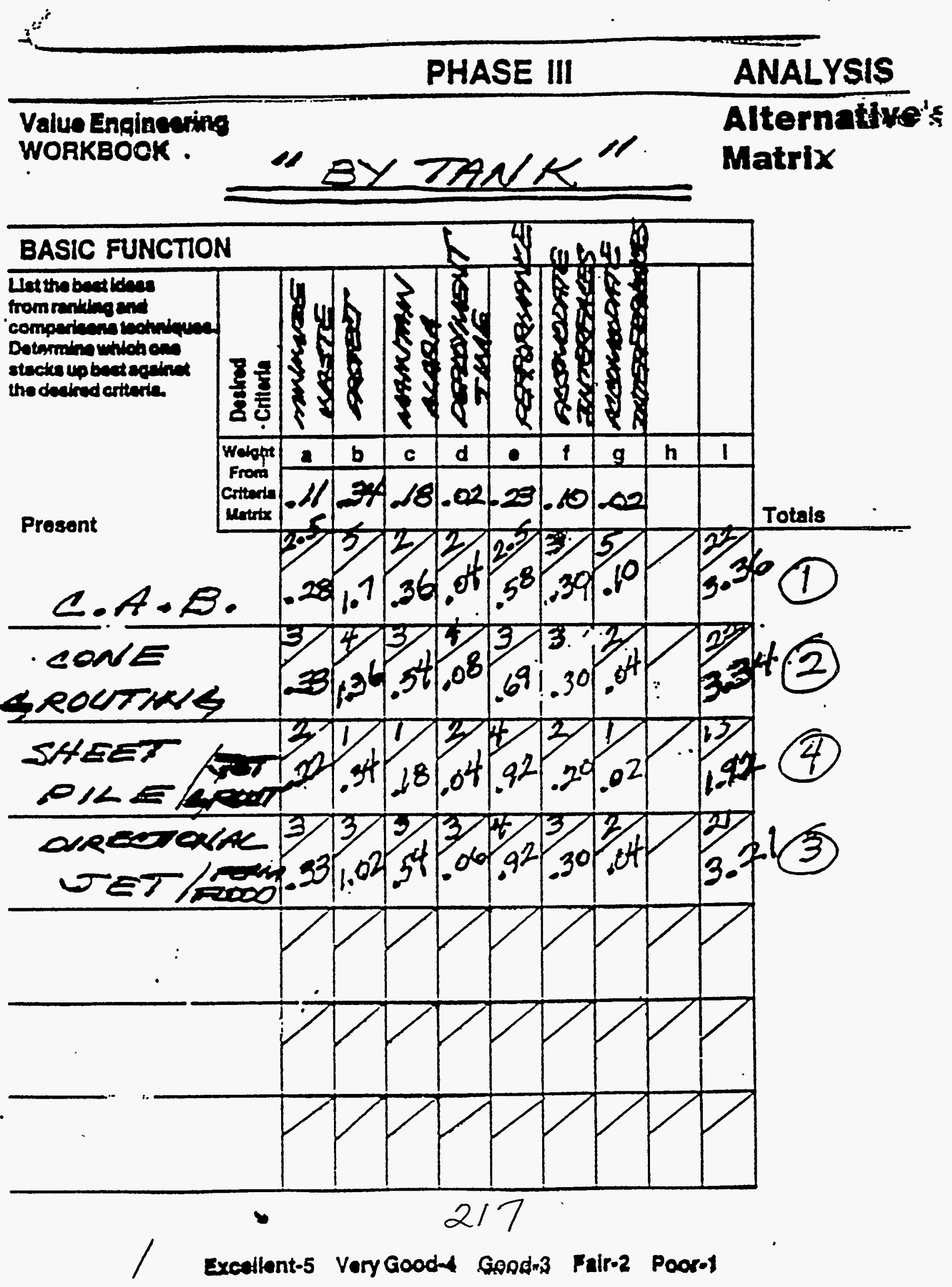


BARRIER OPTIONS

1.) C.A.B.

2.) CONE SROUTING

3.) VERT. SHT.PILING/HORT TET \&EON

4.) DIRECTIONAL JET SGROUT/PEREOD.

218 


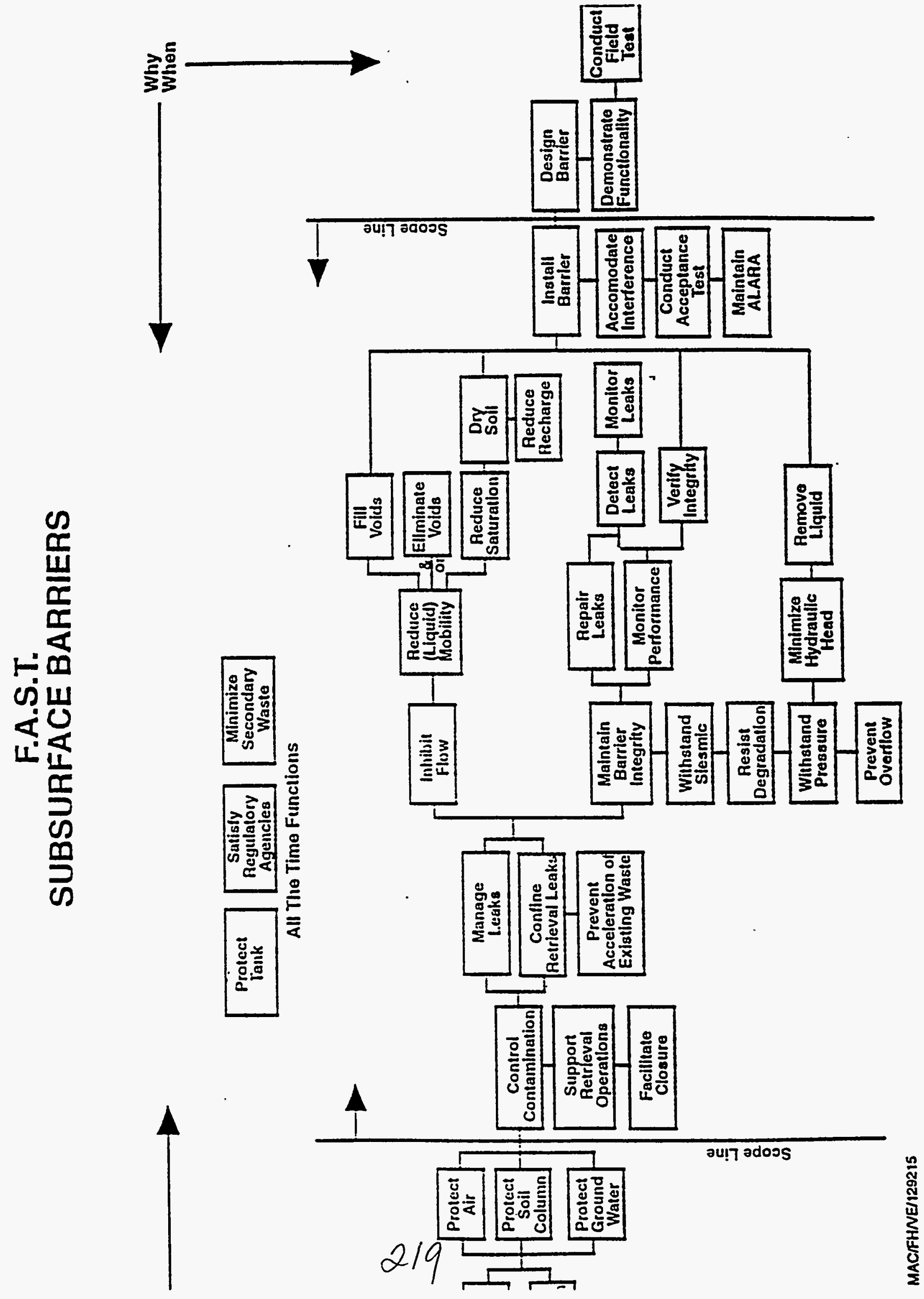


BY TANK

1.) MINIAIZE WRSTE

2.) PROTECT TRUKS

3:.) Mamantan aLARA

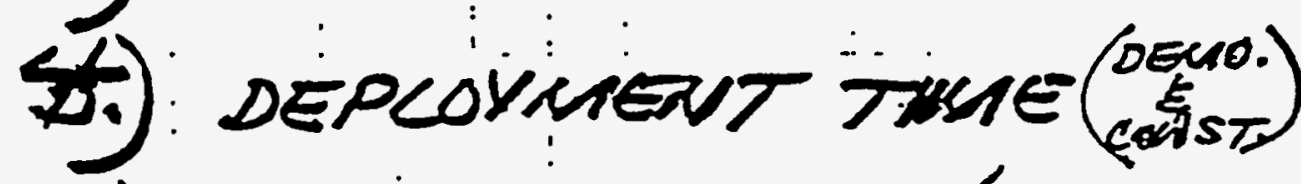

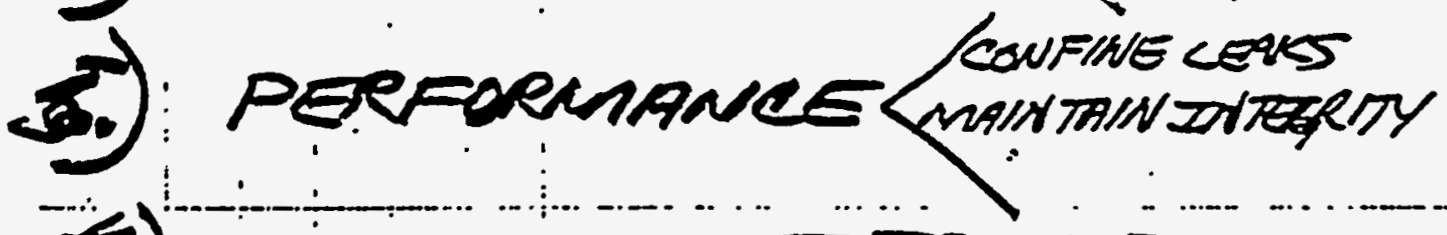

6. ACCOMBDATE zurerntices

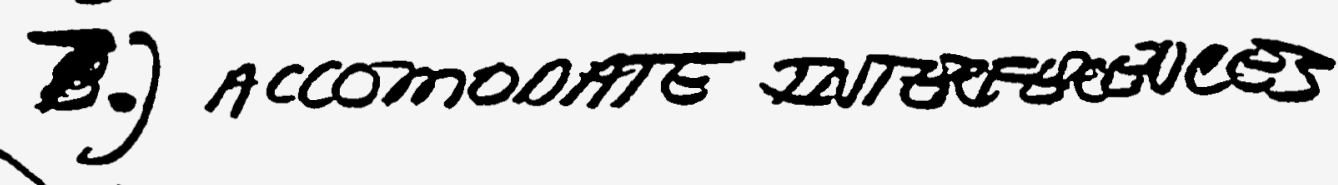

ह)

$\overline{100 \%}$

220 


\section{Value Engineering}

.. WORKEOOK

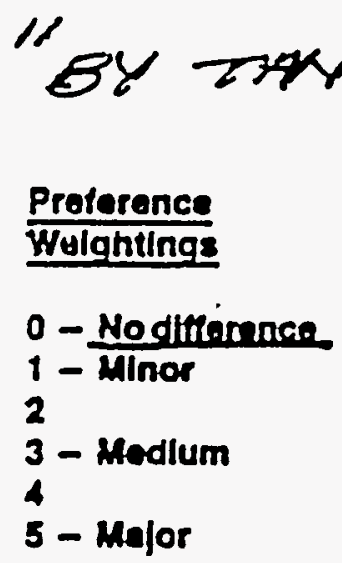

To each box under SCORE, be sure to write both the lettor representing the PROBLEM AREA and the numeral or clpher sepresenting the WEIGHTING for the cholce u foel ls most Important. is

$\log x^{3}$

15 os.

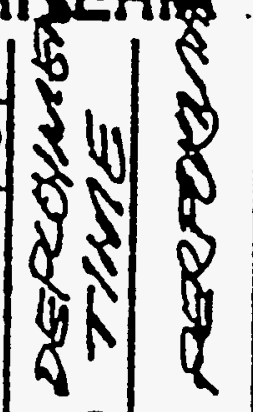

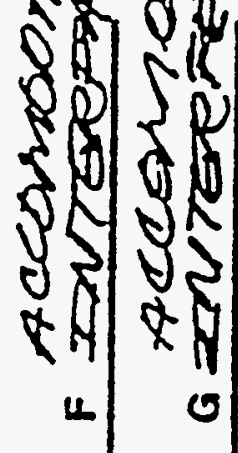

1

Criteria

Matrix
(SUM OF SCORES IN BOTH VEATICAL AND HORIZONTAL) 
ASSUANETLONS

- $\angle$ FARA WIL BE SELETED FOR

- M-O8 TPA MUILESTENE ACTONN.

- THE STATE WILL REASSESS THEIR

- POSITION S AnOD FY CCEAN C COSUR E TO

ALCOU: IS PLACE LAROBILC:

- Fank sone TrNIKS WILL LEAK DURNE SLUICING RETRIEVAL.

- closcike vice zuclude a suraice:

- enRerier

- desigr llFe 30 yones, this ls based ol TPA An-09, ¿COURE BY 2018 .

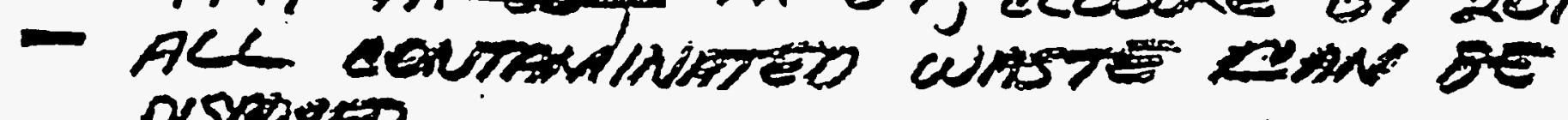

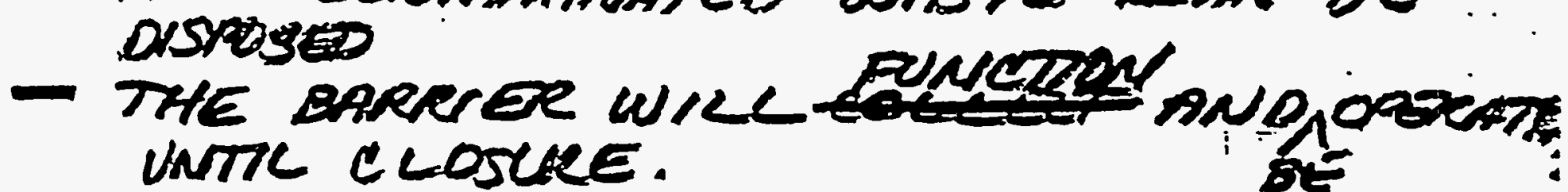

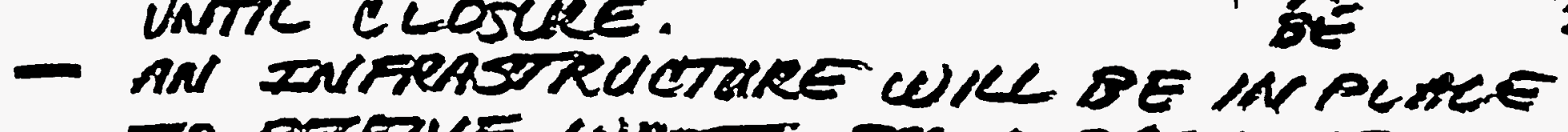

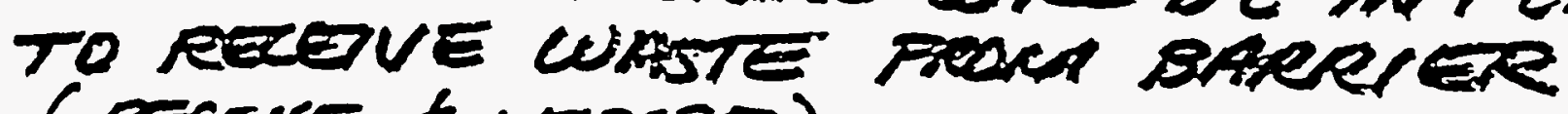
(RECENE \& DNPOSE)

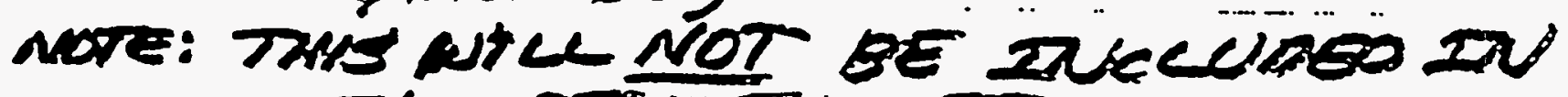
KQI COST ETHMATE.

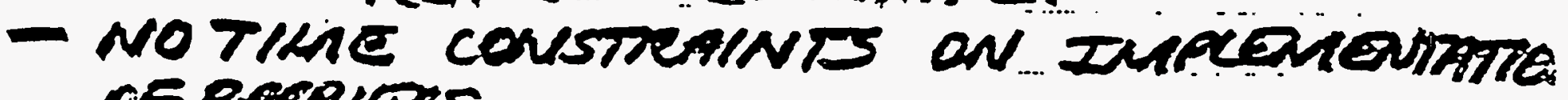
-.. OF Becteres.

222 


\section{ATTACHMENT 5}

\section{ASSUMPTIONS AND UNKNOWNS/UNCERTAINTIES}

223 


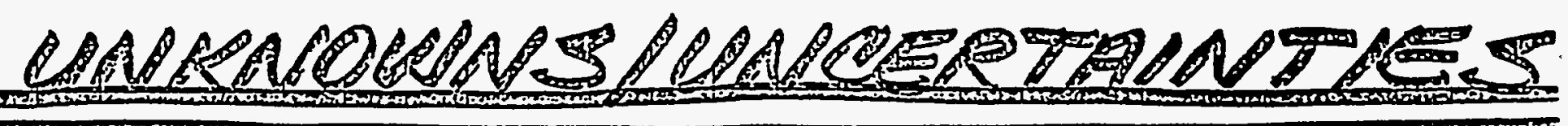

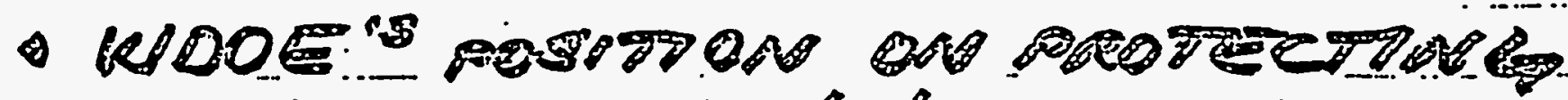

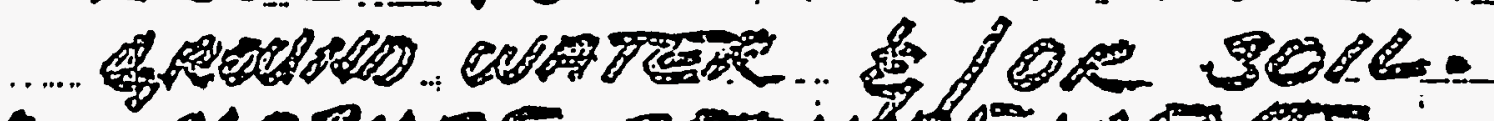

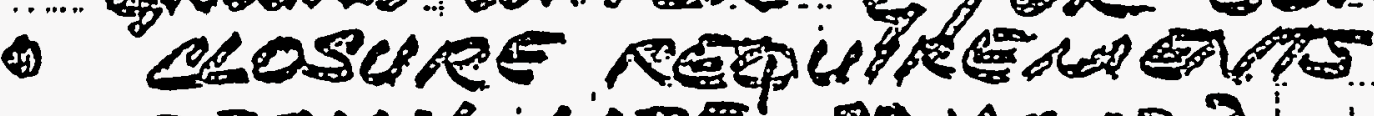

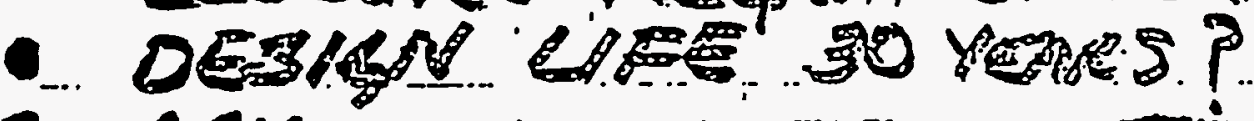

- CAN contranivinted cuasto be DNPOASE

$r T$

224 
ATTACHMENT 6

REQUIREMENTS

225 
REQUIRENENTS (RE'S')

- EXTERNGL ReGSTTS.

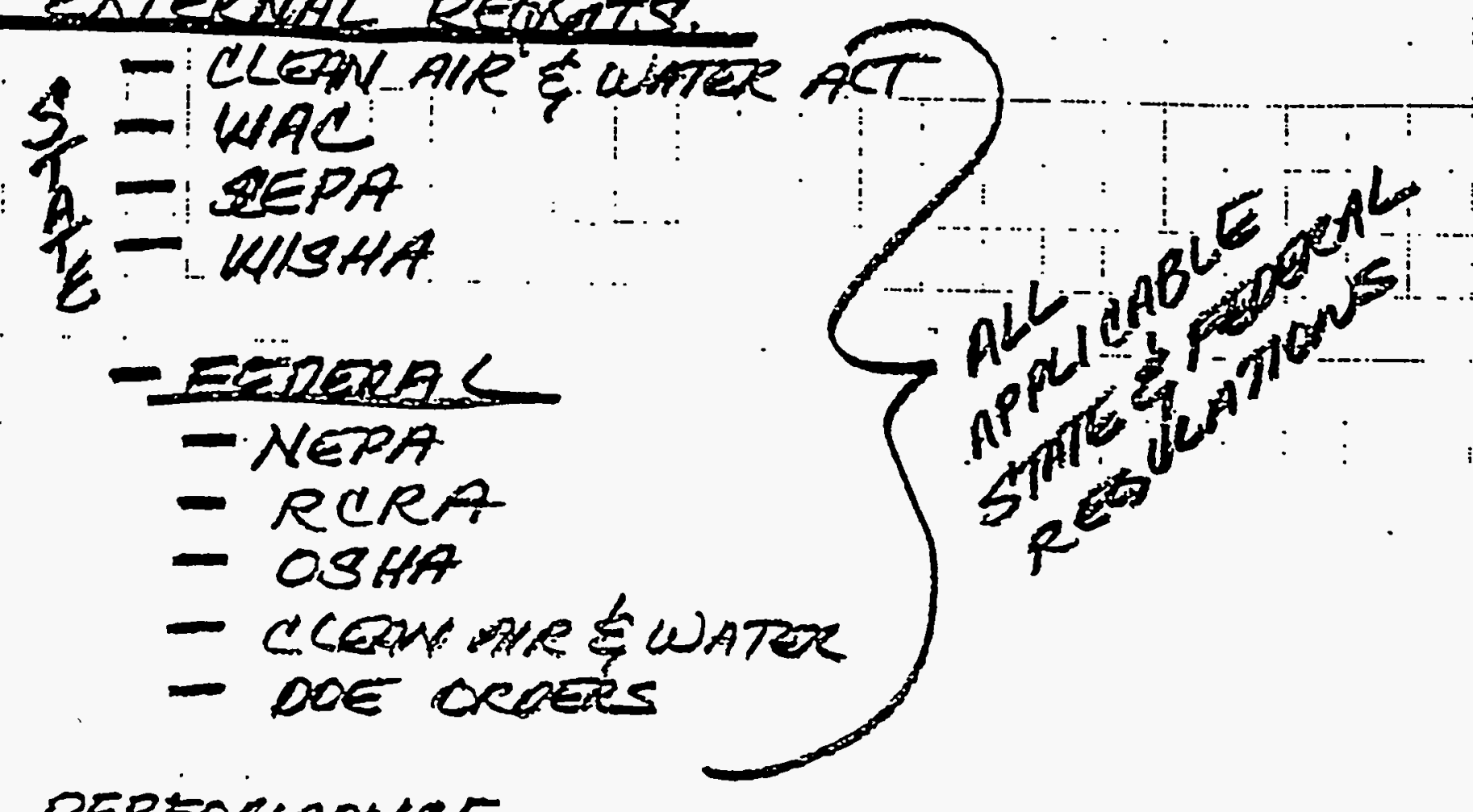

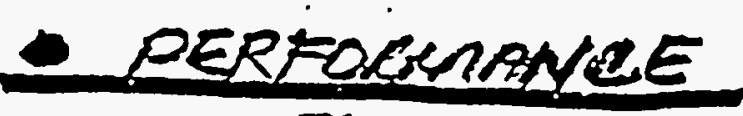

- 50,000 baLS. POL TPANK ANNUALCX-MAX.

- sLUICING SAL:S pore tank

- design cife 50 vears

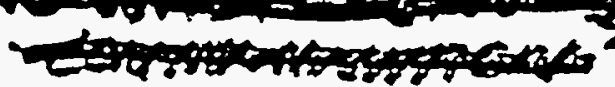

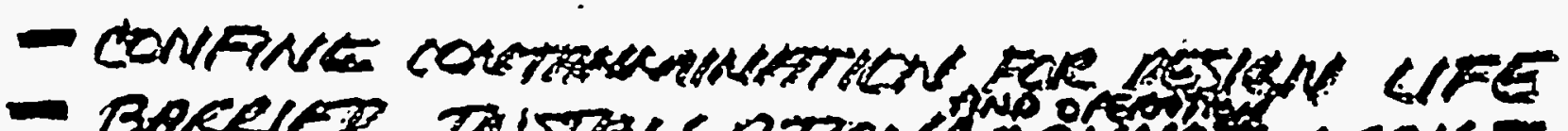

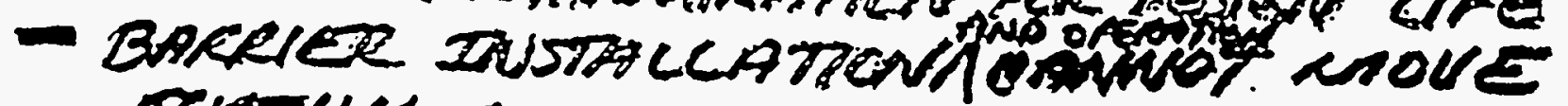

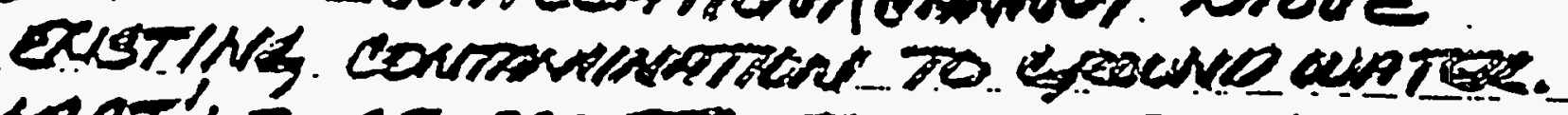

- mat'ls of construction of burcier

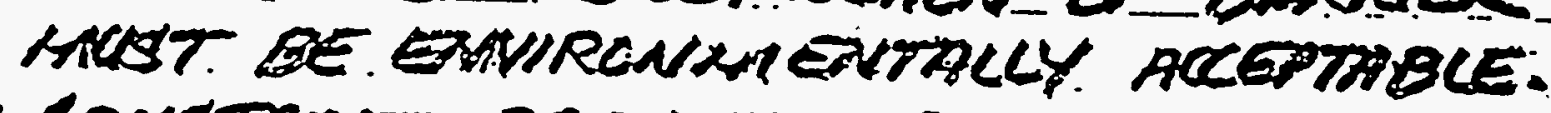

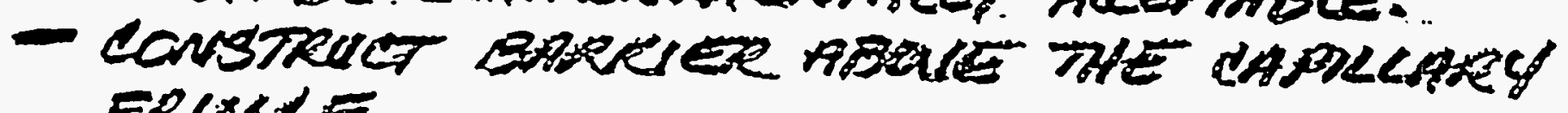
FRINGE

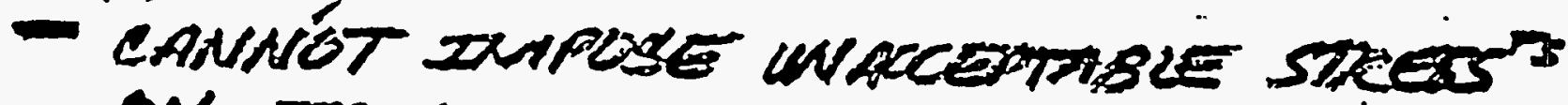

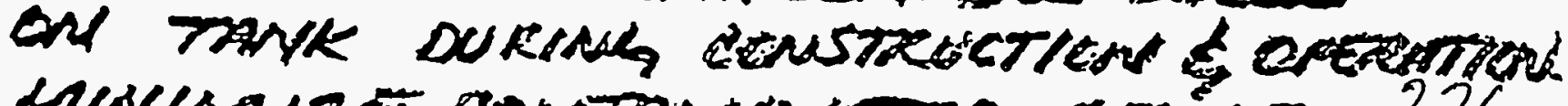

- AINIMIze contrantinitied spoills 226 
REXULEHENTS

(2)

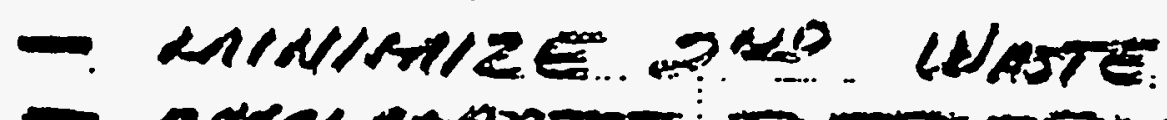

- accunobate duntererdures

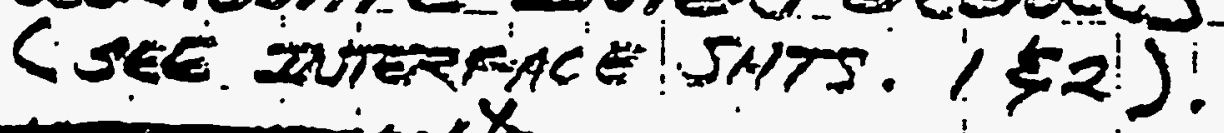

- enciltate bcosure

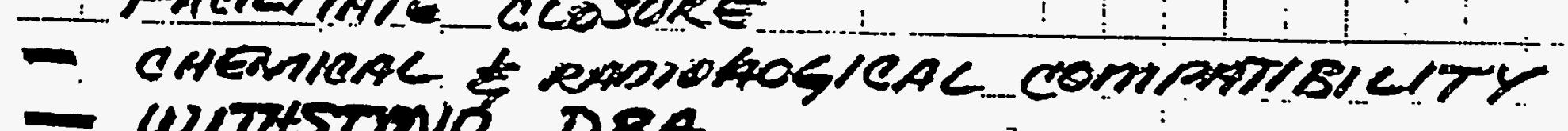

- WITHSTrwo DBA

- inzereace

- intecarce retrieviac

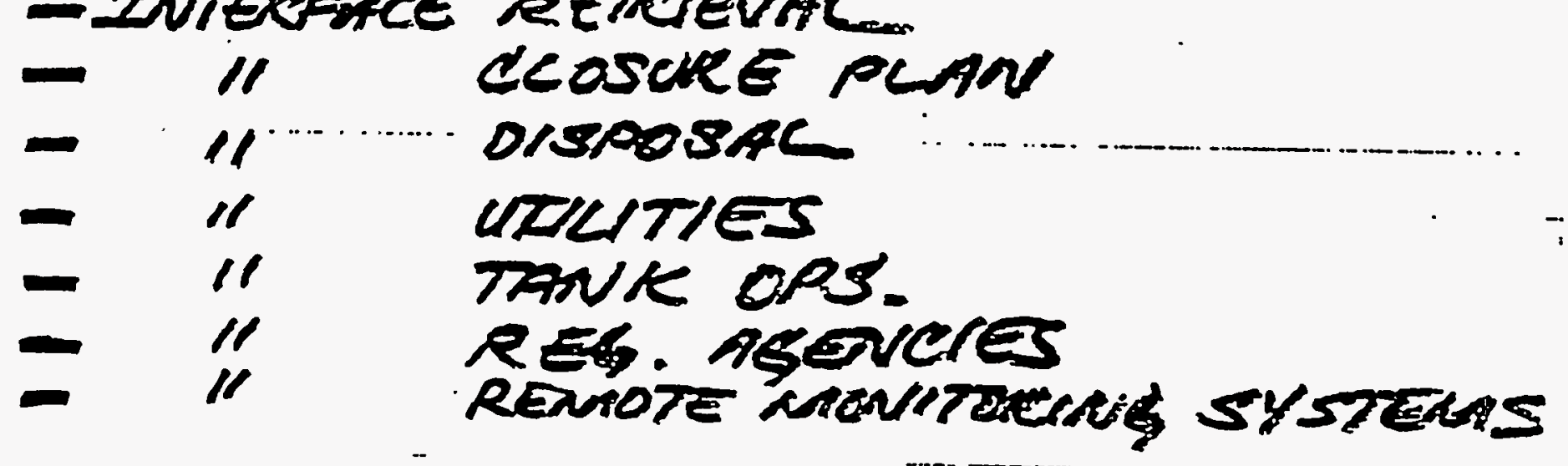

- comentrents

227 
ATTACHMENT 7

INTERFERENCES 
INTEREERENCES

- VERTCAL (NGaR maN)

- vartpal deywells

(1).

- Condrete encasenterat

- Diele Eured pafe

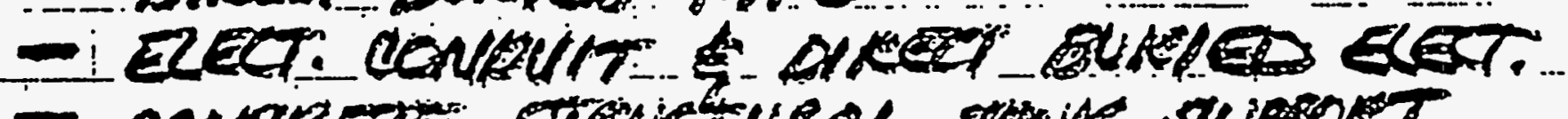

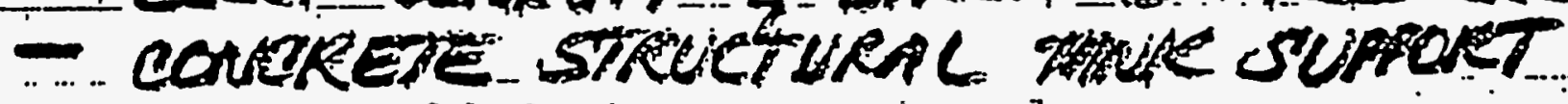

- FCOTINes

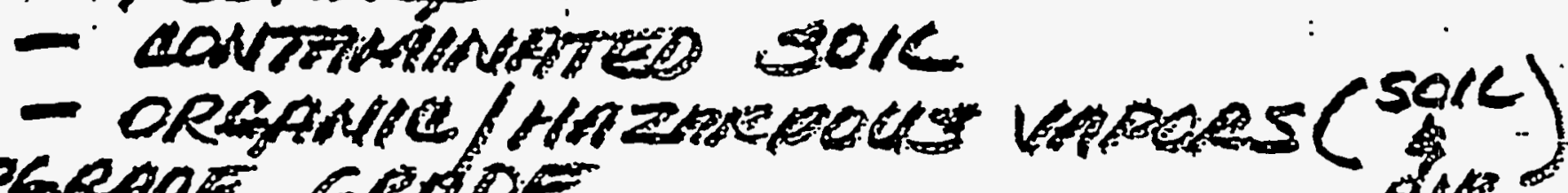

- UPGRADE GRHDE

- HVAC \& Exatpestedes

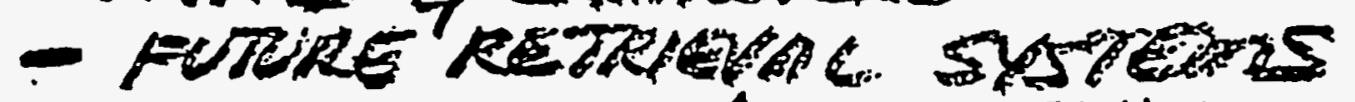

- vacious pats g struetries

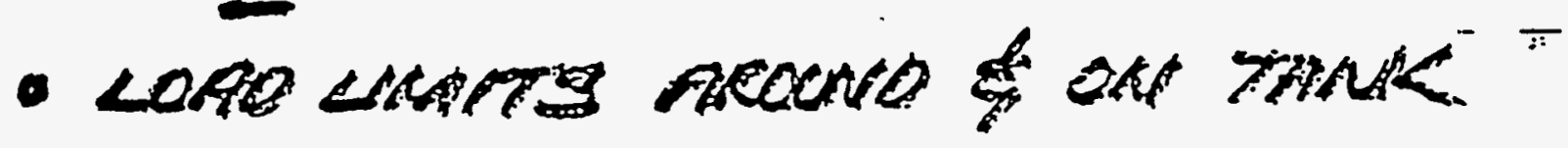

- Thte

- covrecte of groud

- Lopo lantas

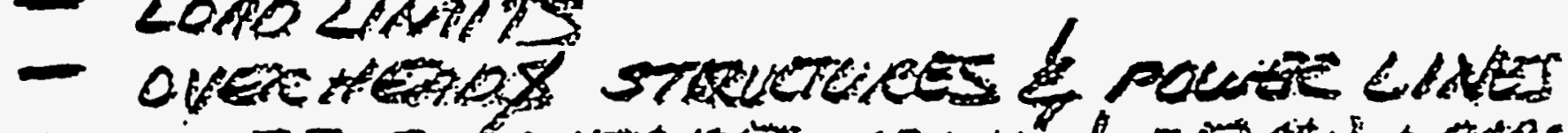

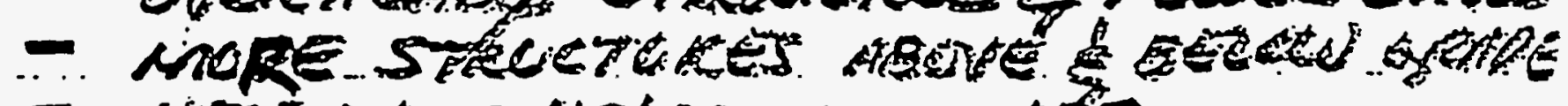

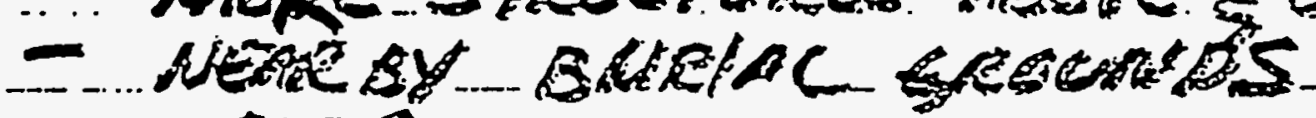

- CRIOS

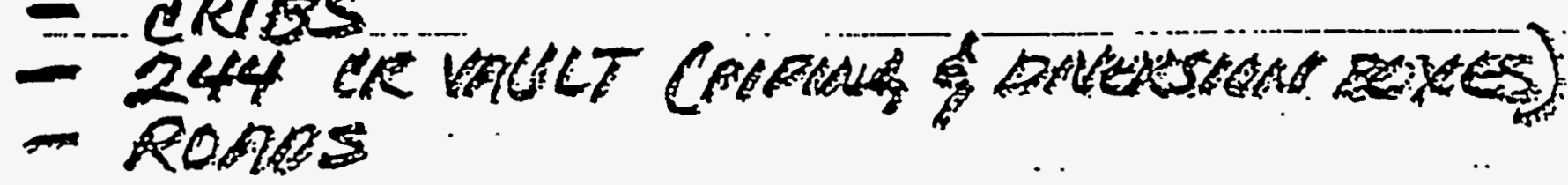

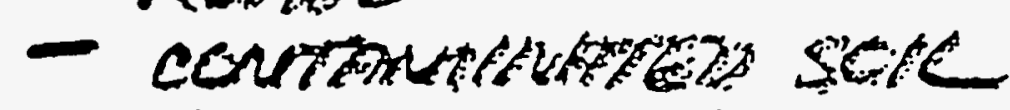

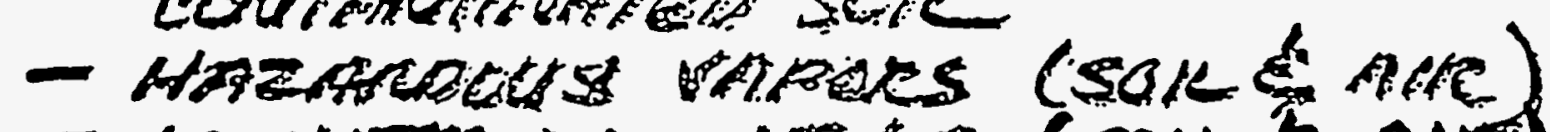

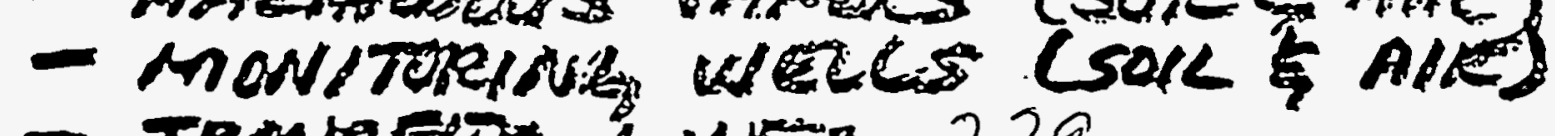

- transfiere lines 229 
INTERFERENCES

(2)

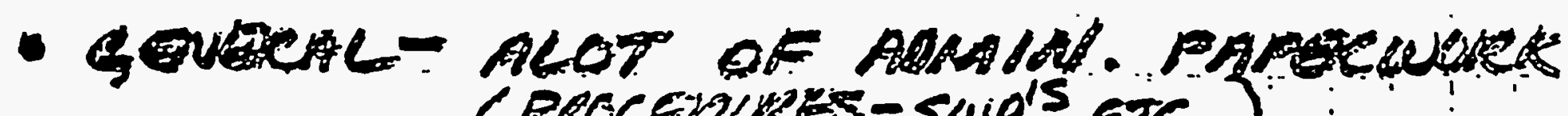
LPREC EDLUES - swip's ETC.

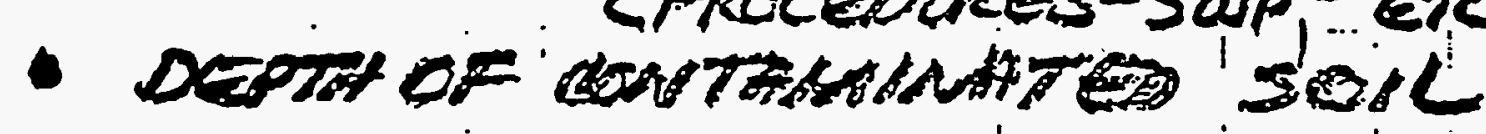

- bolders al cobles (soll properties

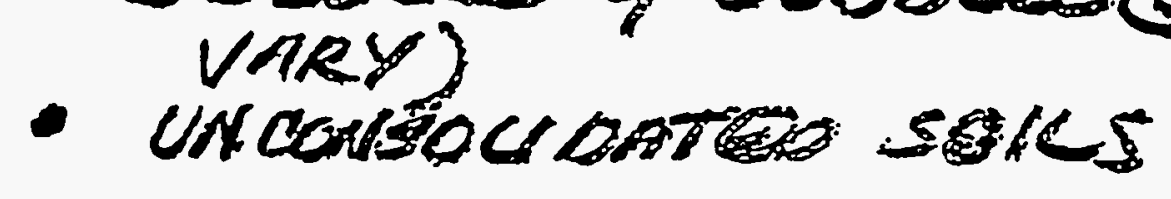

230 
ATTACHMENT 8

FAST DIAGRAM :

232 
ATTACHMENT 9

\section{TUCSON WORKSHOP .}


TULSON WORKSHOP OP

- optTons consioereE (C=106 ONLV)

A.) - LATERAL BARRIER

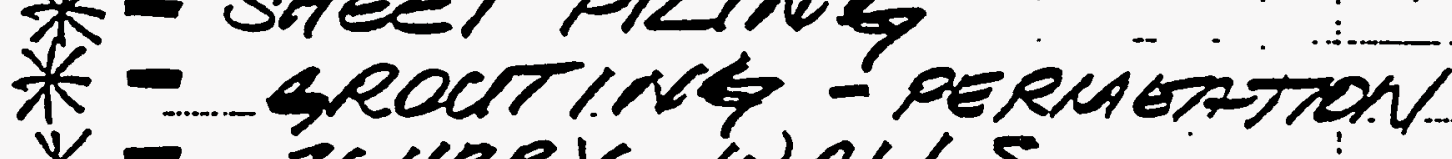

* - scurer walls

- OEEP 5012 NIXING

* = ZNGSTU VIT. (IST)

= FREEZING

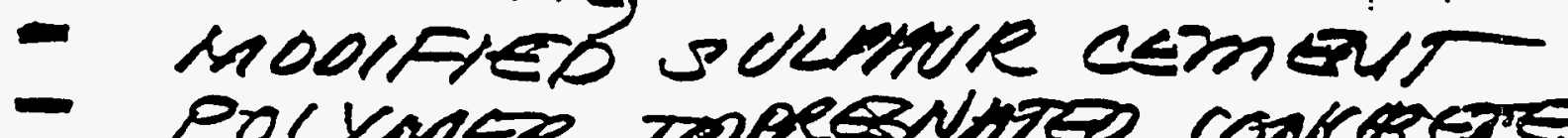
* ALC WERE RATED HILH.

B.) $=$ zRISITU VIT.

H- Geound Freeze

- vorievted curtain

* = MODIFEO SULPHUR coneut

* 2 rates hish

c. He $^{\mathrm{E}}$ equapulation

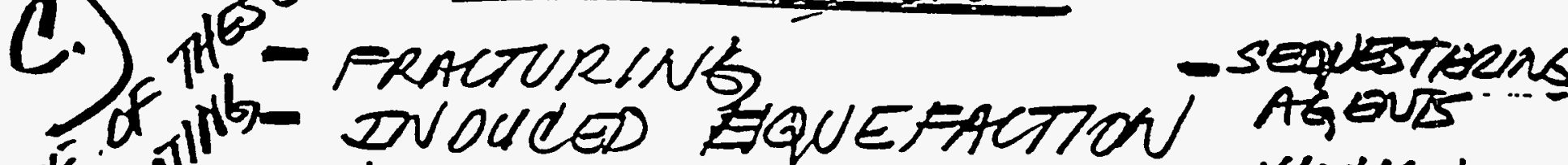

Nov PAN = GROUT ENCAP.

- wieks

WEGAH = CONG WAL MINING 
TUCSON WIOKKSAOP

- BASB - aQSOLUTE CRTERIA

(2)

E TETHIORLCY FETSIBLL

- ZITHTE DQ10. IN 3yNeS.

areanesi

Not at

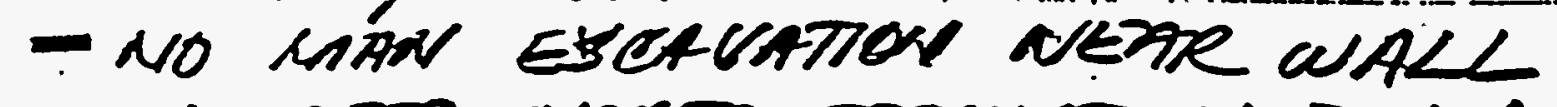

- No deses siored Esotust7or $>10^{\circ}$

- aprucrabe to othodidoe list.

- containa any current reletsises

- abilitr contarn putuke revense

- wont

- wont Linjte pen. closure gorious Drestest

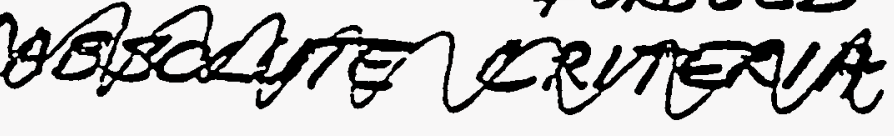

- COULD BE USED ON NULTTPEE USTS.

236 
TULSON WORKSHOP

(3)

- bajla - enkge de selector creteria

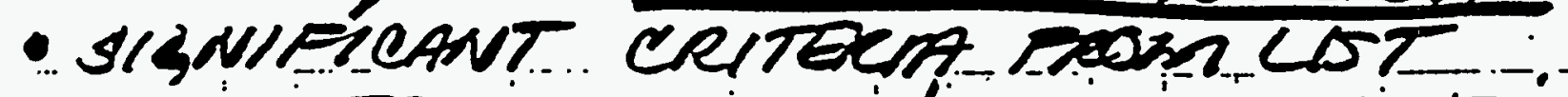

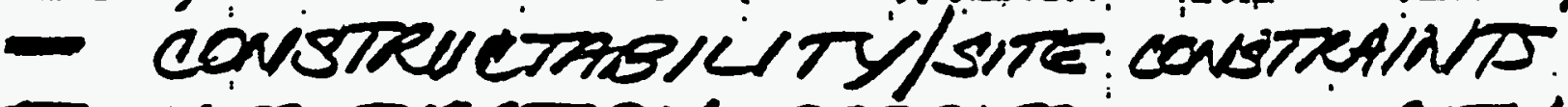

- verifrcation-oneploe antegerty.

- safetY OF TRWK

- pezenner safery.

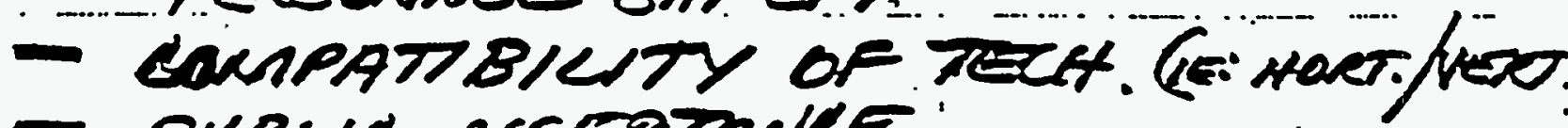

- publie acceptinde

- FunetTONALITY

- Life cycce cost bentefit

- evcavated spolls

- perenitable

- subsiotanee cenatoo

- PRoxienity or Barelens to THKK ( WIASTE MINIIANIZATDON)

- perefountavee criteria

- perach glven local convisians

- STABILE \& STABLE

- repizetion or padronuecides.

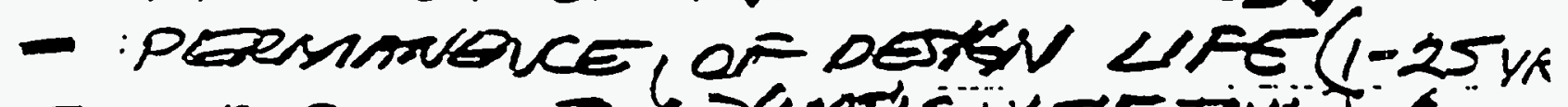

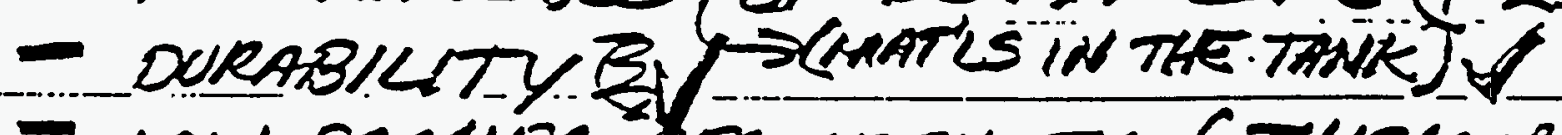

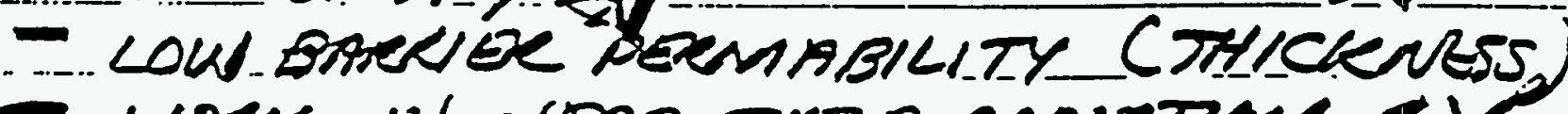

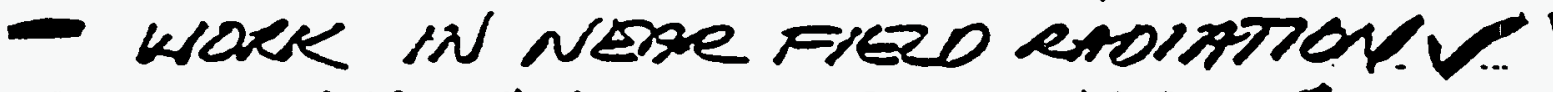

- meen chargeteristies

$23 y$ 
TUESON WOEKSHOP

(4)

- PREFERRED APRPOACHS (2 combInATROUS)

1.) VERTIAL METAL SHT. PILINS COUPLED W/ ATMER HART: VET GPRO UT OF PECM ERTION SROUT.

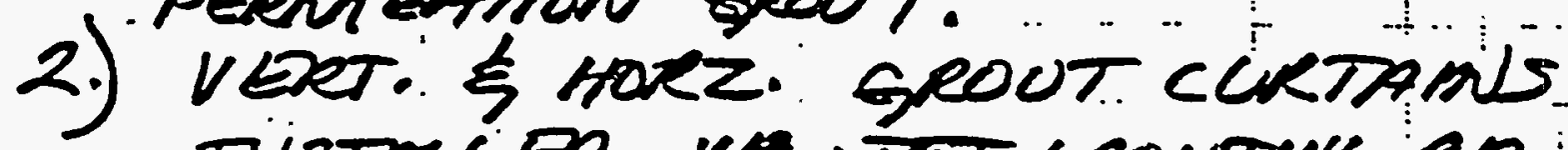

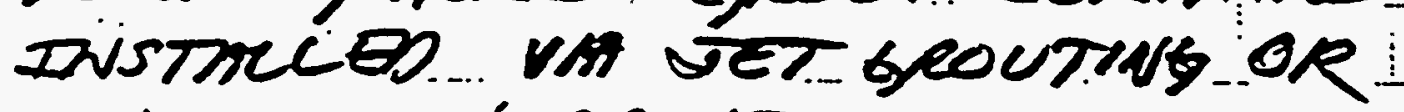
pERMEATION GCOUT.

- AsSUNPTIOYS

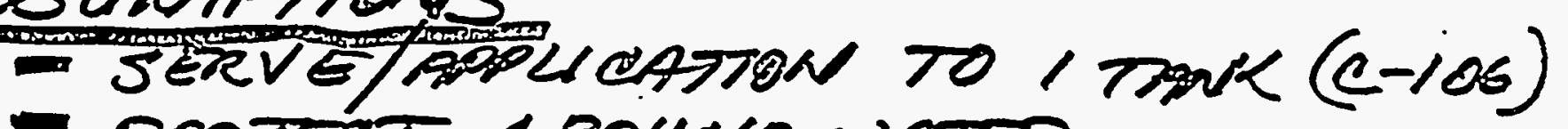

- PROTEUT GROUND WATER

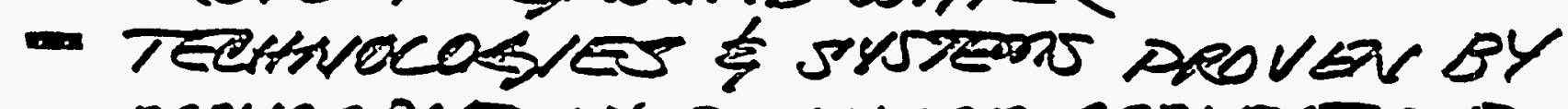

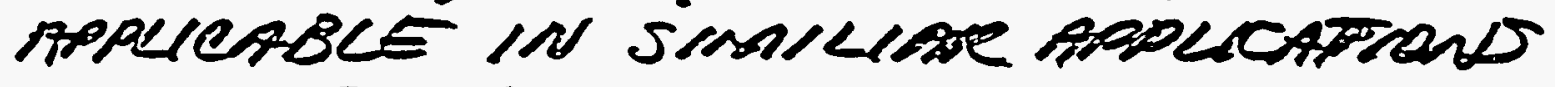

WILL BE DUESUE FIRST.

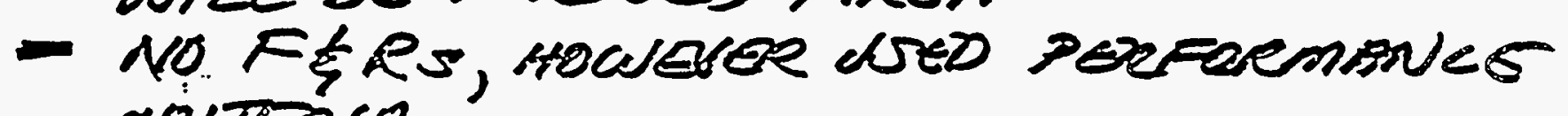
CRITERTA.

- PURPRSE

CONFINE NAT'L' WITHZN THE TANK. THIS AROCESS WILL PROTECT BOTH THE SOIC COLUNAN \& GROUND WATER.

238 


\section{ATTACHMENT 10}

\section{K\&M/BDM ENGINEERING STUDY}


KEM BDAM

(1)

- options consioeced por tank EARU

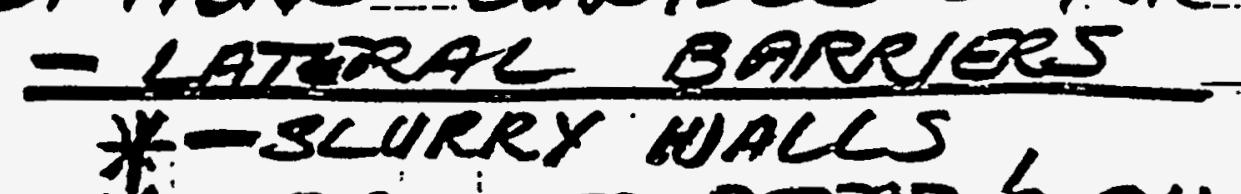

*-oriliced peevs s PILO

ESHEET PILIRS

类- VET Scoutrin's

米= PERMATION GeOUTHS FeEzE Brickex

- HORIzONTAL

* - crec-dín sacerer

* - peematrar gractios

- FRAETURE "

- Looss cunte minioss

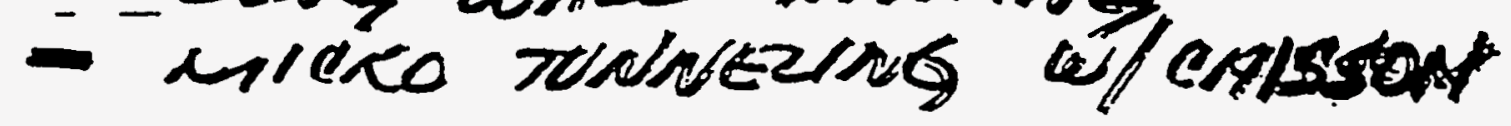

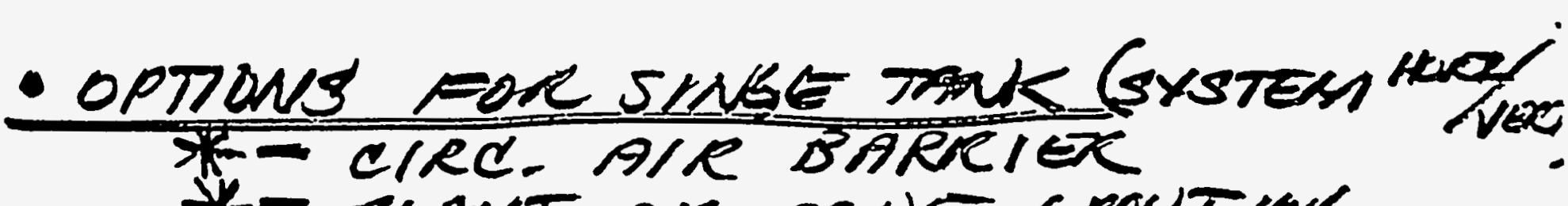

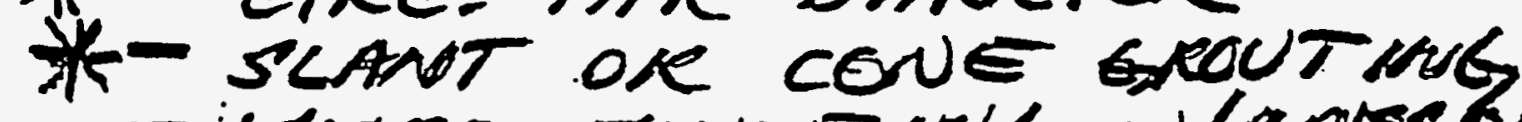

- reicreo tunveuns wilcassar

* = RATED HIGHEST

240 


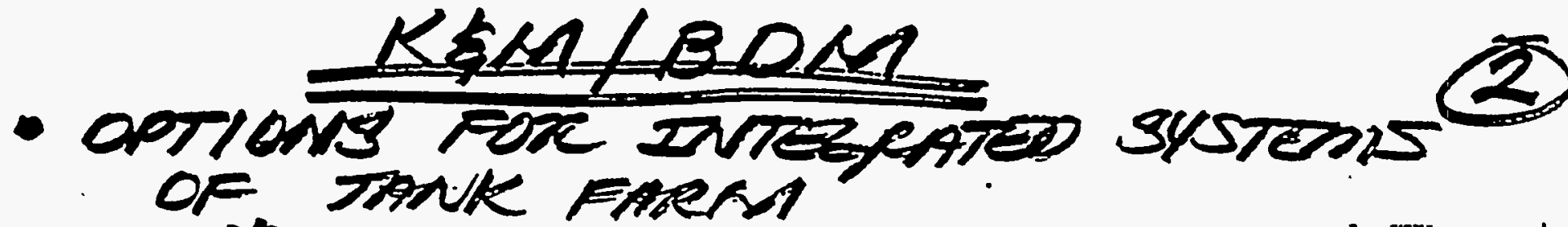

* - cIRc.. nIR BArerex

* - cONE EKOCYTHS

- PEXmextTEN GROCINING:

= FRACTUKED DORO SROUTWG.

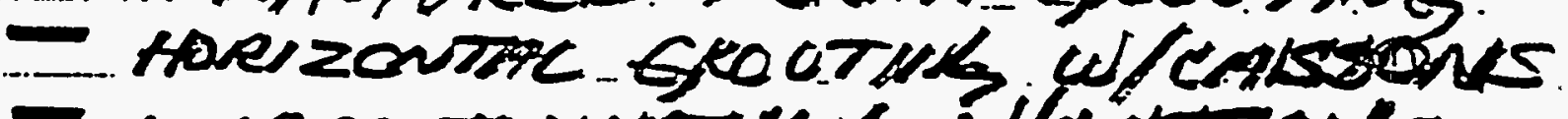

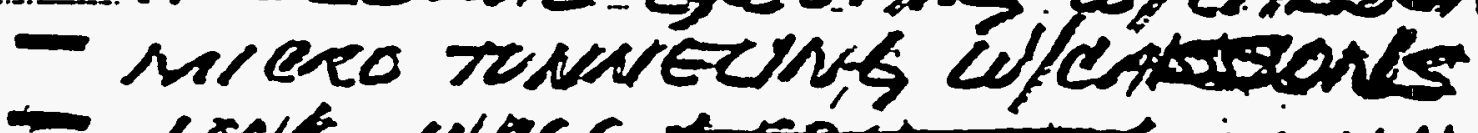

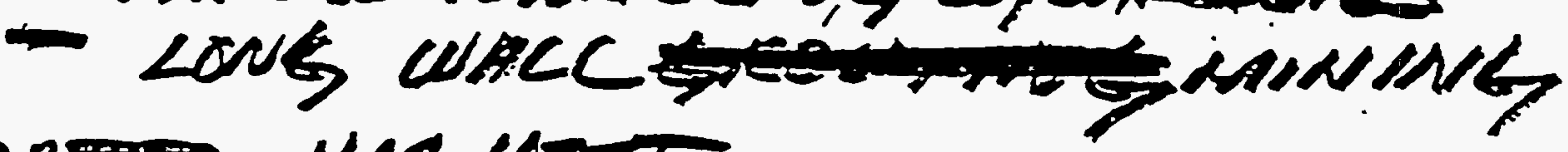

粆ATED HISHEST

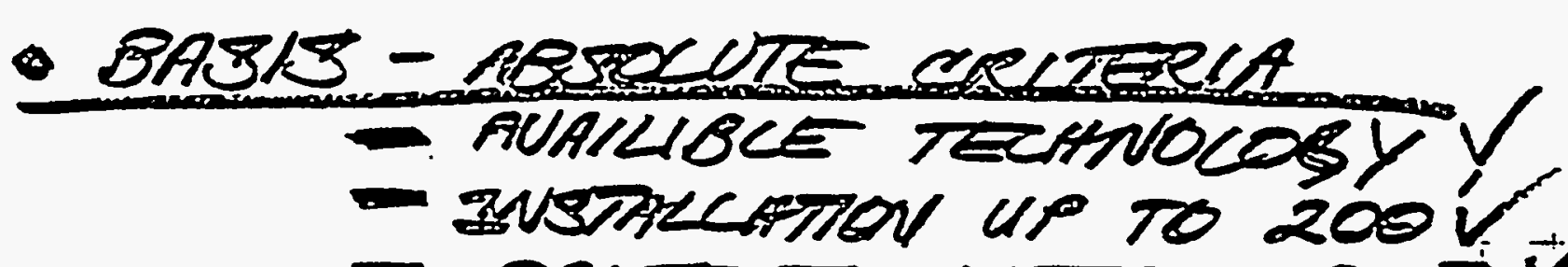

- proted water tisble

- unintair closuke options.v

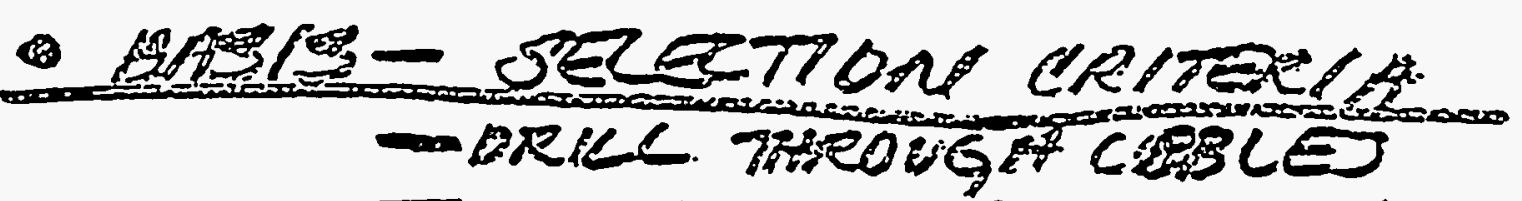

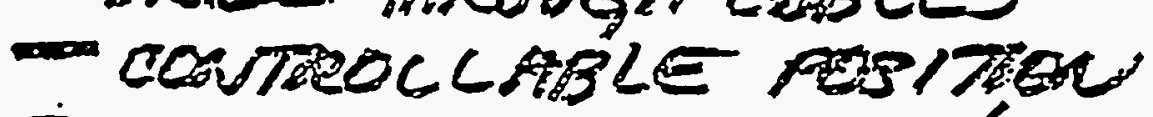

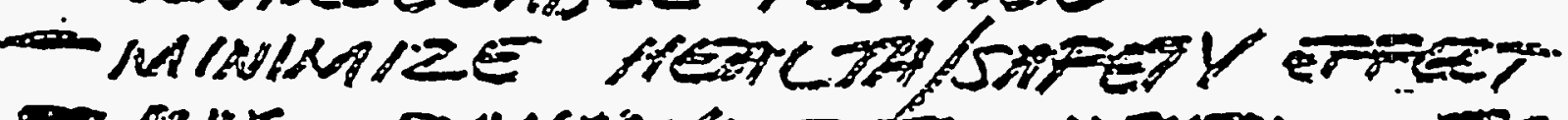

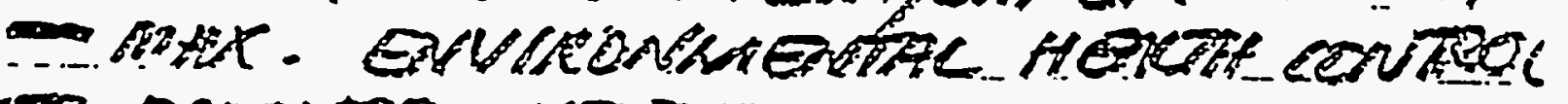

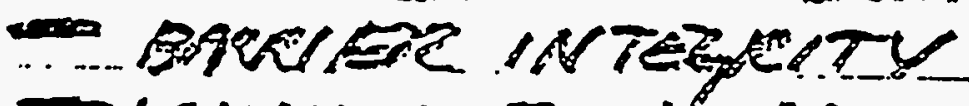

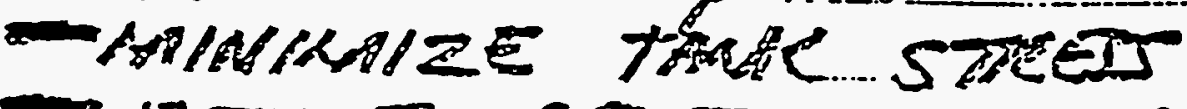

- Resistruce te eftemiancs

- " 70 expen noventent

- verelfr aneclere auteserti.

- arcess domerte vectron

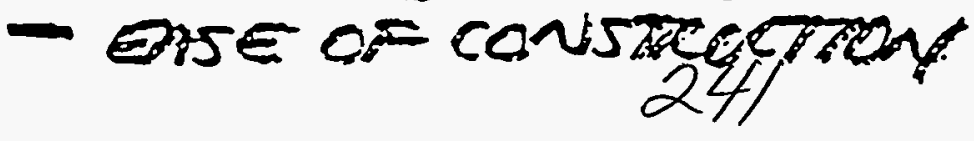


$K E M / B D M$

(3)

- BAs/3 - sezettor critezila cont.

- QTY. OF BPOILS BROUGAT. DO SURAAL:

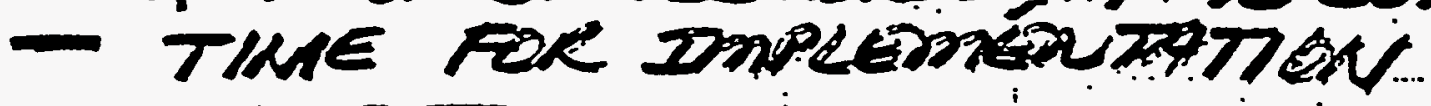

- cost

- confrosace iN apprench: I

- REGULATEKY ACCEPTAULE

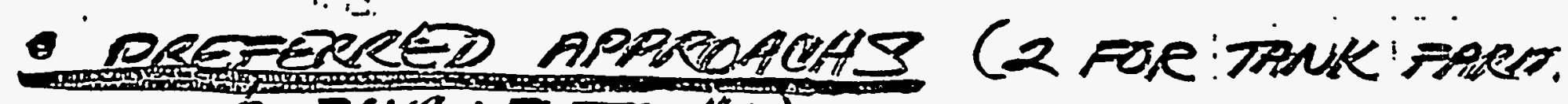
S SINGLE TRNE)

1.) $\triangle A B$

2.) cone groutrat

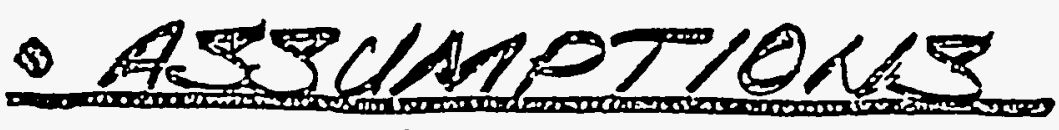

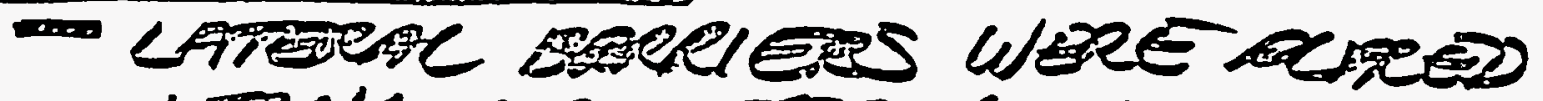

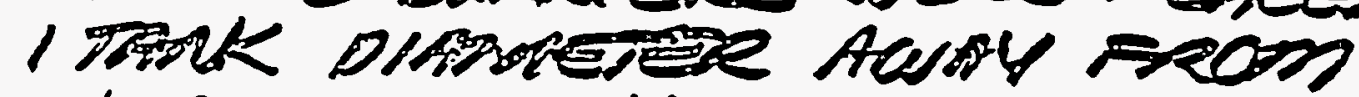
NERESTTHK.

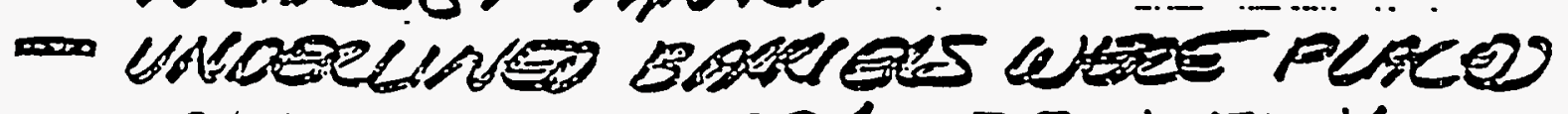

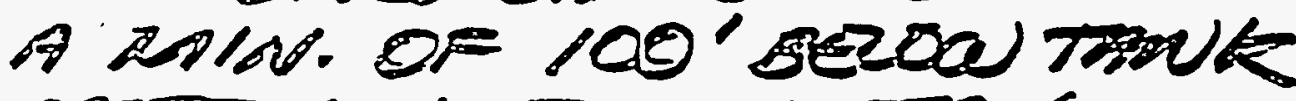

- PeDTEETNG NE WATER (GROCND). For 3o y Res. (octsine Bnerrer)

- DRluLN uILL AVOID conmin-

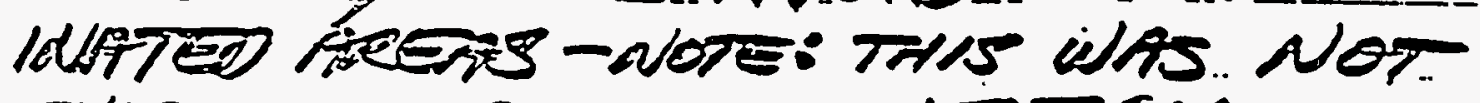
JWTEUE TO DE A LUITATRW.

- JPOILS ARE UANASHRLE.

- pejole couco (In sane cases)

- "WORK UMDERTROUND. 242 
$K E M / B D M$

(4)

- requirenitara

- LAPUIDS Do NoT BO TreavSHA

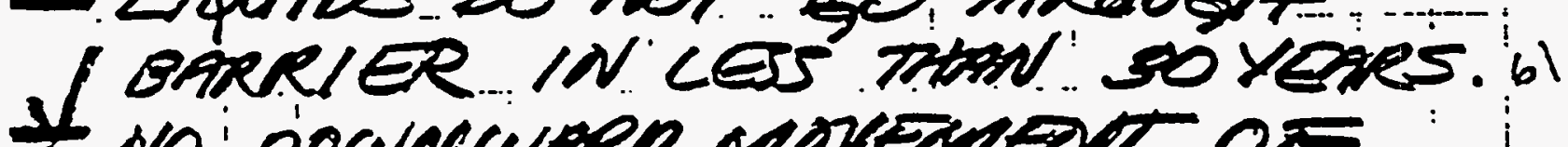

I No DOWN WABR MOVENOW OF

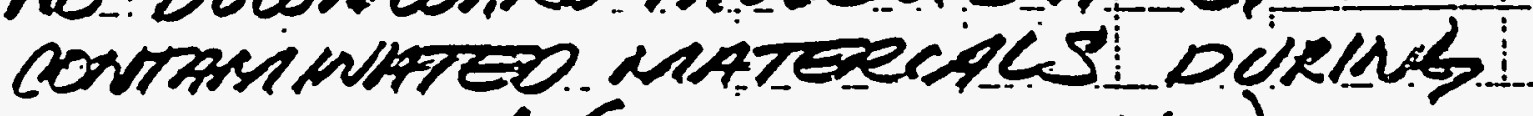

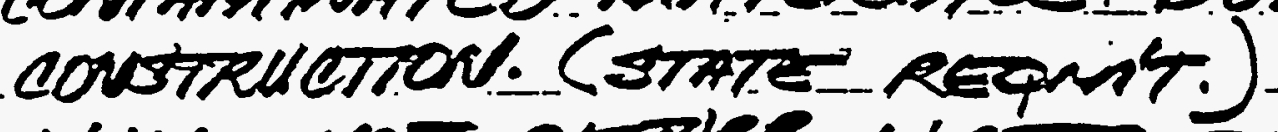
WILL NOT DASTIRS WATER THELEW

7 UIMANGABCE STRESS! LAVES ON

$\checkmark$ TPNKS.

Mninumize DISPOSAL OF RAOIO-

II ACTNE MATORMLS.

I DRILC TROM NE TO SW

I ABILTY TOHORILL IN A UMRIGTY of geOLOSIC SETINLY. (Unconiscuinated rneola)

pupeose

CONDINE THE WASTE WITHAN THE RARERE. THLS Process WILL PROTEZT TRE GRONND WATER:

243 


\section{ATTACHMENT 11}

SUPPLEMENTAL INFORMATION 
BACKSROUND D

- in suppotet of Retrieval effort. - IDENTIFIED TWO TECH. POR RETHEVAL

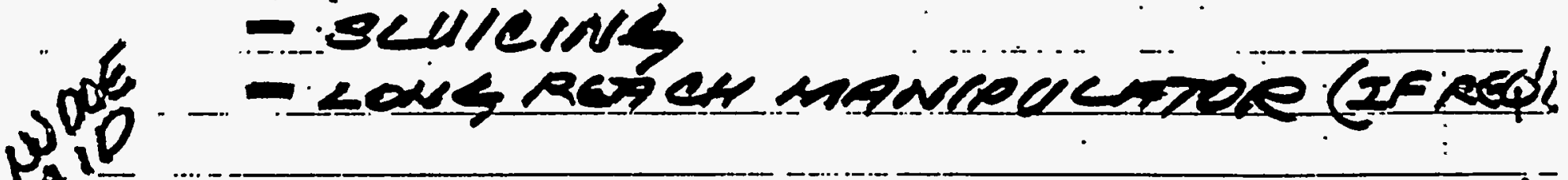

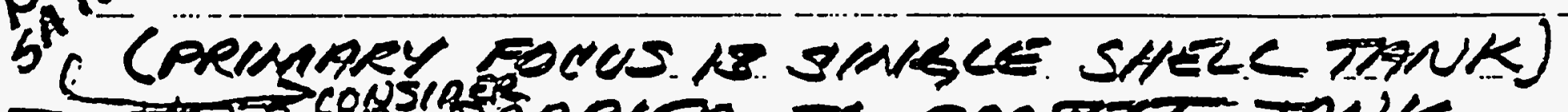
- COBSIgERRRIVR to PROTECT TANK FRon LOAKING.

- regulatore reguits

- Reren hPpules to tank Faken

- DOE bUill TAKE THALS TO CLOSURE, not Full conplinnee w/RereA

- wook wants foll complinnle w/RESS.

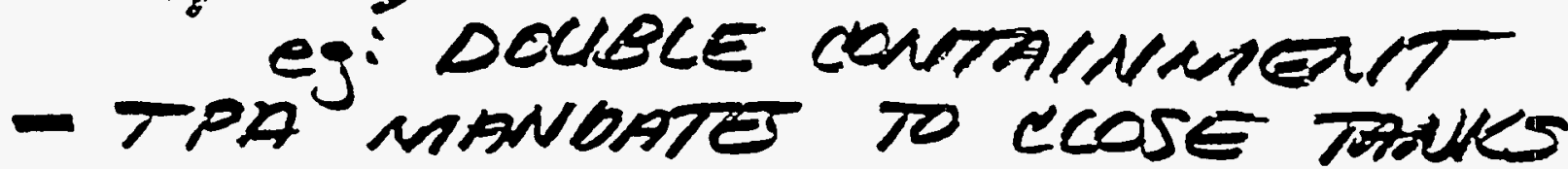
VIA KAC; - CLEAA CLOSLRE

- pencve tanuks

= " piping

- conmanumpeo Jolk

- "anul bapriezes"

- consider tre chtrus to neet.

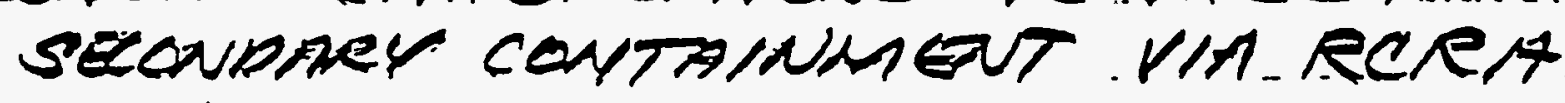

- USINL strs. ougheorins approncht in TIE TWRS SCOPE.

IE- OPTIONS, COST DATA, SCHEOULE

- Doe unents decision by 2193 ON STUICES OF SNBLE SHEZL TANKS.

245 


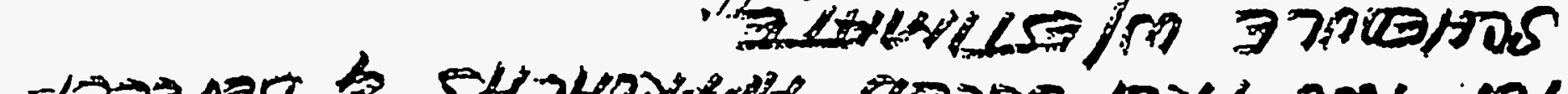

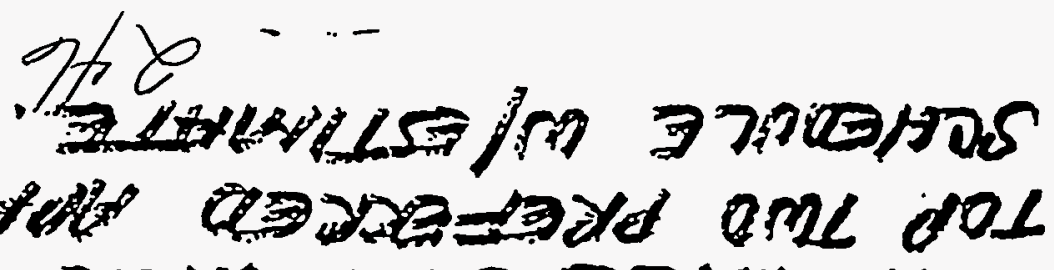

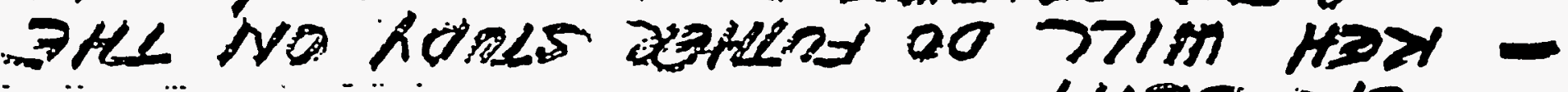
- leV do

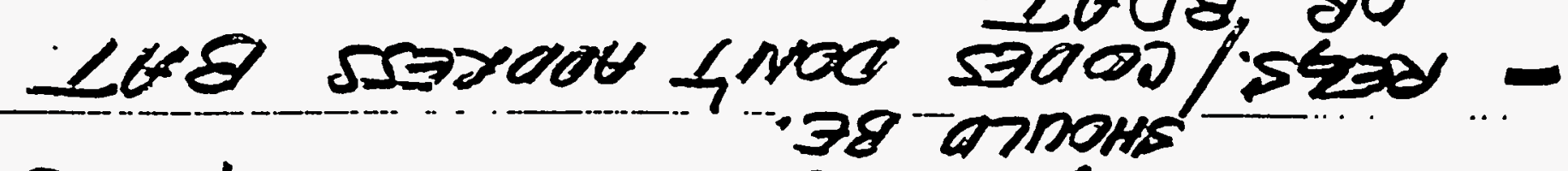

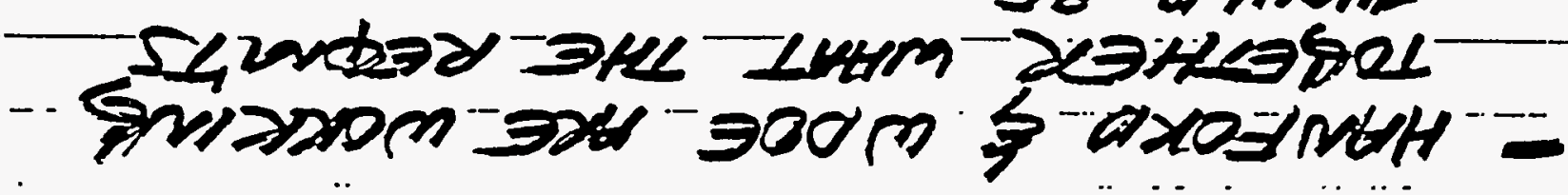

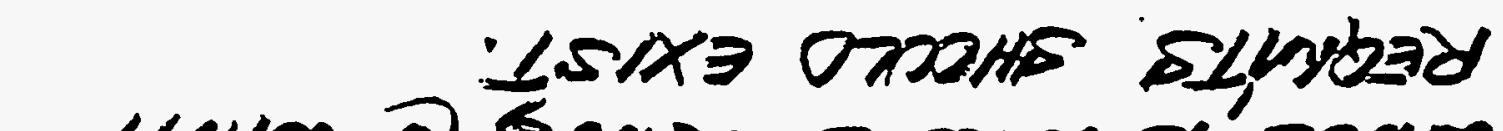

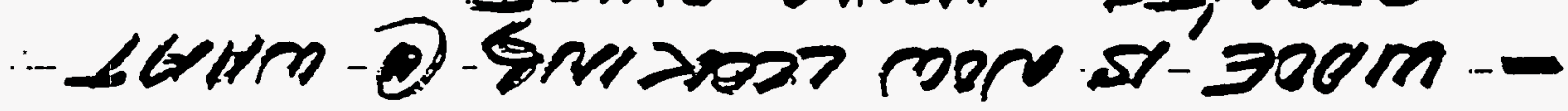

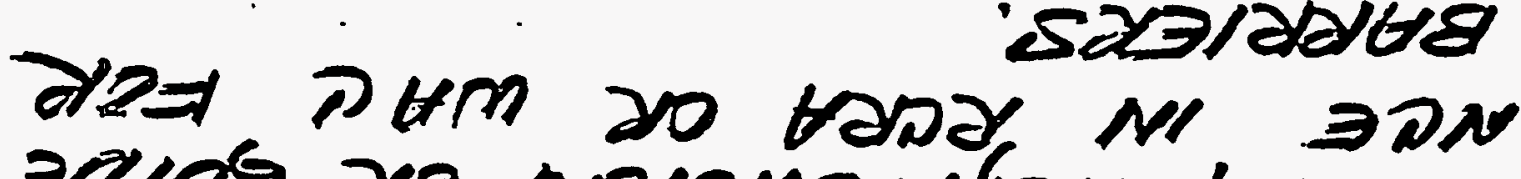
- zains 20 malsinased sumbar gN -

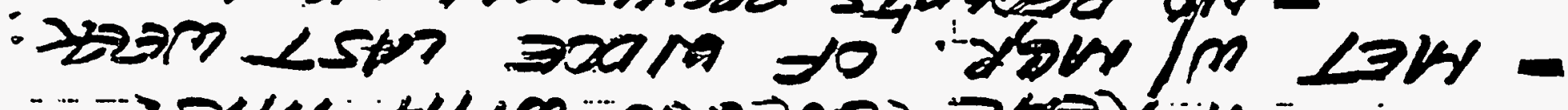

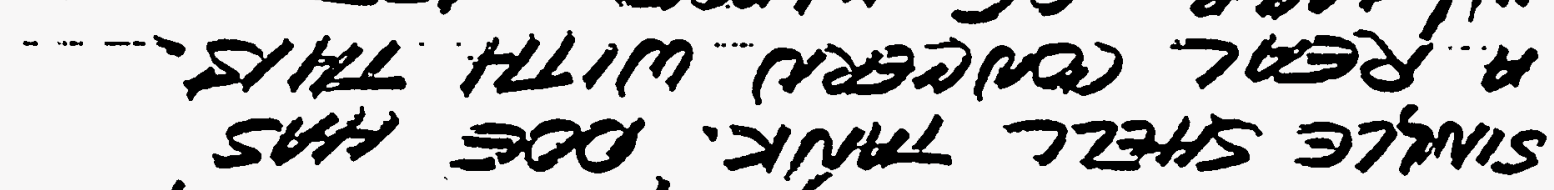

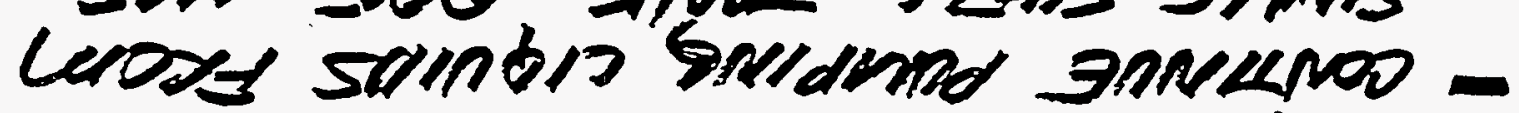

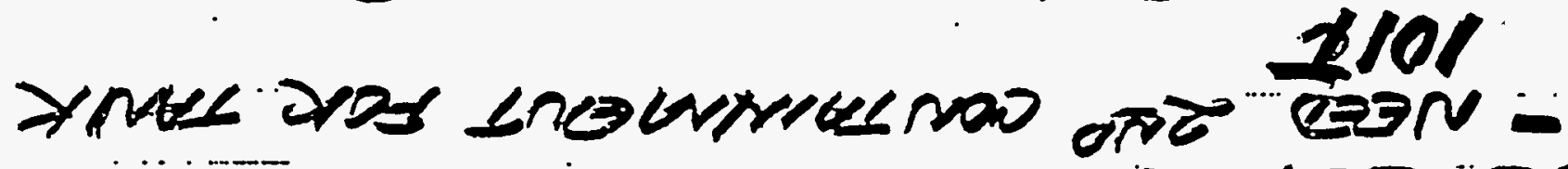

$$
\begin{aligned}
& \text { : } 22 \angle 1 E>=300 \mathrm{~m}- \\
& \begin{array}{l}
\text { ¿-2.10s } \\
\text { um-ONpods }
\end{array}
\end{aligned}
$$

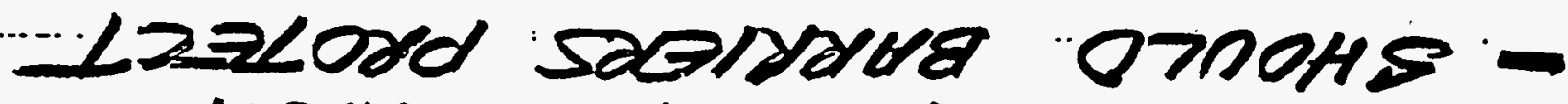

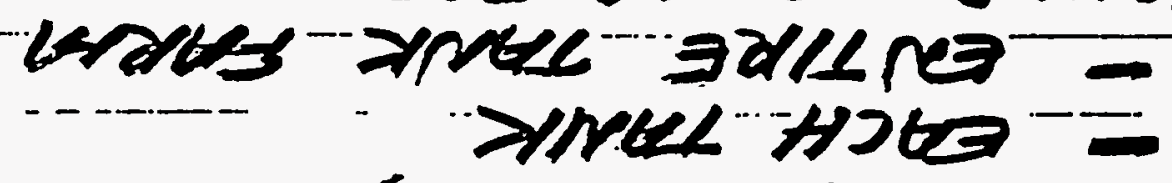

- annoser (s) arposer doalasos -

(2) ONPOX' Yinte 


\section{Late

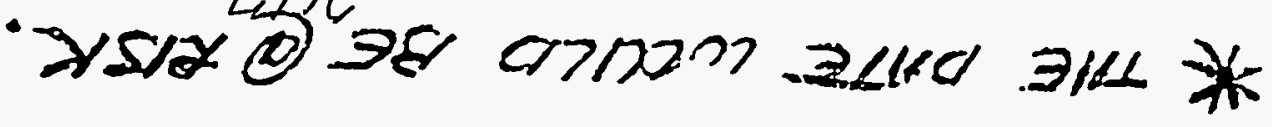

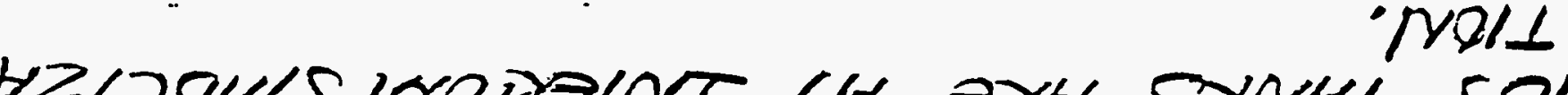

.....

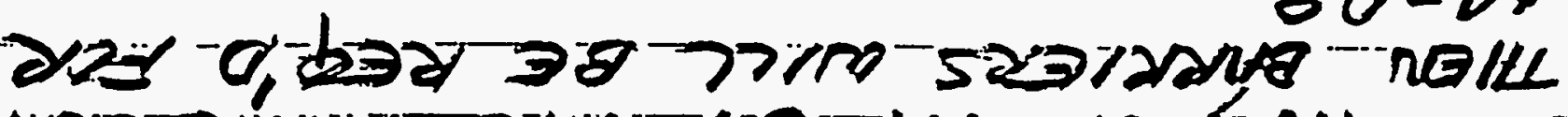

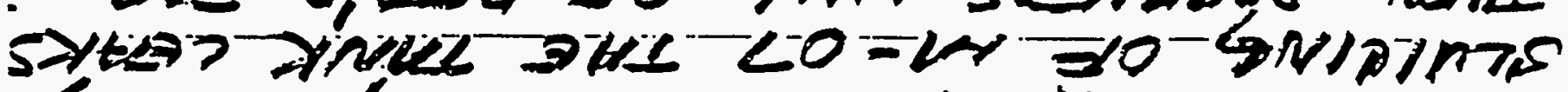

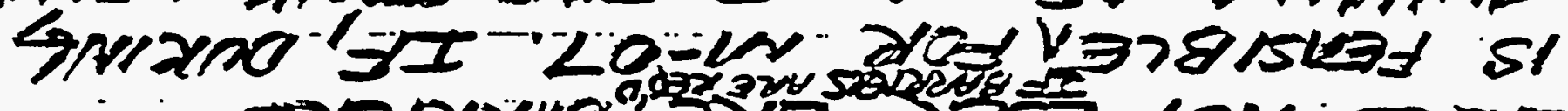

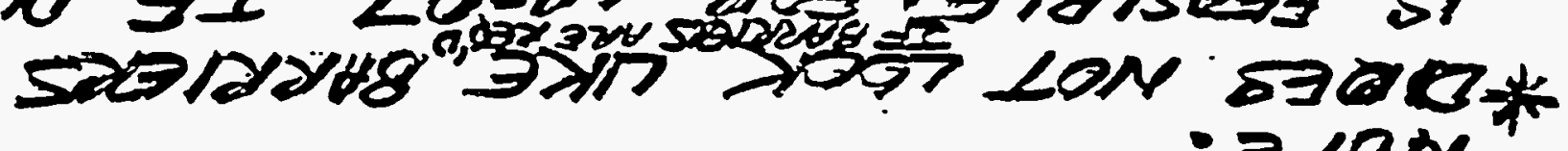

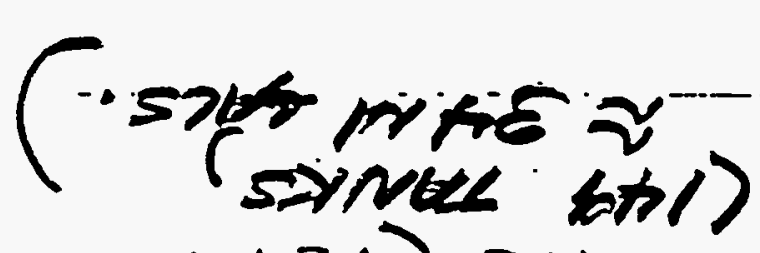

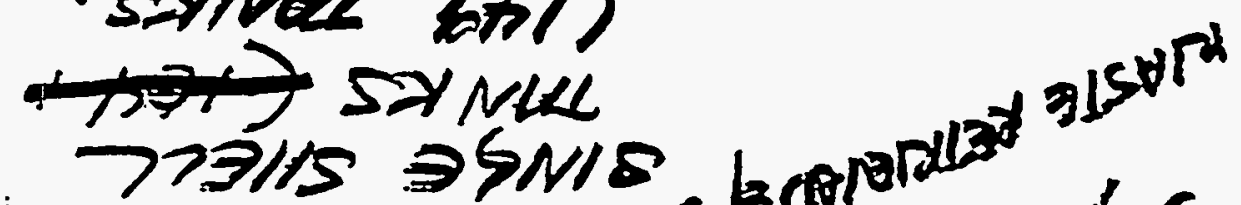

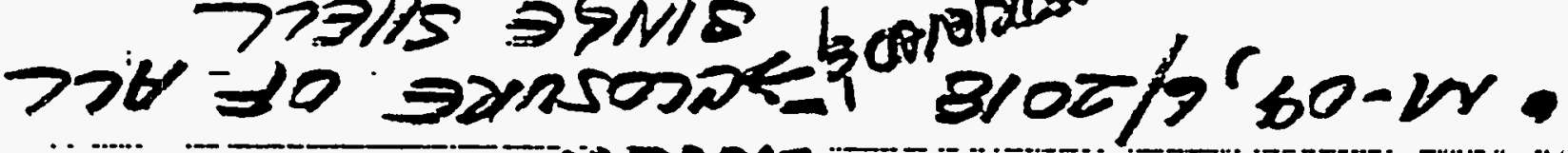
nonar

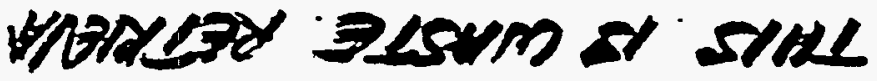

- lasuar ayllana

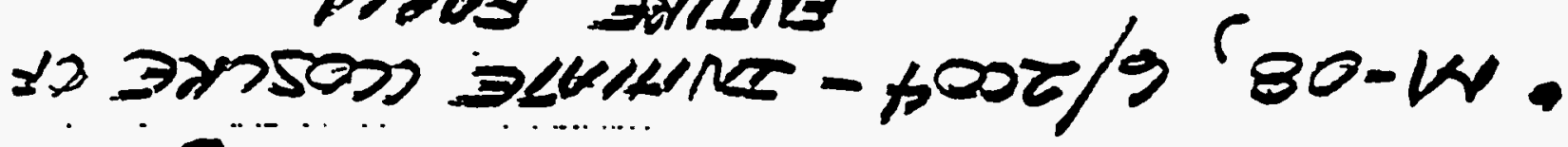

$(901-0) \cdot 2154 \mathrm{M}$

$=19$.356. Jinkel. No

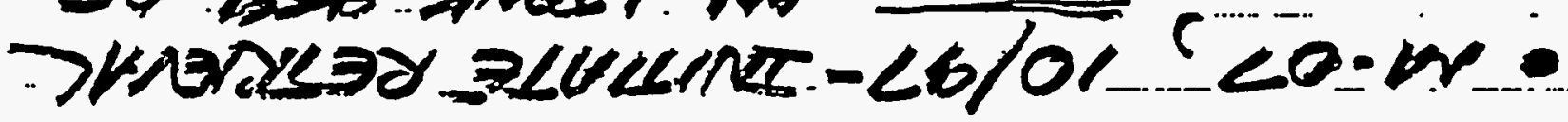

: sarassiur-bell

$$
\because \Rightarrow 7 n C B H D S-
$$

syalba-no

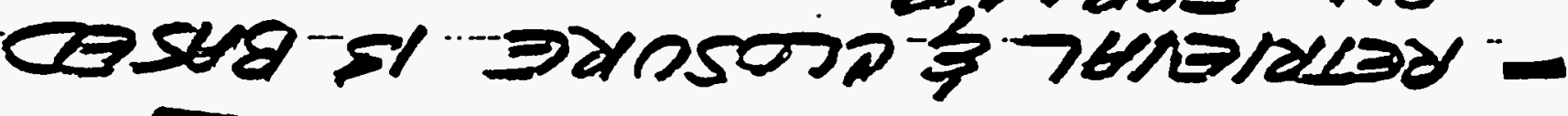

(2)

$$
\text { ONTOS }
$$


(4)

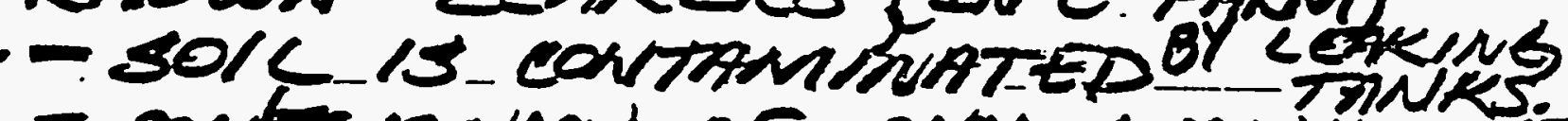

- Donf know of avy spounip autiter conTAMUINATTON.

= C-106 MigAt Becon E- $A$ LEAKEC BY THE TIUE RETKLEVAL IS INITINTED.

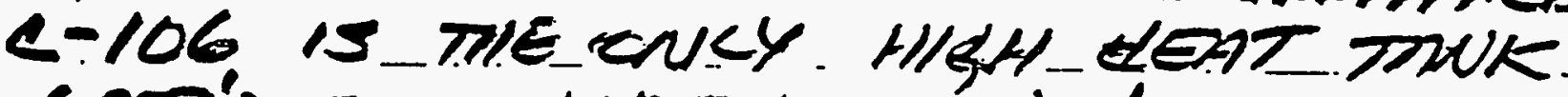
(RER'D IN WIDON BRC) TIE OCDEST TANK. WITER IS BEING nODED CONTINOUSLY TO PNEVEUT HEAT OVERLCAL

STHE CONCKETE OF THUK IS CRACKED.

POSSIBILITY OXISTS DAPT TRANISTER LINES Q C-FARM MAVE LOAKED.

- nOTE: THERE ARE 66 ASSUMED LETKRES

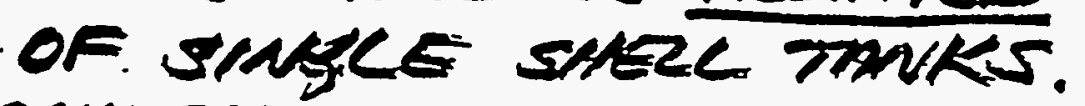

- Is BARKIES LIMKED TO SCUNCINGP NOT REALLY. ALTHOUAH REGLLATCRS

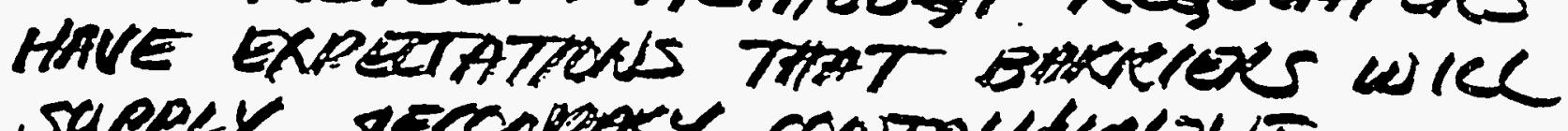

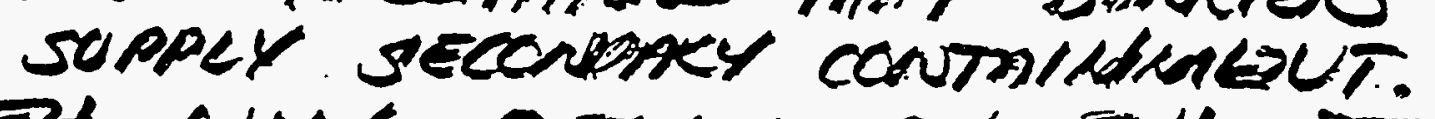

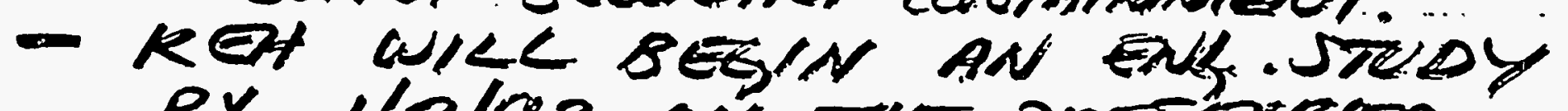
BX 1/2/93 ON THE PKEFGUED APPROACAS.

- WHE- NEEJ EJTIMATTES E- SCHEDULE-BY ENID OF"1/93.

248 
M/SSION

IDENT EUNCTOWS S REVUIREMEUTS SUBSUR FAC E EVAZUATE

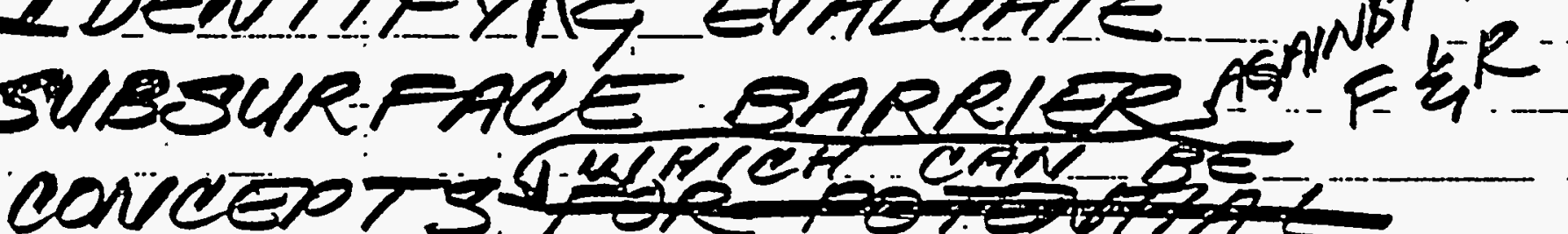
DEPCOY PEA AE C-106 TANK ANQ C TANK FARA, OT TO/AZ. INTHE NEPR Terem.

IDEMTFY Flife \& EVAUATE SUBSUREAACE BARELET CONCEPS AGAINST THOSE FERS AND SERT TWO TO THREE CONBIGUATIOUS WHICH CAN BE

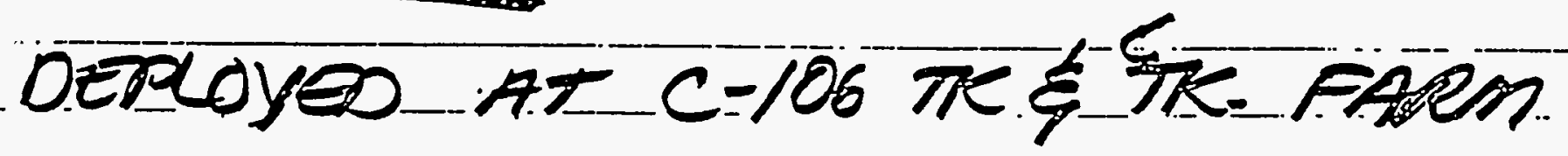
IN THE NEAR TERH.

249 
DEEINITLONS

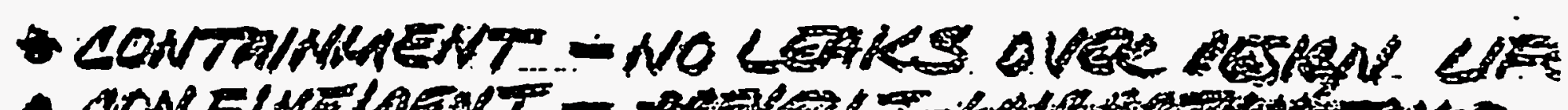

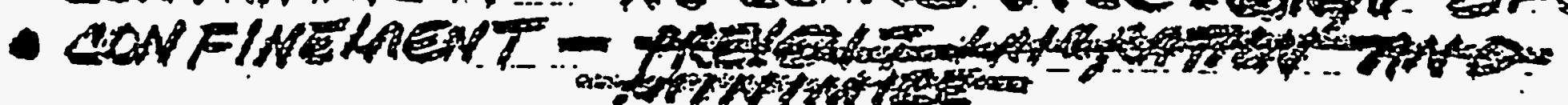

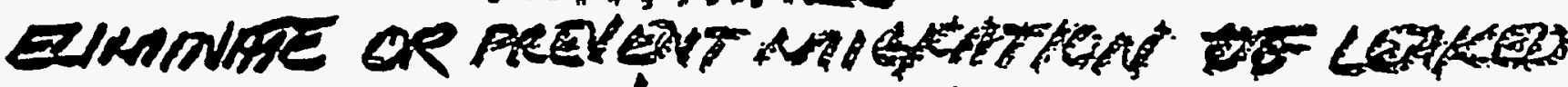

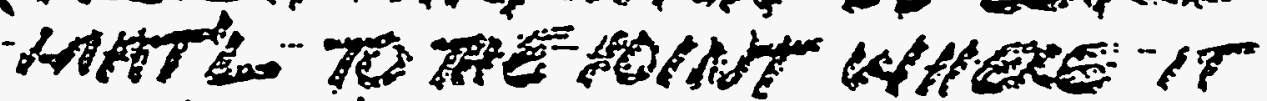

Reses

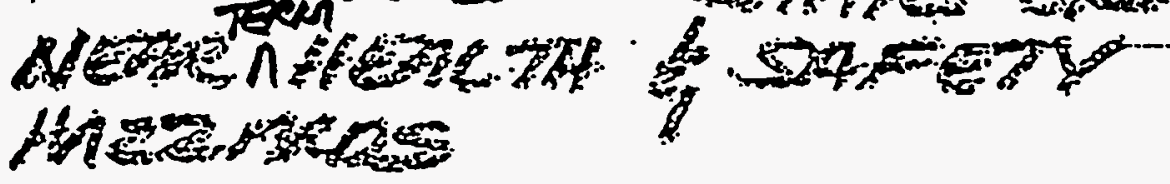

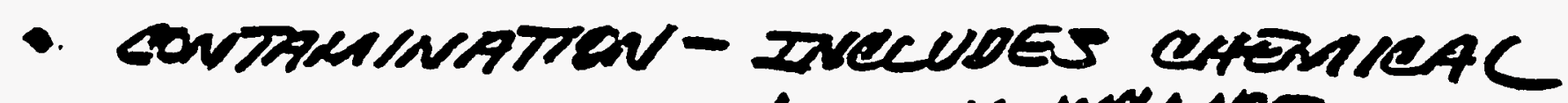
\& RADIONCRCLIOE.

250 
ISSUES/CONCERNS

- FUNDING IMPACTS OF CAPITEL LII. VS. Exsperse ete.

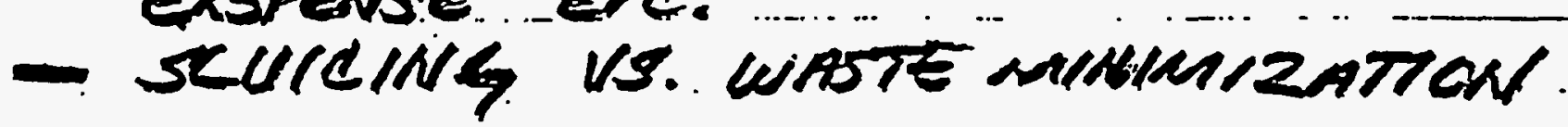


CLOSURE PLAN

- neEs KAC 173-303-610

- TSD PACILITV)

- WAC-173-303-640 IS FDR TANKS.

- PROTECT HUMNON HERLTA ENIKN. RESTORE_LAND

MININIZE NAAINTENANCE OPTIOUS: (RCRA)

1.- clean ccose Cno cumste in purbe

2.- CLOSE CU/WUASTE DN PLOCE

(GarRiERS ON SURPACE ETE.)

$\rightarrow$ REQ'S 30 YR. MINIMUM of MONITORING.

- ULAC 173 - 303-6t0 SUBSEUTEN REQUIRES $100 \%$ OF WFSTE RETRUVUDO QUT OF TANK.

- la8g the state salD we cannot ccose Wf SST DU PLACE.

- TPA Has 2n-0q-2 12/2003 SUBNITT CLOSURE PLAN FOR. IAP TINK

- THE STHE WMUT TO PRETER GROND LUATES.

252 
TNEORMATION NEEDED

Y SET OPS. REP IN STOPK.

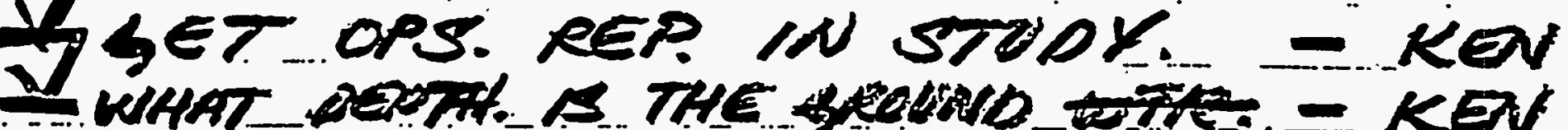

$\checkmark$ contratanovated (SON CELCNON)

IC SET CCOSURE REP IN STROY - kear

TSkUiCING epts. pax tank.

WAC-SD-WM =ES - 218 DRAT B 
MEMORLES

- CONSIDER cenfINEMTENT

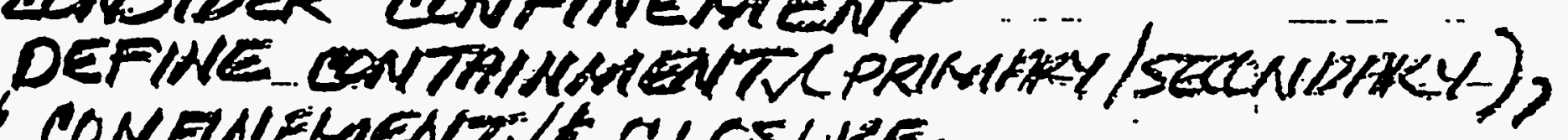
CONANEMENTVE CLCSURE.

I CONGIDER LATERH L UNDERAVING BARRIES

- ANY ORTION CHOSEN SHOULD-IDUCLUDE1 DEVERTANEAT THATE.

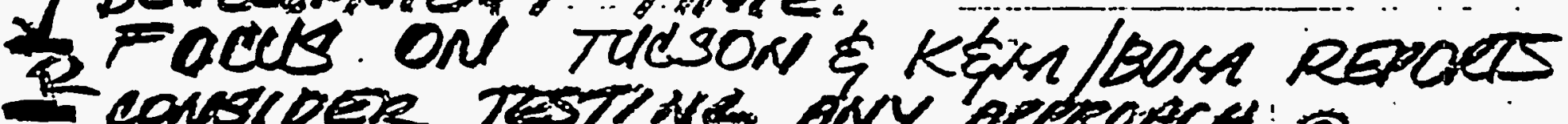
consiber TESTING ANY APRrCACA! ?

A sub

SUB BARRIER TR BELCW BAREIER R CCQHUY SYSTEF.

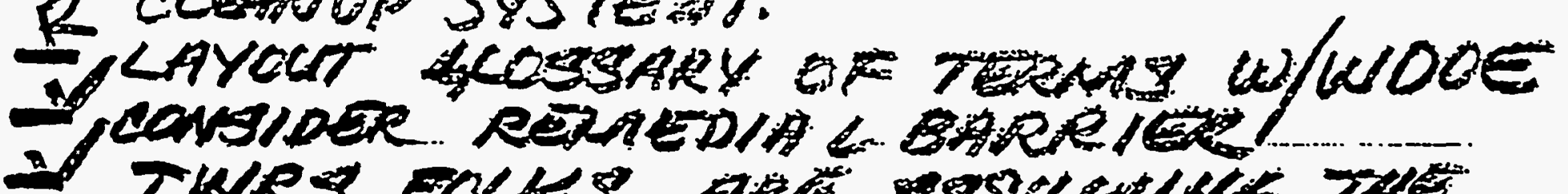

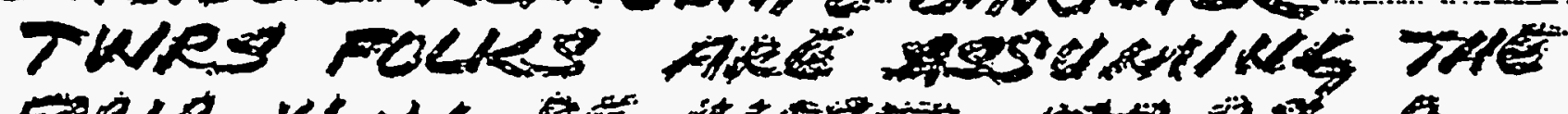

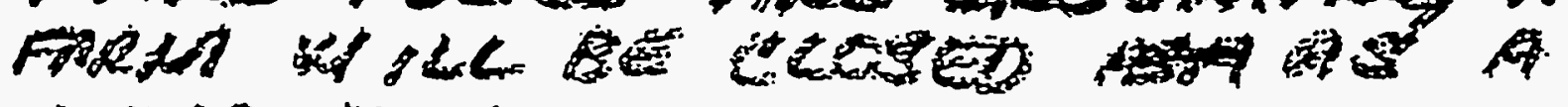

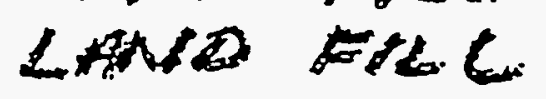

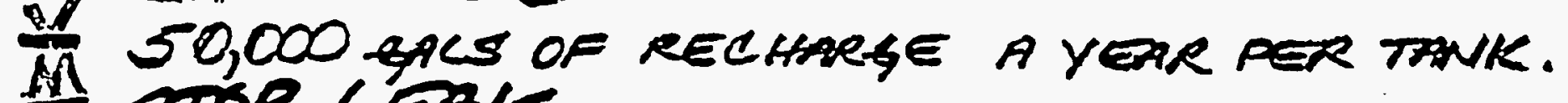

MTOP LEAK

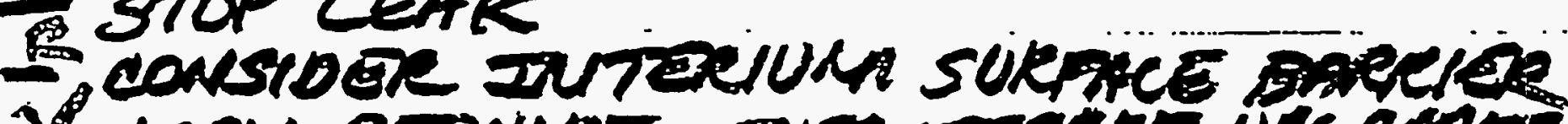

- may requires surratudace ungRades

- consider rulettior avaluatron of practure

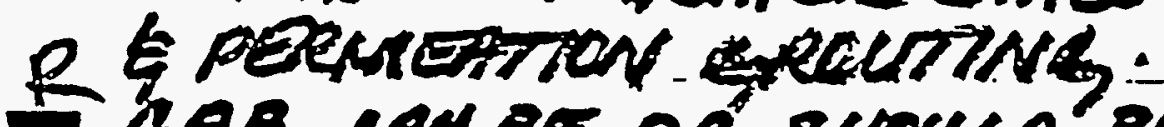

QA.B. LAN BE OR SHOCLD. BE GUTLCATED WITHA OPTISES $2,3 \& 4$

$R=$ RECONANERATILT

$M=$ MENORIE $\$$ SOR POTEUTMC ACTTON 
CRITERIA

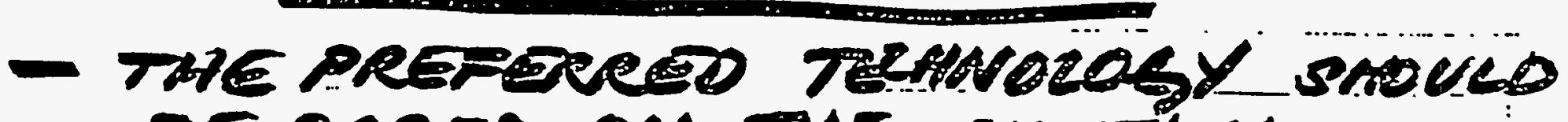
BE -BASED ON THE -EXISTING TECHNOLOGY OR TECHNOLOGIES WITH

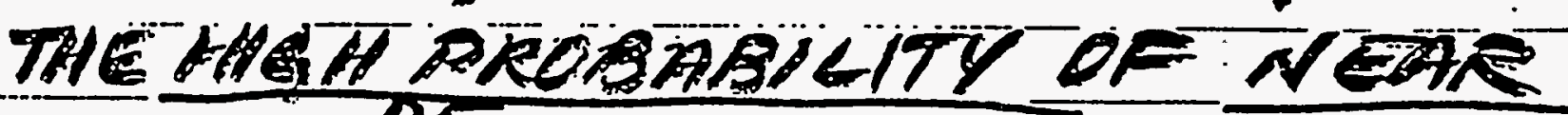
TERA-BEPLYYNENT.

- LIFE cYCLE cOST

255 


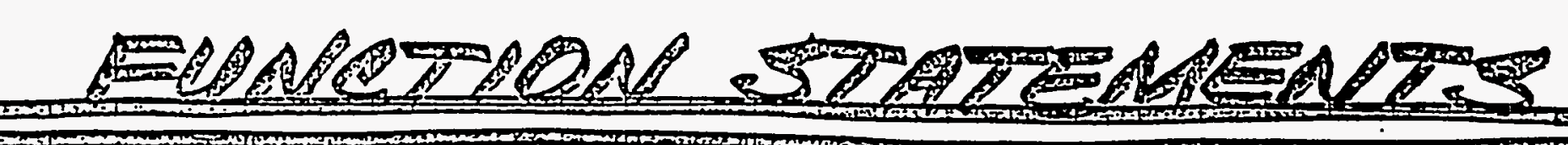

- preverti certer

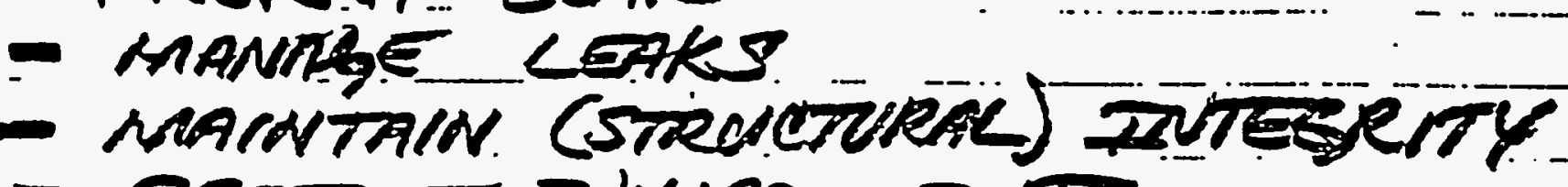

- Protect environeart

- arillevate probcer

- cienrt contrininatien

- sUpPORT RETREVIAC

- SUPPORT CCOSUE SATISFY (RES.) AGENVIE

MITTHTE SPREAD

AVOID DITEFERULS

DISPLACE $50 / 2$

PUMP GROUT

FORM BARCIER

DUAIBIT FLOW

CAPTURE BAD - STUFF

TSOLATE BAD-STUFT

MERIMINILE WASTE

COLCET LEARES

DETECT MONOTR LEAKS

VEXIFY DUTEGRITY

MAINTAIN BARERER DUTESTITY

AINIMAIZE SPREAD

MAIMIMILE LEMTAGE 


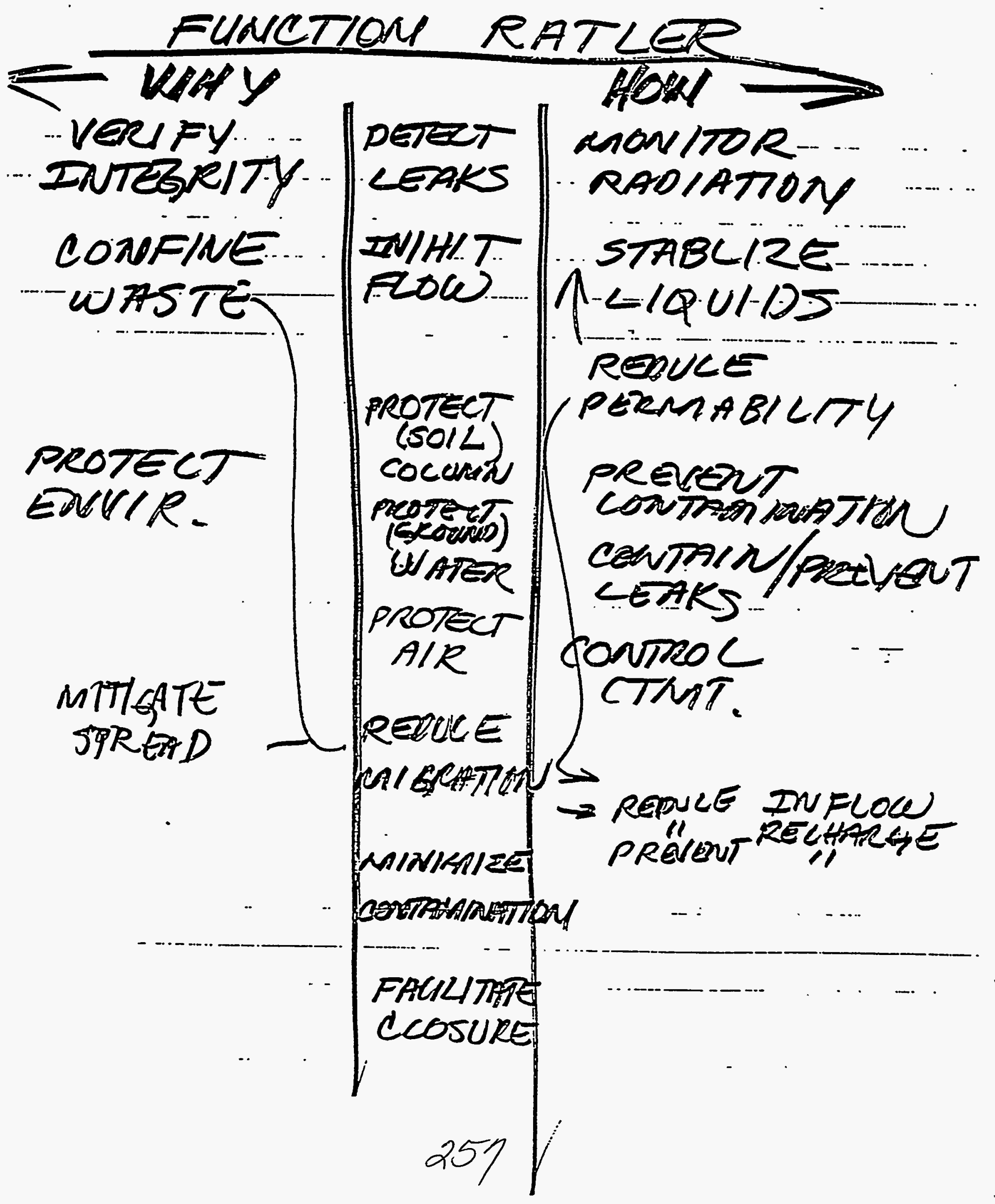




\section{ATTACHMENT 12}

\section{AGENDA, GUIDELINES, AND EXPECTATIONS}




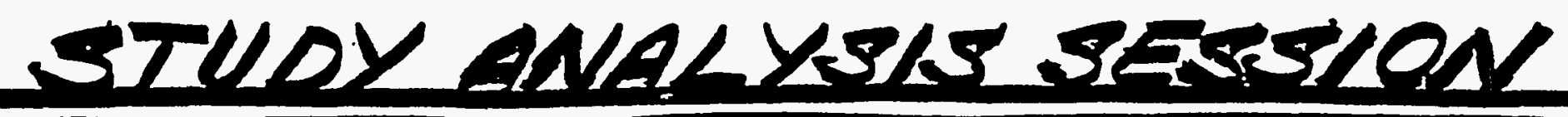

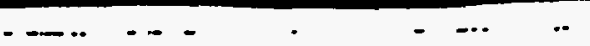

SUBSURFACE-

BARRIERS

$$
\text { FOR }
$$

TANK C-106

$$
\text { 象 }
$$

C TANK FARM
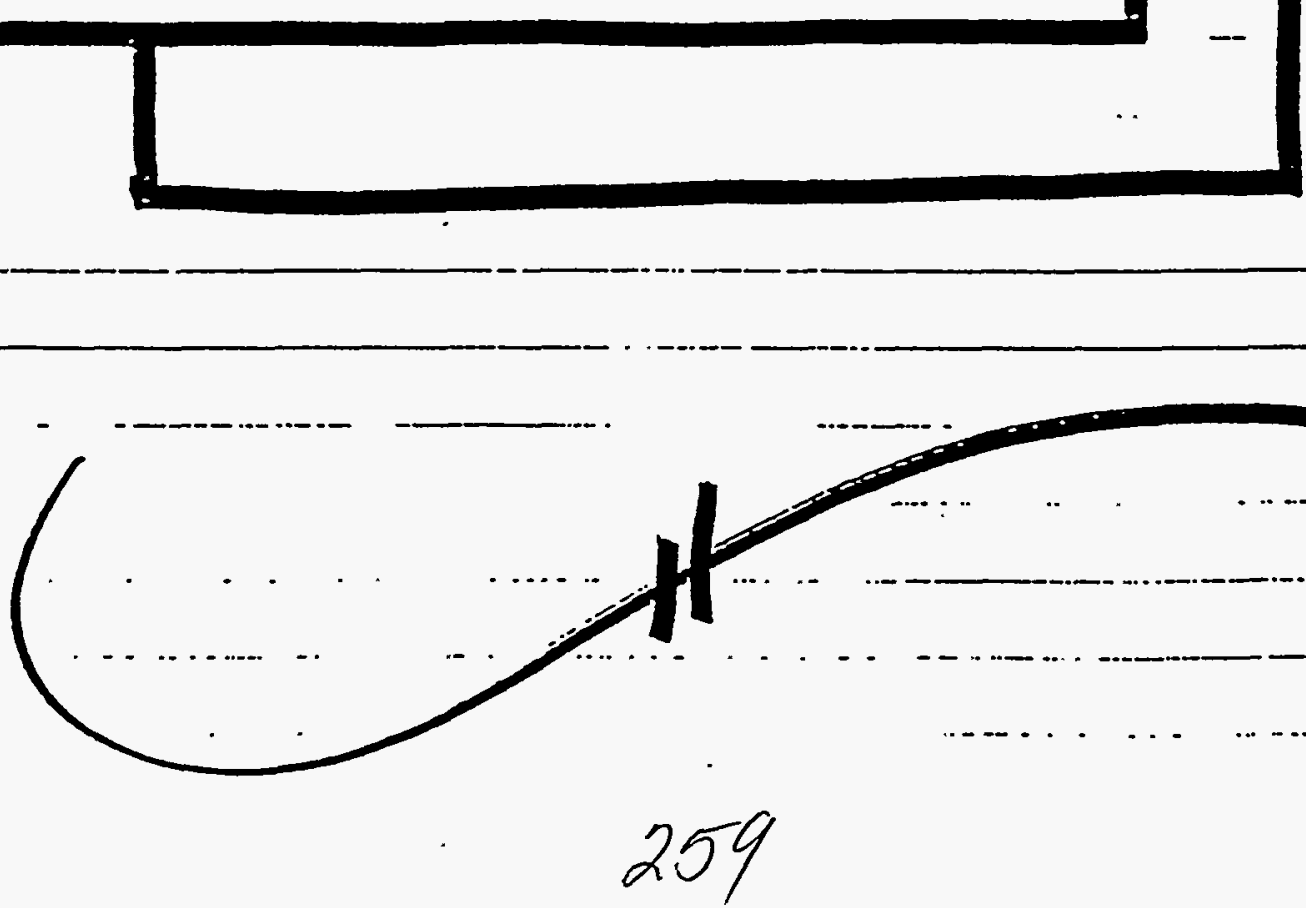
GUIDELNES S EXPECTATTONS

- partial Ve session:

- INVO LRETRVE \& PLANNUNA PHIREES

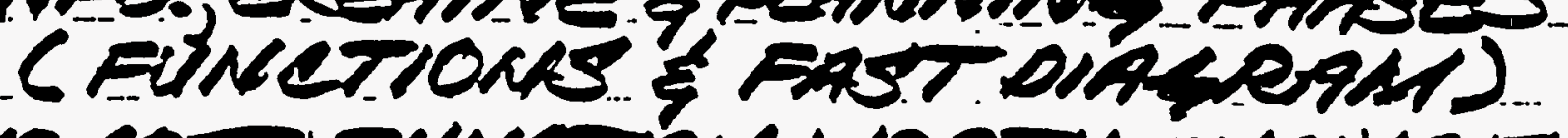

- No corT EUNCTON WORTH maALSS

- NO MLANT PRESENTMMON

- DOING nOT TRAININAS

- aetTVE LISTENINGS

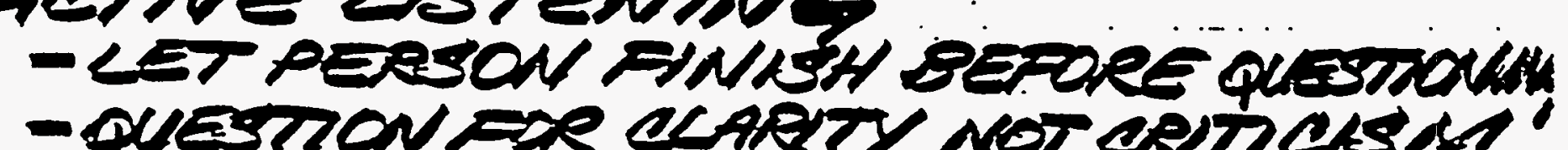

- question fox echetr ner cemcism

- BE SUCCINCT $\longrightarrow$ MAKEE POINTT.

- eraingstoerilns

- no evaluationes

- QuAvitY NOT QUALTY S KEY

- ElRLUATION DOESNOT PEDPLE

- EUIJE TERA- CONEENEU

- UIN-WIN, NO WIN-LOSE

- FacILITATION F́ ELIP CHARTS

= FOR AL TOSEE ATI EVITIN

- DOCUMENTION 260 
GUIDELINES E EXPECTATIONS

- E.A.S.T. DIASRAMINS CANBE ERUSTRATINS!

- CREATES FOCUS

- IDENTIFIES LOGIC

- enhanees creativity

- TNEORMTTINA SHEETS

- INFO. NEEDED

- ASTUAIPTIONS

- UNKNOUNR /UNCERTANTIES

- REQUIREMENTS

- CRITERIA

- InTER FACES

- zisues/lencerens

DOEFINITIONS

- EUNCTION TTATEMEARS

- COFFEE,TEA, DQNUTS-G ENTERTAMUEV.

1.00 ADAY Gepandes

$$
\begin{aligned}
& \text { CALCSOTO CORI } \\
& 261 \text { ब } 376-4986
\end{aligned}
$$


DaY 1

ALENDA

0730 - UELCONE/REVEU ASENOA

- GUIDEUNES E EXPETHTONO

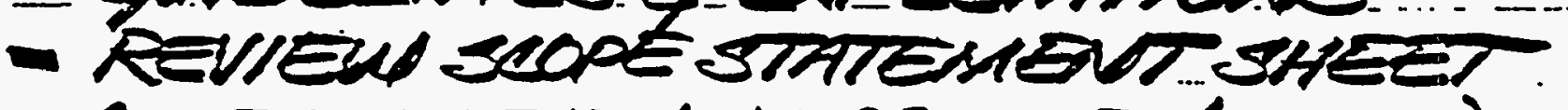

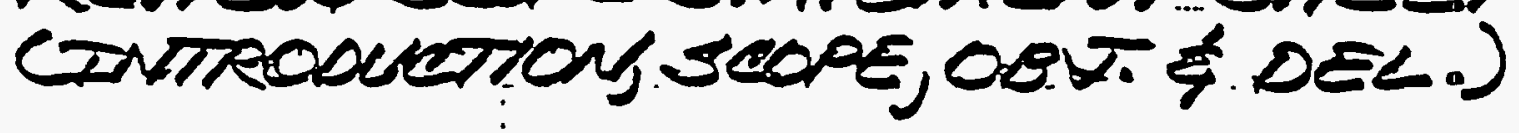

0800 - BACKSTEOHND DUFDPUATTON - HOW WE GOT HERE.

* - WDOE LETER/RequEST

- WHATS BEEN DONE TODATE

O845 - DEVELOOMISSIOW STATELRENT

0930 - EREAK

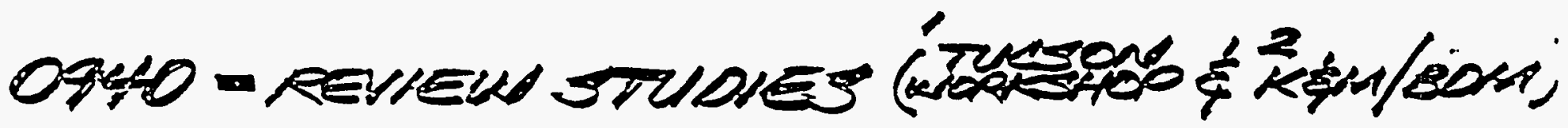
TO oETERMinde optronk, PREFEereo

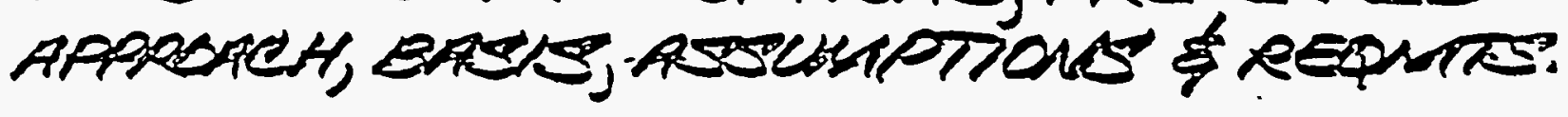

1130 - $\angle U N C H$

12:30- conTINUE STUOY REVIEU

2:30- REVIEU/DEVELOP FUN TTIONS

3:30 - REIIEU/BEGIN FAST. DRGPASI

4:30 - REVIEW RESAINING ASEVOA, GTATLS \& FINEA DAYl.

262 米 EESIN

* END. SHEets 
Pyz

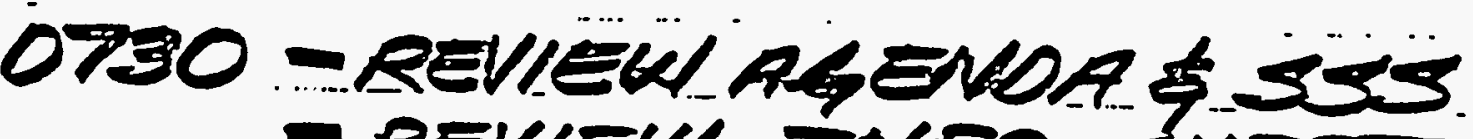
- REVIEW INAOO. SHEETS

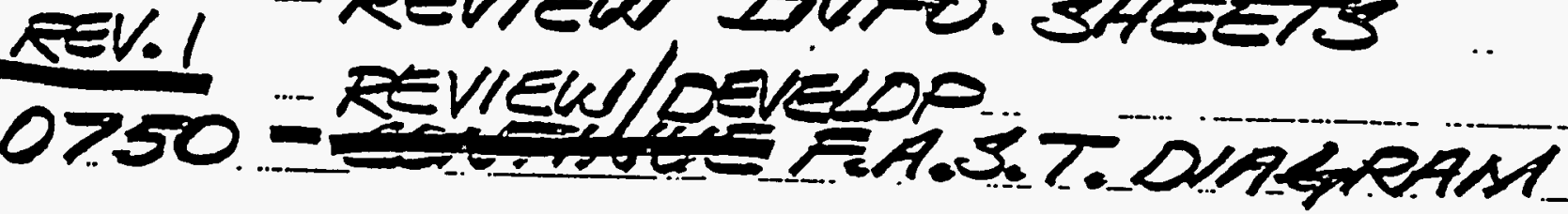

O930 = BREAK

0470 - SONTNUE EUNCTIONS F. F. A.S.T. - BRBED ON COAPLEX TTENRS ANRO ZDEVTIFY $\rightarrow$ OPTIONSS AVAKLELE

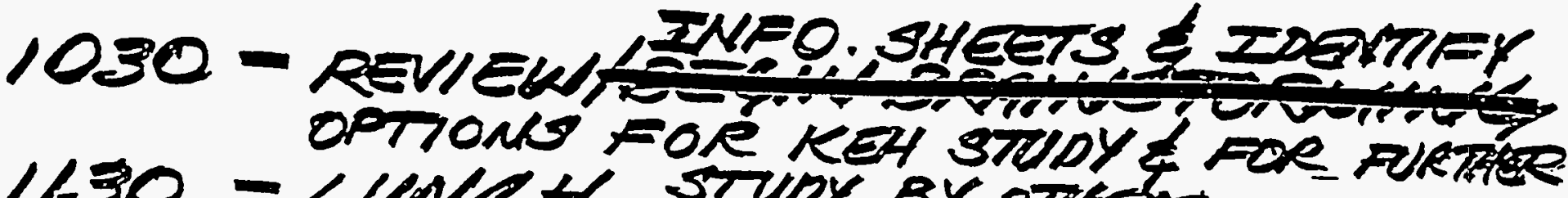
$1 / 30$ - LUNCA STUDY BY otfies DAY 3 T:30- SONTINUS TVFO SHEETS

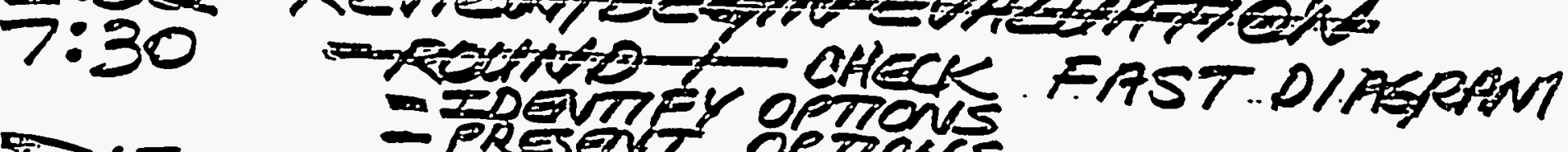
T:45 - PRESAT OPTONS 9:40 - DEVELOP CRITERIA CEEVIEH EXSTRVS - DeVELOP abscLUTE, FO-NO FO

11:45 SUNCH

$12: 30$ -HO - CONTINUE EVALUATTOW-ROUNO \& I

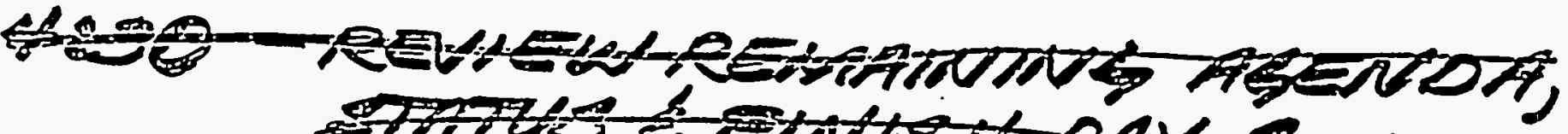

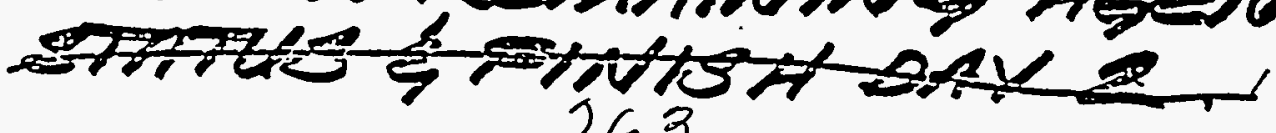
263 